\title{
Synthesis and Performance of Photocatalysts for Photocatalytic Hydrogen Production: Future Perspectives
}

\author{
Salvador Escobedo (D) and Hugo de Lasa * \\ Chemical Reactor Engineering Centre (CREC), Faculty of Engineering, Western University, 1151 Richmond Street, \\ London, ON N6A 5B9, Canada; sescobe@uwo.ca \\ * Correspondence: hdelasa@uwo.ca; Tel.: +1-519-661-2144; Fax: +1-519-850-2931
}

Citation: Escobedo, S.; de Lasa, H. Synthesis and Performance of Photocatalysts for Photocatalytic Hydrogen Production: Future Perspectives. Catalysts 2021, 11, 1505. https://doi.org/10.3390/ catal11121505

Academic Editor: Vasile I. Parvulescu

Received: 9 November 2021

Accepted: 4 December 2021

Published: 10 December 2021

Publisher's Note: MDPI stays neutral with regard to jurisdictional claims in published maps and institutional affiliations.

Copyright: (c) 2021 by the authors. Licensee MDPI, Basel, Switzerland. This article is an open access article distributed under the terms and conditions of the Creative Commons Attribution (CC BY) license (https:// creativecommons.org/licenses/by/ $4.0 /)$.

\begin{abstract}
Photocatalysis for "green" hydrogen production is a technology of increasing importance that has been studied using both $\mathrm{TiO}_{2}$-based and heterojunction composite-based semiconductors. Different irradiation sources and reactor units can be considered for the enhancement of photocatalysis. Current approaches also consider the use of electron/hole scavengers, organic species, such as ethanol, that are "available" in agricultural waste, in communities around the world. Alternatively, organic pollutants present in wastewaters can be used as organic scavengers, reducing health and environmental concerns for plants, animals, and humans. Thus, photocatalysis may help reduce the carbon footprint of energy production by generating $\mathrm{H}_{2}$, a friendly energy carrier, and by minimizing water contamination. This review discusses the most up-to-date and important information on photocatalysis for hydrogen production, providing a critical evaluation of: (1) The synthesis and characterization of semiconductor materials; (2) The design of photocatalytic reactors; (3) The reaction engineering of photocatalysis; (4) Photocatalysis energy efficiencies; and (5) The future opportunities for photocatalysis using artificial intelligence. Overall, this review describes the state-of-the-art of $\mathrm{TiO}_{2}$-based and heterojunction composite-based semiconductors that produce $\mathrm{H}_{2}$ from aqueous systems, demonstrating the viability of photocatalysis for "green" hydrogen production.
\end{abstract}

Keywords: green hydrogen; photocatalysts synthesis; electron/hole scavengers; energy efficiencies; artificial intelligence

\section{Introduction}

Today, the increased energy demands of a growing world population, as well as the need to drastically reduce the environmental impact of energy production, represent a major technical challenge [1,2]. These higher energy demands lead to the overexploitation of nonrenewable resources, such as oil and natural gas, and to a steady increase in greenhouse gas emissions, which may result in both health problems [3] and climate change [4,5].

Recent studies recommend the use of hydrogen as a "green energy fuel". Hydrogen is the simplest and most abundant element in the universe, and yet it is not easily available on the planet. Hydrogen does not occur alone naturally, and can always be found combined with other elements, such as water and organic compounds [6,7]. Furthermore, hydrogen is high in energy density (120-143 MJ/kg), with this being approximately three times greater than in fossil fuels [8-10].

Hydrogen is a very important chemical for numerous chemical industries. It is believed that hydrogen could provide a future source of energy for the residential, transportation, and industrial sectors [11,12]. Unfortunately, approximately $95 \%$ of the hydrogen generated today requires the use of fossil fuels, such as methane, for its production $[13,14]$. Thus, the development of clean renewable technologies for hydrogen production is needed to provide the clean energy that is so urgently needed.

In recent years, photocatalytic hydrogen production has attracted the attention of the scientific community because it is a new sustainable technology that can generate 
green hydrogen from near-UV and visible light (i.e., solar energy) [15-18]. Furthermore, hydrogen can be produced by using photocatalysis, which removes a wide range of organic pollutants from water, such as phenols, ketones, alcohols, alkenes, carboxylic acids, and others compounds [19]. However, to be a viable source of energy, and for its successful implementation, green hydrogen production from photocatalysis needs to overcome important technical barriers [11,14]: (a) It must be economically competitive and scalable, as compared to other available technologies that generate hydrogen from nonrenewable sources; and (b) It must produce hydrogen with high photon conversion efficiency [20].

Fujishima and Honda [21] were the pioneers of photocatalytic water splitting. These researchers discovered that $\mathrm{TiO}_{2}$ and $\mathrm{Pt}$ behave as the anode and cathode in a photoelectrochemical cell, respectively, splitting water into hydrogen and oxygen, under UV irradiation. This concept has been broadly applied to the development of $\mathrm{TiO}_{2}$-based semiconductors that are used to produce hydrogen from water, under both near-UV and visible light [22]. One should note that $\mathrm{TiO}_{2}$-based semiconductors are environmentally friendly, reliable, corrosion-free, photostable, and inexpensive materials [23-26]. Photocatalysis for hydrogen production is also a process that is simple to engineer and that operates at near to atmospheric pressure and temperature. On this basis, it is believed that photocatalysis for hydrogen production, using $\mathrm{TiO}_{2}$-based semiconductors, could provide, in the short term, a valuable alternative energy source for isolated communities around the world.

However, hydrogen production rates using $\mathrm{TiO}_{2}$ are still low and the photon efficiencies must be enhanced. In this respect, photocatalytic efficiencies can be improved by: (a) Increasing the semiconductor specific surface area [27,28]; (b) Depositing or doping metals ( $\mathrm{Pt}, \mathrm{Pd}, \mathrm{Au}, \mathrm{Rh}, \mathrm{Ag}, \mathrm{Ni}, \mathrm{Cu}, \mathrm{Co}$ ) [29-39] or nonmetals ( $\mathrm{N}$ or S) $[40,41]$ on the $\mathrm{TiO}_{2}$ photocatalyst; (c) Coupling $\mathrm{TiO}_{2}$ with other semiconductors [42-44]; (d) Dye-sensitizing $\mathrm{TiO}_{2}$ [45-48]; and (e) Adding chemical additives or sacrificial agents (i.e., electron/hole scavengers) to the aqueous photocatalytic suspension [49-53]. These anticipated changes to photocatalysts for hydrogen production are of great importance to radically increase the "green" hydrogen availability.

The activity of $\mathrm{TiO}_{2}$-based semiconductors depends on their surface properties, as well as on other added components (transition or noble metals). Thus, new approaches are required to achieve: (1) Reduced electron/hole $\left(e^{-} / h^{+}\right)$recombination; (2) Diminished energy band gap $\left(E_{\mathrm{bg}}\right)$; and (3) Increased specific surface area for both enhanced organic pollutants adsorption, and the effective absorption of photon energy. These desirable changes on $\mathrm{TiO}_{2}$-based semiconductors are expected to diminish both the manufacturing and the operational costs of new technologies to produce photocatalytic hydrogen. In addition, other $\mathrm{TiO}_{2}$-based semiconductors, including heterojunction photocatalysts consisting of graphitic carbon nitride $\left(\mathrm{g}-\mathrm{C}_{3} \mathrm{~N}_{4}\right)$, sulfur-contained species $\left(\mathrm{CdS}, \mathrm{CuInS} \mathrm{S}_{2}\right)$, and other materials, can also be valuable to achieve these goals. These new types of semiconductors can lead to enhanced charge separation and to the increase in the photogenerated pair charge duration under visible light [54-57].

Sacrificial agents (SAs) can transform the thermodynamically inhibited water splitting reaction $\left(\Delta \mathrm{G}^{0}=237 \mathrm{KJ} \mathrm{mol}^{-1}\right)$ into a feasible reaction for hydrogen production [58]. As a result, the addition of $e^{-} / h^{+}$scavengers allows the hydrogen production to proceed, with an increase in the photon utilization efficiency. There are two types of $e^{-} / h^{+}$SAs: (a) Organic chemical species (hydrocarbons, alcohols, and organic acids); and (b) Inorganic chemical species (sulfides, sulfites, iodates, iodides). These $e^{-} / h^{+}$SAs have the following functions: (1) They capture photogenerated holes $\left(h^{+}\right)$, which minimizes the probability of $e^{-} / h^{+}$ recombination; (2) They suppress the formation of water (back reaction), avoiding water splitting with $\mathrm{O}_{2}$ production; and (3) They act as additional sources of protons $[59,60]$. Organic sacrificial agents are likely the ones with better chances of being adopted, given their permittivity and oxidation potential [60]. Furthermore, the use of SAs for hydrogen production must also be evaluated vis-à-vis of their availability and cost. For instance, organic chemicals from biomass waste, or, alternatively, ethanol obtained from the fer- 
mentation of agricultural residues, may offer good and inexpensive options as sacrificial agents [41,61-64].

Hydrogen production via photocatalysis must be evaluated on the basis of photon utilization using quantum yields (QYs). QYs represent the ratio of the moles of hydrogen radicals $\left(\mathrm{H}^{\bullet}\right)$ produced, over the moles of photons absorbed $[27,65,66]$. With regard to the moles of photons absorbed, they can be calculated using macroscopic irradiation energy balances (MIEB) [67-69]. Furthermore, the hydrogen production efficiencies can be gauged using the photocatalytic thermodynamic efficiency factors (PTEFs), which determine the photon energy utilization efficiency [39,70]. In this respect, both QYs and PTEFs have become the standard key parameters for the evaluation of photocatalytic reactors for hydrogen production. These parameters provide a comprehensive basis from which to establish the optimal design and operation of scaled-up photocatalytic reactors units [28,71-74].

Photocatalysis for hydrogen production, as well as for other applications, has been impacted by artificial intelligence (AI). This new cognitive system is usually demonstrated with two subsets: machine learning (ML), or artificial neural networks (ANNs) [75]. ML or ANN models can be evaluated by considering the photocatalytic process inputs and the desired outputs, leading to more informed and accurate decisions. Furthermore, these methods can consider unstructured experimental data, which allows for accurate predictions for complex and large-scale chemical processes [76]. In photocatalysis for hydrogen production, these techniques can lead to identifying the optimal operational parameters required to obtain the maximum hydrogen generation [77]. This is critical for the future scaling up of "green hydrogen" technologies.

This review reports and compares the most up-to-date research and background information on photocatalysis for hydrogen production. Special emphasis is given to new approaches in photocatalysis accounting for sacrificial agents, reaction networks, kinetic models with included adsorption phenomena, energy efficiency, and possible AI applications. Our objective is to provide a comprehensive guide, as a reference for future research, in the field of photocatalytic hydrogen production.

\section{Synthesis and Characterization of Heterojunction Composite Photocatalysts for Hydrogen Production}

This section reviews the most widely studied photocatalysts and designed heterojunction semiconductors, including those that are based on $\mathrm{TiO}_{2}$, sulfides ( $\left.\mathrm{CdS}, \mathrm{CuInS}_{2}\right)$, graphite carbon nitride $\left(\mathrm{g}-\mathrm{C}_{3} \mathrm{~N}_{4}\right)$, and perovskite $\left(\mathrm{La}_{2} \mathrm{Ti}_{2} \mathrm{O}_{7}\right)$. Our objective is to identify the semiconductors that are more responsive to visible light, and the ones that are most effective for photocatalytic hydrogen generation. Appendix A Table A1 and Appendix B Table A2 report the morphologies, the optical properties, the $\mathrm{H}_{2}$ reaction rates, and the energy efficiencies of different photocatalysts.

\section{1. $\mathrm{TiO}_{2}$-Based Photocatalysts}

$\mathrm{TiO}_{2}$ is one of the most commonly studied materials in photocatalysis. This oxide semiconductor material is not consumed during the photoinduced reaction and assists in accelerating chemical reactions by absorbing photons on its surface. Then main features that influence the activity of a photocatalyst are set during the synthesis of the semiconductor. These include: (1) Wavelength activation; (2) Resistance to mechanical stress and photocorrosion; (3) Crystallinity; and (4) Surface properties [71,78,79].

$\mathrm{TiO}_{2}$ naturally exists in three different microcrystal structures, including rutile, anatase, and brookite [80-82]. Table 1 reports: (a) The band gap energy $\left(E_{B G}\right)$, the difference between the valence band (VB) and the conduction band (CB); and b) The wavelength activation required to excite $\mathrm{TiO}_{2}$, in its various polymorphic phases. $\mathrm{E}_{\mathrm{BG}}$ can be estimated with Equation (1). Thus, the $\mathrm{E}_{\mathrm{BG}}$ determines the photon energy required to activate a photocatalyst, promoting excited electrons $\left(e^{-}\right)$to move from the VB to the $\mathrm{CB}$. Furthermore, the result- 
ing $\left(e^{-} / h^{+}\right)$pairs migrate to the surface of the semiconductor and initiate photocatalytic reduction/oxidation reactions with adsorbed organic species (refer to Figure 1) [6,71].

$$
E_{B G}(\mathrm{eV})=\frac{1240}{\lambda(\mathrm{nm})}
$$

Table 1. $\mathrm{TiO}_{2}$ polymorphic phases as described via physical and optical properties [6,82].

\begin{tabular}{ccccc}
\hline Semiconductor Phase & Crystalline Form & Density $\left(\mathbf{g ~ c m}^{-\mathbf{3}}\right)$ & Wavelength (nm) & Band Gap Energy (eV) \\
\hline Rutile & Tetragonal & 4.27 & 413 & 3.0 \\
\hline Anatase & Tetragonal & 3.90 & 388 & 3.2 \\
\hline Brookite & Orthogonal & 4.13 & 365 & 3.4 \\
\hline
\end{tabular}

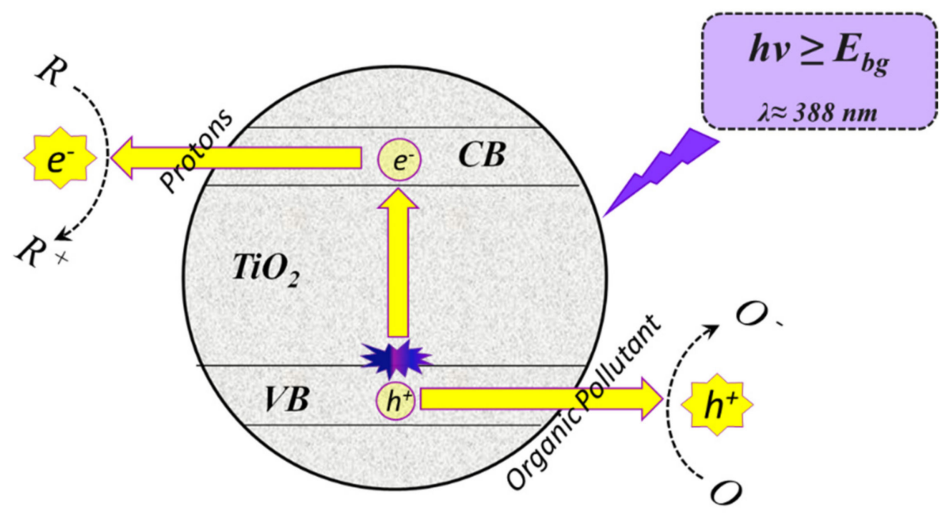

Figure 1. Schematic diagram of the $\mathrm{TiO}_{2}$ particle activation with photons and through the photocatalytic oxidation $(\mathrm{O})$ /reduction $(\mathrm{R})$ process.

$\mathrm{TiO}_{2}$, however, presents two main drawbacks: (1) The photoactivation is limited, given that it can only use 4 to $5 \%$ of the sunlight spectrum; and (2) The recombination rate of $\left(e^{-} / h^{+}\right)$pairs is relatively quick, even though the light absorption time (ca. $10^{-15} \mathrm{~s}$ ) occurs faster than the recombination time (ca. $10^{-10} \mathrm{~s}$ ) [81]. To address these issues, the $\mathrm{TiO}_{2}$ has been modified by combining different methods and preparation steps, such as the impregnation/doping with metals $[65,83,84]$ and nonmetals [85], the preparation of composite materials containing $\mathrm{TiO}_{2}$ heterojunctions [86], the control of the polymorphic phases [87], and porosity (micro or meso) [27,66,88,89].

Escobedo et al. [65] loaded platinum (Pt) particles onto $\mathrm{TiO}_{2}$ Evonik Degussa-P25 (DP25), designated as Pt/DP25, using the incipient wetness impregnation method to improve both the semiconductor optical properties and the agglomerate particle size distribution. First, DP25 was dried at $140{ }^{\circ} \mathrm{C}$ for $6 \mathrm{~h}$, to desorb the water and other gas species. Following this, hexachloroplatinic acid hydrate $\left(\mathrm{H}_{2} \mathrm{PtCl}_{6} \times \mathrm{H}_{2} \mathrm{O}\right)$ was dissolved in $4 \mathrm{~mL}$ of distilled water. Next, a first $2 \mathrm{~mL}$ of Pt solution volume was added dropwise on $5 \mathrm{~g}$ DP25. The resulting slurry was dried at $140{ }^{\circ} \mathrm{C}$ for $2 \mathrm{~h}$, and fine ground. Then, the remaining $2 \mathrm{~mL}$ of promotor solution was further impregnated on the $\mathrm{H}_{2} \mathrm{PtCl}_{6} / \mathrm{DP} 25$ precursor. The resulting powder was dried at $160{ }^{\circ} \mathrm{C}$ for $3 \mathrm{~h}$, and then calcined at $450{ }^{\circ} \mathrm{C}$ for $3 \mathrm{~h}$ to ensure chlorine removal. Finally, the samples were reduced using an $\mathrm{Ar} / \mathrm{H}_{2}(90 / 10 \%$ Praxair composition) gas blend at $1 \mathrm{~cm}^{3} \mathrm{~s}^{-1}$, in a flow reactor unit, and heated at $400{ }^{\circ} \mathrm{C}$ for $3 \mathrm{~h}$. This method allowed for the obtainment of well-dispersed metallic $\mathrm{Pt}^{0}$ particles, formed on the $\mathrm{TiO}_{2}$ outer surface. A similar wetness impregnation method was employed by Bahruji et al. [90]. These authors loaded different Pd amounts on DP25 by dissolving $\mathrm{PdCl}_{2}$ in $1.5 \mathrm{~mL}$ of deionised water. This was acidified at a $\mathrm{pH}$ of 1 , using a $\mathrm{HCl}$ solution. Then, the precursor solution was added dropwise onto $2 \mathrm{~g}$ of DP25 powder. The samples were dried at $120^{\circ} \mathrm{C}$ for $2 \mathrm{~h}$, followed by $3 \mathrm{~h}$ of calcination at $500{ }^{\circ} \mathrm{C}$ [91]. Montoya et al. also used a DP25 surface-modified semiconductor. These authors loaded DP25 with copper 
$(\mathrm{Cu})$ and nickel $(\mathrm{Ni})$, at different metal loadings, by using a UV photodeposition method, in a methanol solution. The prepared solution was degassed with Ar. This was performed to favor the reduction conditions of the DP25 photocatalysts loaded with $\mathrm{Cu}$ and $\mathrm{Ni}$.

Guayaquil-Sosa et al. [27] proposed a sol-gel method to synthesize a new mesoporous $\mathrm{TiO}_{2}\left(\mathrm{mpTiO}_{2}\right)$ semiconductor and obtained an improved photocatalyst surface area and pore size. These authors employed pluronic F-127 as a structure-directing template, as well as titanium (IV) isopropoxide, ethanol, citric acid, hydrochloric acid, and a hexachloroplatinic acid hydrate dopant as reagents for the solution. The doped sol-gel phase was loaded with different $\mathrm{Pt}$ amounts and agitated for $24 \mathrm{~h}$. Then, it was calcined gradually at $550{ }^{\circ} \mathrm{C}$ for $6 \mathrm{~h}$. The resulting doped mesoporous powder was designated as $x$ wt. $\%$ $\mathrm{Pt} / \mathrm{mpTiO}_{2}-550^{\circ} \mathrm{C}$, where $x$ was the loaded amount of metallic Pt. A similar sol-gel method was employed by Rusinque et al. [88]. However, in this case, a palladium (II) chloride $\left(\mathrm{PdCl}_{2}\right)$ dopant was incorporated instead. The calcination step took place under an air atmosphere at $500{ }^{\circ} \mathrm{C}$ for $6 \mathrm{~h}$. Furthermore, and considering that Pd oxidizes during the calcination step, the resulting semiconductor powder had to be reduced. The reduction was controlled in two consecutive steps: (1) The Pd species reduction took place in a flow reactor unit, under a $1 \mathrm{~cm}^{3} / \mathrm{s}$ of $\mathrm{Ar} / \mathrm{H}_{2}\left(90 / 10 \%\right.$ Praxair composition) gas blend, at $500{ }^{\circ} \mathrm{C}$ for $3 \mathrm{~h}$; and (2) Following this, further photoreduction of the photocatalyst took place in the PCW-II reactor by exposing the photocatalyst to near-UV light at room temperature for $1 \mathrm{~h}$. This resulted in a designated $x \mathrm{wt} . \% \mathrm{Pd} / \mathrm{mpTiO}_{2}-500{ }^{\circ} \mathrm{C}$ photocatalyst. A photodeposition method for Pt on DP25 was also considered by Estahbanati et al. [75]. These authors suspended $1 \mathrm{~g}$ of DP25 in $120 \mathrm{~mL}$ of a $10 \mathrm{vol} . \%$ ethyl alcohol solution. Then, the precursor material was sonicated for $30 \mathrm{~min}$ and a hexachloroplatinic acid solution was poured on it. The mixture was purged with $\mathrm{N}_{2}$ for $15 \mathrm{~min}$ to remove dissolved or adsorbed oxygen. Next, the sample was stirred at $500 \mathrm{rpm}$, and irradiated for $3 \mathrm{~h}$ with a $20 \mathrm{~W}$ Black-Ray mercury lamp to achieve Pt photodeposition. Finally, the Pt/DP25 photocatalyst was filtered, washed, and dried overnight at $110{ }^{\circ} \mathrm{C}$.

Rayees Ahmad et al. [92] prepared a mesoporous $\mathrm{Cu}-\mathrm{TiO}_{2}\left(\mathrm{mpCu}-\mathrm{TiO}_{2}\right)$ photocatalyst for $\mathrm{H}_{2}$ production that was shown to be active under direct solar irradiation. This photocatalyst was first synthesized by template synthesis, in a blend of titanium butoxide $\left(\mathrm{Ti}(\mathrm{OBu})_{4}\right)$, ethylene glycol, acetone, distillate water, and acetic acid. This was stirred at $35^{\circ} \mathrm{C}$ for $3 \mathrm{~h}$, resulting in a precipitate of titanium glycolate. Then, the resulting slurry was stirred at $80-100^{\circ} \mathrm{C}$ for $8 \mathrm{~h}$, and washed with $\mathrm{H}_{2} \mathrm{O}$ and ethanol. Following this, it was dried at $100{ }^{\circ} \mathrm{C}$, and finally calcined at $250{ }^{\circ} \mathrm{C}$ for $5 \mathrm{~h}$ to produce mesoporous $\mathrm{TiO}_{2}\left(\mathrm{mpTiO}_{2}\right)$. The deposition of copper nanoparticles ( $\mathrm{Cu}$ NPs) was achieved by wet impregnation. A total of $100 \mathrm{mg}$ of $\mathrm{mpTiO}_{2}$ was suspended in $10 \mathrm{~mL}$ of water and sonicated for $10 \mathrm{~min}$. The $3 \mathrm{wt} . \%$ $\mathrm{Cu}$ NP loadings were added to the suspension and stirred for $24 \mathrm{~h}$. Finally, the mpCu- $\mathrm{TiO}_{2}$ photocatalyst was separated by centrifugation and dried at room temperature.

Similarly, Choi and Kang [93] synthesized a $\mathrm{TiO}_{2}$ photocatalyst with an anatase structure using a sol-gel method, and added $\mathrm{Cu}$ particles while utilizing the impregnation method. Ruban and Sellappa [94] also synthesized core-shell nanoparticles (NPs) by using a CdS-ZnS/ DP25 photocatalyst. This photocatalyst was developed in two steps: (1) Through the hydrothermal synthesis of $\mathrm{TiO}_{2}$; and (2) By the coprecipitation of CdS-ZnS NPs on $\mathrm{TiO}_{2}$. First, $500 \mathrm{~mL}$ of $0.1 \mathrm{M}$ of cadmium acetate and zinc acetate were mixed and stirred. Next, $3.5 \mathrm{~g}$ of DP25, 7.6 g of thiourea, and $0.2 \mathrm{M}$ of $\mathrm{Na}_{2} \mathrm{~S}$ were added to it. The formed crystals were separated by ultracentrifugation, washed thoroughly (deionized water and isopropanol), and dried at $110{ }^{\circ} \mathrm{C}$. The final weight ratio of this new photocatalyst was 1:1:1 (CdS:ZnS:DP25).

Rivero et al. [95] prepared a Pt/graphene- $\mathrm{TiO}_{2}$-based photocatalyst in order to improve the photocatalytic properties of simple $\mathrm{TiO}_{2}$-based materials for $\mathrm{H}_{2}$ production. First, the polyol method was employed for the synthesis of Pt/DP25. Then, the Pt precursor $\left(\mathrm{H}_{6} \mathrm{PtCl}_{6} 6 \mathrm{H}_{2} \mathrm{O}\right)$ and DP25 were slurried in ethylene glycol. The resulting suspension was mixed, stirred, and heated at $140{ }^{\circ} \mathrm{C}$ for $2 \mathrm{~h}$. The residual solids were washed, recovered by centrifugation, and dried overnight at $50{ }^{\circ} \mathrm{C}$. Then, the synthesis of $5 \mathrm{wt} . \%$ of rGO/DP25 
was developed using a hydrothermal method. In this case, DP25 was added to a reduced graphene oxide (rGO) solution, stirred for $2 \mathrm{~h}$, and then maintained at $120^{\circ} \mathrm{C}$ for $3 \mathrm{~h}$ (in a Teflon-lined stainless-steel autoclave). The remaining particulate material was recovered by centrifugation, rinsed, washed with ultrapure water, and dried overnight at $50{ }^{\circ} \mathrm{C}$. The solid powder was designated as a Pt/rGO/DP25 photocatalyst. Other photocatalysts have also been studied for the preparation of junction materials, such as $\mathrm{NiO}$ (p-type) $/ \mathrm{TiO}_{2}$ (n-type) for photocatalytic hydrogen production.

Ruixia Lui et al. [96] and Fujita et al. [97] loaded $\mathrm{NiO}_{\mathrm{x}}$ on $\mathrm{TiO}_{2}$. To accomplish this, $\mathrm{TiO}_{2}$ powder (Catalyst So. of Japan) was doped using an impregnation method: $1 \mathrm{~g}$ of $\mathrm{TiO}_{2}$ was dispersed in a $10-\mathrm{mL} \mathrm{Ni}\left(\mathrm{NO}_{3}\right)_{2}$ solution at $0.15 \mathrm{M}$. The formed slurry was continuously stirred during an overnight period to ensure adequate impregnation. Then, it was dried at $80^{\circ} \mathrm{C}$ for $12 \mathrm{~h}$ and ground. Finally, the resulting powder was calcined at $450{ }^{\circ} \mathrm{C}$ for $3 \mathrm{~h}$, under a flow of air of $50 \mathrm{~cm}^{3}$, to obtain the $\mathrm{NiO}_{\mathrm{x}} / \mathrm{TiO}_{2}$ photocatalyst.

Sadanandam et al. [98] prepared a cobalt (Co)-doped DP25 photocatalyst for $\mathrm{H}_{2}$ production under solar light irradiation. These authors synthesized the photocatalyst by using the impregnation method. DP25 was added to a $1 \mathrm{wt} . \%$ cobalt $\left(\mathrm{Co}\left(\mathrm{CH}_{3} \mathrm{COO}\right)_{2}\right.$ $4 \mathrm{H}_{2} \mathrm{O}$ ) solution in distilled water. The solution was constantly stirred under slow heating to evaporate excess water till dryness was obtained. Then, the dry powder was calcined at $400{ }^{\circ} \mathrm{C}$ in $5 \mathrm{~h}$. Finally, the photocatalyst was reduced using a $30 \% \mathrm{H}_{2} / \mathrm{N}_{2}$ gas blend at $450{ }^{\circ} \mathrm{C}$ for $5 \mathrm{~h}$. These procedures allowed the Co (II) formation on the DP25 surfaces.

Another subject of critical importance for $\mathrm{H}_{2}$ production is the particle concentration of various $\mathrm{TiO}_{2}$-based photocatalysts. The following, Figure 2, reports the importance of the photocatalyst particle concentration, used to produce $\mathrm{H}_{2}$ at different experimental conditions, as previously explained in this section.

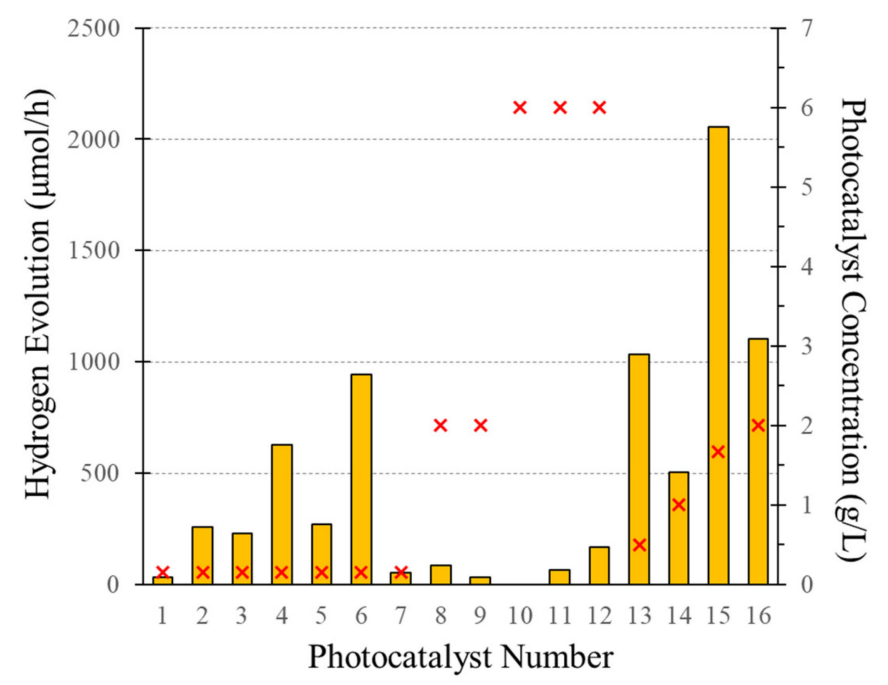

Figure 2. $\mathrm{H}_{2}$ Production with various photocatalyst particle concentrations using different $\mathrm{TiO}_{2}$ based photocatalysts. Notes: (1) bars report hydrogen production; (2) red crosses show photocatalyst concentration $(\mathrm{g} / \mathrm{mL})$; and (3) various photocatalysts are referred to with numbers, as reported in Appendix A Table A1.

\subsection{Assorted Frames (No $\mathrm{TiO}_{2}$ )-Based Photocatalysts}

Recent studies report the development of graphitic carbon nitride $\left(g-C_{3} N_{4}\right)[55-57,99-101]$ and sulfide-based (CdS, CuInS 2 ) [40,102-104] photocatalysts. Although metal sulfides usually present photocorrosion issues, their strong visible light absorption, narrow band gaps, and excellent electronic charge transfer have attracted significant researcher attention [58]. Wang et al. [60] studied $\mathrm{Zn}_{0.5} \mathrm{Cd}_{0.5} \mathrm{~S}$ and g- $\mathrm{C}_{3} \mathrm{~N}_{4}$. These materials were prepared in several steps. First, a solution of diethyldithiocarbamate trihydrate (DDTC) was prepared to form $\mathrm{Cd}(\mathrm{DDTC})_{2}$ and $\mathrm{Zn}(\mathrm{DDTC})_{2}$. These two chemicals were equimolarly mixed in $100 \mathrm{~mL}$ of oleylamine (80-90\%). The resulting slurry was stirred, heated at $240{ }^{\circ} \mathrm{C}\left(\right.$ at $\left.5^{\circ} / \mathrm{min}\right)$, and 
kept for $1 \mathrm{~h}$ under a $\mathrm{N}_{2}$ atmosphere. The resulting blend was later separated by centrifugation, and the formed precipitate was washed with ethanol. The products were collected and stored using cyclohexane. Following this, $35 \mathrm{~mL}$ of acetic acid was added to form $\mathrm{Zn}_{0.5} \mathrm{Cd}_{0.5} \mathrm{~S}$. The formed slurry was stirred for $10 \mathrm{~h}$, in a heating bath at $70{ }^{\circ} \mathrm{C}$, with the photocatalyst precursor, which was initially hydrophobic but became hydrophilic. In the case of the formed $\mathrm{g}-\mathrm{C}_{3} \mathrm{~N}_{4}$ powder, fine melamine powder was added. The resulting solid blend was heated up to $550^{\circ} \mathrm{C}$ (at $2.5^{\circ} \mathrm{C} / \mathrm{min}$ ) and kept for $4 \mathrm{~h}$ under a $\mathrm{N}_{2}$ atmosphere.

Katsumata et al. [105] synthesized a $\mathrm{WO}_{3} / \mathrm{g}-\mathrm{C}_{3} \mathrm{~N}_{4}$ photocatalyst by a simple calcination method for hydrogen generation (refer to Figure 3). A commercial Aldrich reagent of tungsten trioxide $\left(\mathrm{WO}_{3}\right)$ nanoparticles was used. The formation of $\mathrm{g}-\mathrm{C}_{3} \mathrm{~N}_{4}$ powders was obtained by heating urea at $500{ }^{\circ} \mathrm{C}$ for $2 \mathrm{~h}$, in a covered alumina crucible, at a heating rate of $20^{\circ} \mathrm{C} / \mathrm{min}$. Further heating treatment was performed at $520^{\circ} \mathrm{C}$ for $2 \mathrm{~h}$. The acquired product was cooled down to room temperature, fine ground, and collected. The $\mathrm{WO}_{3} / \mathrm{g}-\mathrm{C}_{3} \mathrm{~N}_{4}$ photocatalyst was prepared by blending and grinding $\mathrm{WO}_{3}$, with $\mathrm{g}-\mathrm{C}_{3} \mathrm{~N}_{4}$, in an agate mortar for $30 \mathrm{~min}$. The resulting powder mixture was calcined at $450{ }^{\circ} \mathrm{C}$ for $4 \mathrm{~h}$, with a temperature ramp of $20^{\circ} \mathrm{C} / \mathrm{min}$ and was then fine ground again. Jiang et al. [106] also prepared a g- $\mathrm{C}_{3} \mathrm{~N}_{4}$-based photocatalyst, but loaded it with silver sulfide $\left(\mathrm{Ag}_{2} \mathrm{~S}\right)$ by employing the precipitation method. The g- $\mathrm{C}_{3} \mathrm{~N}_{4}$ was synthesized by thermal treatment. A total of $10 \mathrm{~g}$ of urea was dried at $80{ }^{\circ} \mathrm{C}$ for $24 \mathrm{~h}$. Then, the precursor was calcined at $550{ }^{\circ} \mathrm{C}$ for $4 \mathrm{~h}$, at a heating rate of $2.3^{\circ} \mathrm{C} / \mathrm{min}$. The resultant yellowish powder was washed twice with nitric acid [0.1M], and three times with deionized water and absolute ethanol. The final product was dried at $60^{\circ} \mathrm{C}$ for $12 \mathrm{~h}$. The $A g{ }_{2} \mathrm{~S} / \mathrm{g}-\mathrm{C}_{3} \mathrm{~N}_{4}$ photocatalyst was prepared in situ, at room temperature. With this end, $0.092 \mathrm{~g}$ of $\mathrm{g}-\mathrm{C}_{3} \mathrm{~N}_{4}$ powder and $\mathrm{Ag}_{2} \mathrm{~S}$ were dispersed (depending on the $x$ wt.\% desired) in $50 \mathrm{~mL}$ of absolute ethanol, and were ultrasonicated for $20 \mathrm{~min}$. Next, thioacetamide (TAA) was incorporated into the mixture, and was stirred for $4 \mathrm{~h}$. The final product was collected by centrifugation, washed with distilled water and absolute ethanol, and dried at $60^{\circ} \mathrm{C}$, for $12 \mathrm{~h}$, to obtain the $\mathrm{Ag}_{2} \mathrm{~S} / \mathrm{g}-\mathrm{C}_{3} \mathrm{~N}_{4}$ photocatalyst.

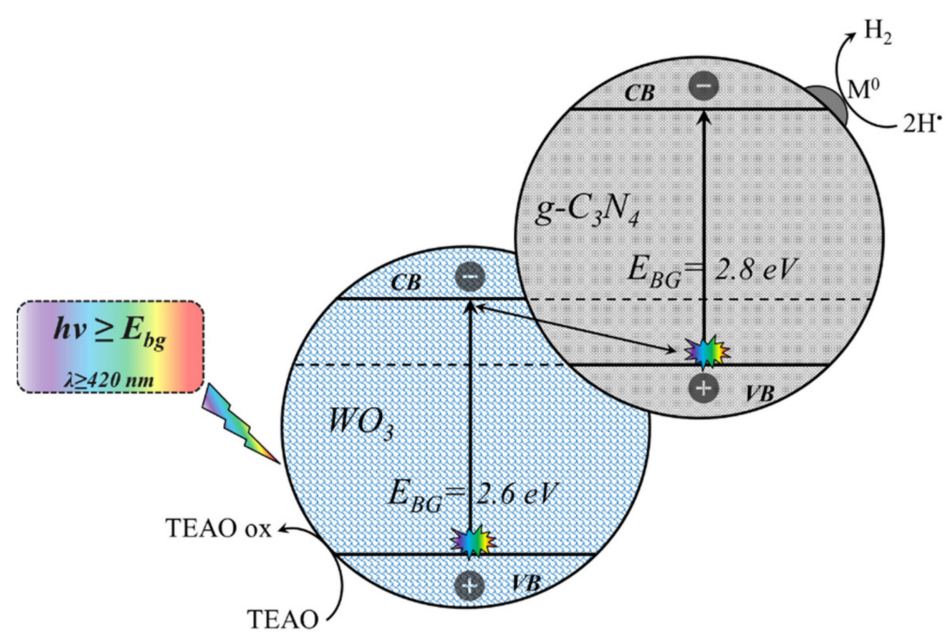

Figure 3. Schematic diagram of the particle activation for heterojunction photocatalyst of $\mathrm{WO}_{3} / \mathrm{g}$ $\mathrm{C}_{3} \mathrm{~N}_{4}$ during the production of hydrogen using a TEAO aqueous solution [105].

Z. Shen et al. [107] successfully prepared cadmium sulfide (CdS) nanocrystals, embedded in molybdenum trioxide $\left(\mathrm{MoO}_{3}\right)$ core-shell nanospheres, for both $\mathrm{H}_{2}$ production and photodegradation under visible light irradiation. These authors used a sonochemistry method at room temperature and normal pressure, with no templates or surfactants required. The synthesis of $\mathrm{MoO}_{3} / \mathrm{CdS}$ was carried out at different molar ratios. A mixture of $\mathrm{Cd}(\mathrm{Ac})_{2} 2 \mathrm{H}_{2} \mathrm{O}$ [3 mmol], $\left(\mathrm{NH}_{4}\right)_{6} \mathrm{Mo}_{7} \mathrm{O}_{24} 4 \mathrm{H}_{2} \mathrm{O}$ [0.0143 mmol], and thioacetamide [6.2 mmol] was dissolved in $8 \mathrm{~mL}$ of acetone. The mixed solution was immersed in the reaction solution and sonicated at room temperature for $1 \mathrm{~h}$. During the selected reaction 
time, the suspension temperature was maintained at lower than $50{ }^{\circ} \mathrm{C}$. This time period helped to generate the precipitates of $\mathrm{MoO}_{3} / \mathrm{CdS}$ photocatalyst that were collected by centrifugation, washed with ethanol, and air-dried for several hours.

Other authors, such as Gupta et al. [108], developed two CdS-based photocatalysts with titanium disulfide $\left(\mathrm{TiS}_{2}\right)$ and tantalum (IV) sulfide $\left(\mathrm{TaS}_{2}\right)$. The $\mathrm{TiS}_{2}$ was prepared with a blend of Ti metal and sulfur powder. The blend was then heated at $800{ }^{\circ} \mathrm{C}$ for $72 \mathrm{~h}$. In the case of the $\mathrm{TaS}_{2}$, a commercial powder was used (Alfa Aesar, $99.8 \%$ metal basis). The few-layers of $\mathrm{TaS}_{2}$ and $\mathrm{TiS}_{2}$ were formed by soaking $1 \mathrm{~g}$ of metal disulfides in $3.5 \mathrm{~mL}$ of n-butyllithium [1.6 M] in a $12-\mathrm{mL}$ hexane solution. The solution was heated at $27^{\circ} \mathrm{C}$ for $72 \mathrm{~h}$. Next, the samples were exfoliated by ultrasonication in distilled water, in a closed vial, for $4 \mathrm{~h}$. The suspension was centrifuged, and the resulting solid product was collected. The few-layer $\mathrm{TaS}_{2}$ and $\mathrm{TiS}_{2}$ nanocomposites, together with the CdS nanoparticles, were prepared by adding $10 \mathrm{~mL}$ of sodium sulfide $\left(\mathrm{Na}_{2} \mathrm{~S}\right)[0.1 \mathrm{mM}]$ to $10 \mathrm{~mL}$ of cadmium acetate $\left(\mathrm{Cd}\left(\mathrm{CH}_{3} \mathrm{COO}\right)_{2}\right)[0.1 \mathrm{mM}]$, and stirring this mixture steadily until it resulted in a precipitate material. The formed precipitate was centrifuged and dried at $60{ }^{\circ} \mathrm{C}$. To prepare the nanocomposite photocatalyst of $\mathrm{Ti}(\mathrm{Ta}) \mathrm{S}_{2} / \mathrm{CdS}$, with a mass ratio of 1:1.4, $10 \mathrm{mg}$ of $\mathrm{TaS}_{2}$ or $\mathrm{TiS}_{2}$ was dispersed in $10 \mathrm{~mL}$ of water by sonication for $1 \mathrm{~h}$. Then, [0.1 mM] of $\mathrm{Cd}\left(\mathrm{CH}_{3} \mathrm{COO}\right)_{2}$ was added to it, and the mixture was mixed for $8 \mathrm{~h}$, followed by the addition of $[0.1 \mathrm{mM}] \mathrm{Na}_{2} \mathrm{~S}$ in $10 \mathrm{~mL}$ of water. The final product, which consisted of yellow CdS particles, was centrifuged and dried in air at $60^{\circ} \mathrm{C}$ for $12 \mathrm{~h}$.

$\mathrm{S}$. Chen et al. [109] synthesized a $\mathrm{CuNi@C}=\mathrm{O} / \mathrm{g}-\mathrm{C}_{3} \mathrm{~N}_{4}$ photocatalyst for hydrogen production, which was found to be active under visible light. The preparation for this photocatalyst started with the development of $\mathrm{CuNi@C}=\mathrm{O}$ nanoparticles. In order to obtain these, a blend of $0.755 \mathrm{~g}$ of copper (II) nitrate $\left(\mathrm{Cu}\left(\mathrm{NO}_{3}\right)_{2} 3 \mathrm{H}_{2} \mathrm{O}\right), 1.210 \mathrm{~g}$ of nickel (II) nitrate $\left(\mathrm{Ni}\left(\mathrm{NO}_{3}\right)_{2} 6 \mathrm{H}_{2} \mathrm{O}\right)$, and $1.876 \mathrm{~g}$ of tartaric acid $\left(\mathrm{C}_{4} \mathrm{H}_{6} \mathrm{O}_{6}\right)$ was stirred in $20 \mathrm{~mL}$ of deionized water to form solution A. Next, $5 \mathrm{~g}$ of polyethylene glycol was dissolved in a mixture of $48 \mathrm{~mL}$ glycerol, and $12 \mathrm{~mL}$ of water to produce solution $\mathrm{B}$. The two solutions ( $\mathrm{A}$ and $\mathrm{B}$ ) were mixed and sonicated for $1 \mathrm{~h}$, until a uniform blend was reached. Then, this new solution was transferred into a hydrothermal reactor, and kept at $150{ }^{\circ} \mathrm{C}$ for $3 \mathrm{~h}$. The resulting product was washed and centrifuged with ethanol three times, and dried at $100{ }^{\circ} \mathrm{C}$. Finally, the dried sample was calcined at $800{ }^{\circ} \mathrm{C}$ for $2 \mathrm{~h}$, under an inert Ar atmosphere, in order to obtain black $\mathrm{CuNi@C}=\mathrm{O}(\mathrm{CN})$ nanoparticles. The $\mathrm{CN}$ samples with different concentrations of $\mathrm{Cu}$ and $\mathrm{Ni}$ were achieved by adding two different mole ratios of $\mathrm{Cu}\left(\mathrm{NO}_{3}\right)_{2} 3 \mathrm{H}_{2} \mathrm{O}$ and $\mathrm{Ni}\left(\mathrm{NO}_{3}\right)_{2} 6 \mathrm{H}_{2} \mathrm{O}$. The g- $\mathrm{C}_{3} \mathrm{~N}_{4}$ material was prepared by a calcination method, with $20 \mathrm{~g}$ of urea being placed in a crucible and calcined in air, at $600{ }^{\circ} \mathrm{C}$ for $2 \mathrm{~h}$, resulting in a pale-yellow powder. Then, the $\mathrm{CuNi} @ \mathrm{C}=\mathrm{O} / \mathrm{g}-\mathrm{C}_{3} \mathrm{~N}_{4}$ photocatalyst was developed using a grinding-calcination-grinding method. Typically, to obtain this material, $\mathrm{CuNi@C}=\mathrm{O}$ and $\mathrm{g}-\mathrm{C}_{3} \mathrm{~N}_{4}$ were ground in an agate mortar for $1 \mathrm{~h}$, and then calcined under a $\mathrm{N}_{2}$ flow at $150{ }^{\circ} \mathrm{C}$ for $2 \mathrm{~h}$, and finally ground again.

Other types of photocatalysts, such as $\mathrm{Fe} / \mathrm{Al}_{2} \mathrm{O}_{3}-\mathrm{MCM}-41$ and $\mathrm{In}_{2} \mathrm{O}_{3} / \mathrm{Ta}_{2} \mathrm{O}_{5}$, were also studied and developed as efficient materials for hydrogen production, under visible light. Pradhan et al. [110] synthesized the mesoporous (mp) Fe $/ \mathrm{Al}_{2} \mathrm{O}_{3}-\mathrm{MCM}-41$ photocatalyst by sol-gel, followed by the application of an incipient wetness impregnation method. The mp- $\mathrm{Al}_{2} \mathrm{O}_{3}$ was prepared by using sucrose as a template. In order to obtain the mp$\mathrm{Al}_{2} \mathrm{O}_{3}-\mathrm{MCM}-41, \mathrm{mp}-\mathrm{Al}_{2} \mathrm{O}_{3}$ was incorporated into the MCM-41. A surfactant consisting of cetyltrimethylammonium bromide $\left(\mathrm{CTAB}, \mathrm{C}_{19} \mathrm{H}_{42} \mathrm{NBr}\right)$, and a source of silica consisting of tetraethyl orthosilicate (TEOS, $\mathrm{C}_{8} \mathrm{H}_{20} \mathrm{O}_{4}$ ) were used. The $\mathrm{Si} / \mathrm{Al}$ ratio in the mp- $\mathrm{Al}_{2} \mathrm{O}_{3}$ MCM-41 material was maintained at 10. The preparation of MCM-41 was adopted from Trens et al. [111]. The loads of $x \mathrm{wt} . \%$ iron $(\mathrm{Fe})$ were introduced onto the mp- $\mathrm{Al}_{2} \mathrm{O}_{3}-\mathrm{MCM}$ 41 by using an incipient wetness impregnation method, using a ferrous sulphate $\left(\mathrm{FeSO}_{4}\right)$ solution. Finally, the $\mathrm{Fe} / \mathrm{Al}_{2} \mathrm{O}_{3}-\mathrm{MCM}-41$ photocatalyst was calcined at $600{ }^{\circ} \mathrm{C}$ for $6 \mathrm{~h}$.

Leilei et al. [112] formulated the indium (III) oxide/tantalum (V) $\left(\mathrm{In}_{2} \mathrm{O}_{3} / \mathrm{Ta}_{2} \mathrm{O}_{5}\right)$ photocatalyst for hydrogen production. The tantalum pentoxide $\left(\mathrm{Ta}_{2} \mathrm{O}_{5}\right)$ microspheres were prepared by adding $0.4 \mathrm{~g}$ of $\mathrm{Ta}_{2}\left(\mathrm{OC}_{2} \mathrm{H}_{5}\right)_{5}$ to $10 \mathrm{~mL}$ of ethylene glycol in a $\mathrm{N}_{2}$ chamber, 
while stirring for $8 \mathrm{~h}$ at room temperature, until the formation of a transparent solution was obtained. Then, the solution was poured into a bath of $100 \mathrm{~mL}$ of acetone, containing $0.5 \mathrm{vol} . \%$ of water, and was stirred for $10 \mathrm{~min}$. After aging for $30 \mathrm{~min}$, the obtained white precipitate was removed by centrifugation. It was then washed with ethanol and deionized water (threefold). Finally, the resulting clean material was dried in a vacuum oven at $60^{\circ} \mathrm{C}$ for $24 \mathrm{~h}$ to obtain well-dispersed $\mathrm{Ta}_{2} \mathrm{O}_{5}$ microspheres. To acquire the resulting photocatalyst of $\mathrm{In}_{2} \mathrm{O}_{3} / \mathrm{Ta}_{2} \mathrm{O}_{5}$, an amount of $0.22 \mathrm{~g}$ of $\mathrm{Ta}_{2} \mathrm{O}_{5}$ microspheres was ultrasonically dispersed in $50 \mathrm{~mL}$ of water for $10 \mathrm{~min}$. Next, an $x$ amount of indium nitrate $\left(\operatorname{In}\left(\mathrm{NO}_{3}\right)_{3} n \mathrm{H}_{2} \mathrm{O}\right)$ was added to this, while stirring at ambient temperature. To obtain a precipitate, a solution of ammonia was added with constant stirring until the $\mathrm{pH}>9$. Subsequently, the obtained precipitate was separated by centrifugation, and washed with ethanol and deionized water. Then, the resulting solids were dried at $60^{\circ} \mathrm{C}$ for $24 \mathrm{~h}$ and annealed at $800{ }^{\circ} \mathrm{C}$ for $2 \mathrm{~h}$ to obtain a white powder of $\mathrm{In}_{2} \mathrm{O}_{3} / \mathrm{Ta}_{2} \mathrm{O}_{5}$ photocatalyst.

Figure 4 reports the hydrogen evolution and the photocatalyst particle concentrations for different heterojunction composite photocatalysts. For codes for different photocatalysts, refer to Appendix B Table A2.

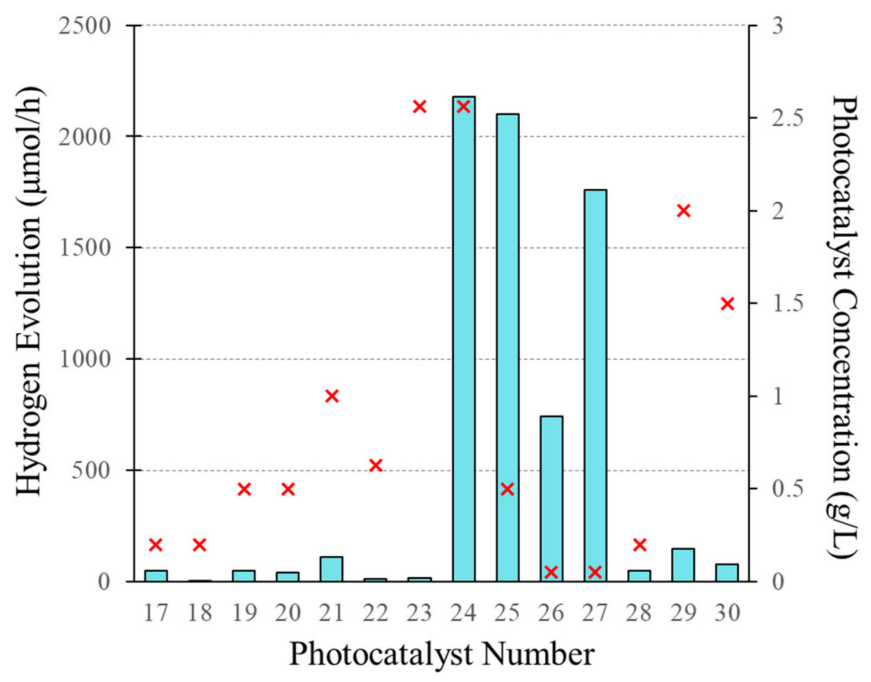

Figure 4. $\mathrm{H}_{2}$ Production and photocatalyst concentrations employed by different heterojunction composites. Notes: (1) bars represent hydrogen production; (2) cross-marks describe photocatalyst concentration (g/L); (3) for codes for various photocatalysts, refer to Appendix B Table A2.

In summary, this section reports the great diversity in the currently employed methods used to synthesize new $\mathrm{TiO}_{2}$-based and heterojunction composite photocatalysts for hydrogen formation, at near ambient temperature and pressure. These photocatalysts have the important property of being active under both near-UV and visible light irradiation. It is our view that $\mathrm{TiO}_{2}$-based photocatalysts are significantly more effective than heterojunction-based composites. In principle, the preparation methods for the $\mathrm{TiO}_{2}$-based photocatalysts are simpler, and the photochemical reaction for $\mathrm{H}_{2}$ production uses both small concentrations of photocatalyst loadings and less costly scavenger reagents (e.g., organic pollutants or ethanol at low concentrations). These features, we believe, make $\mathrm{TiO}_{2}$-based photocatalysts preferable for the development of new semiconductor materials and for reaction processes for the photocatalytic production of hydrogen.

\section{Photocatalytic Reactors for Hydrogen Production}

A central issue in the development of new technologies for hydrogen production is the availability of suitable kinetics. The rate equations that are involved in such kinetic modeling should allow one to evaluate the energy efficiencies and the photocatalytic reactor scale-up. In addition, and for a successful reactor scale-up, the following is recommended: (a) Homogeneous and uniform reactor light irradiation distribution; (b) A significant 
number of absorbed photons promoting $e^{-} / h^{+}$formation; and (c) Adequate mixing flow conditions for the slurry.

Given the above, photocatalytic reactors can be classified using the following criteria: (1) The type of irradiation used; (2) The position of the light sources; and (3) The photocatalyst deposition method [71]. Thus, and to address this matter, several photocatalytic reactor configurations and light sources are described in this literature review. These descriptions are accompanied by a comparison of their various photoreactor performances, as relevant for the degradation of different organic compounds with hydrogen production.

\subsection{Type of Light Source}

Photocatalytic hydrogen production relies heavily on the light source used. Most of the experimental data reported in this review were produced using different types of synthetic light sources, such as near-UV lamps and visible light lamps, which provide a limited fraction of the sun spectrum. Photocatalytic reactors using sunlight are, in principle, the best ones, given that the sun is a renewable source of photon energy (refer to Figure 5).

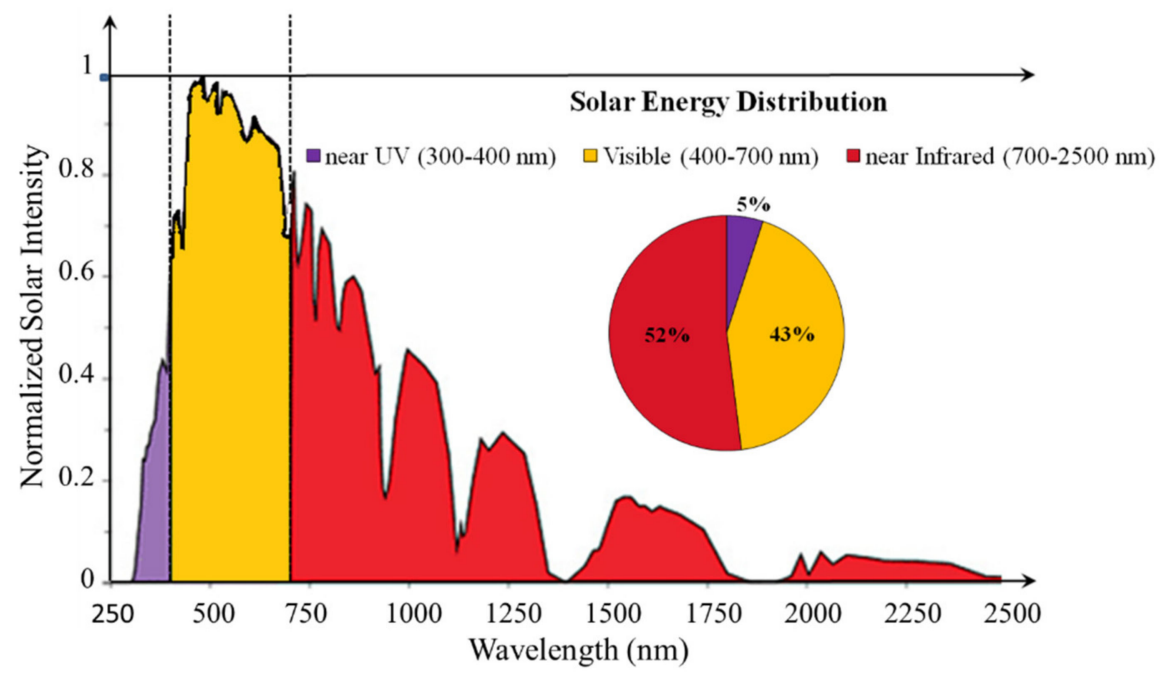

Figure 5. Solar energy spectrum distribution. This figure is reproduced with the permission of Catalysts, an MDPI research journal [113].

Table 2 summarizes the wavelength and power of an assortment of different types of commercial lamps, which are regularly employed for photocatalytic processes, including hydrogen generation, air purification, and water/wastewater pollution oxidation, and are reported in the technical literature.

\subsection{Location of Light Source}

Photoreactor design and performance are influenced by the position and the location of incident light sources. Figure $6 \mathrm{a}-\mathrm{d}$ report the photon flux irradiation patterns when using different types of light irradiation distributions. In photoreactors, the effect of radiation in Pyrex transmission walls is a minor one (less than $10 \%$ for near-UV), as documented in $[27,39,71]$.

Figure $6 \mathrm{a}, \mathrm{b}$ describe two possible tubular reactor configurations: (a) a single-lamp annular unit; and (b) a multilamp annular unit. These units show an enhanced photon absorption, with transmitted photons being transported through inner or outer lamp sources [115]. Furthermore, one can also see that the symmetrical light irradiation distributions facilitate the evaluation of the photons absorbed via the calculation of the macroscopy irradiation energy balances [39,65,66,116,117].

On the other hand, Figure $6 \mathrm{c}, \mathrm{d}$ show asymmetric light irradiation distributions. These light irradiation distributions are typical of photoreactor units using sun irradiation, with 
asymmetrical light irradiation making the evaluation of the absorbed light irradiation much more complex [118-121].

Table 2. Wavelengths and powers of different types of commercial light sources used in photocatalytic reactors for water and air treatment, as well as for hydrogen generation processes.

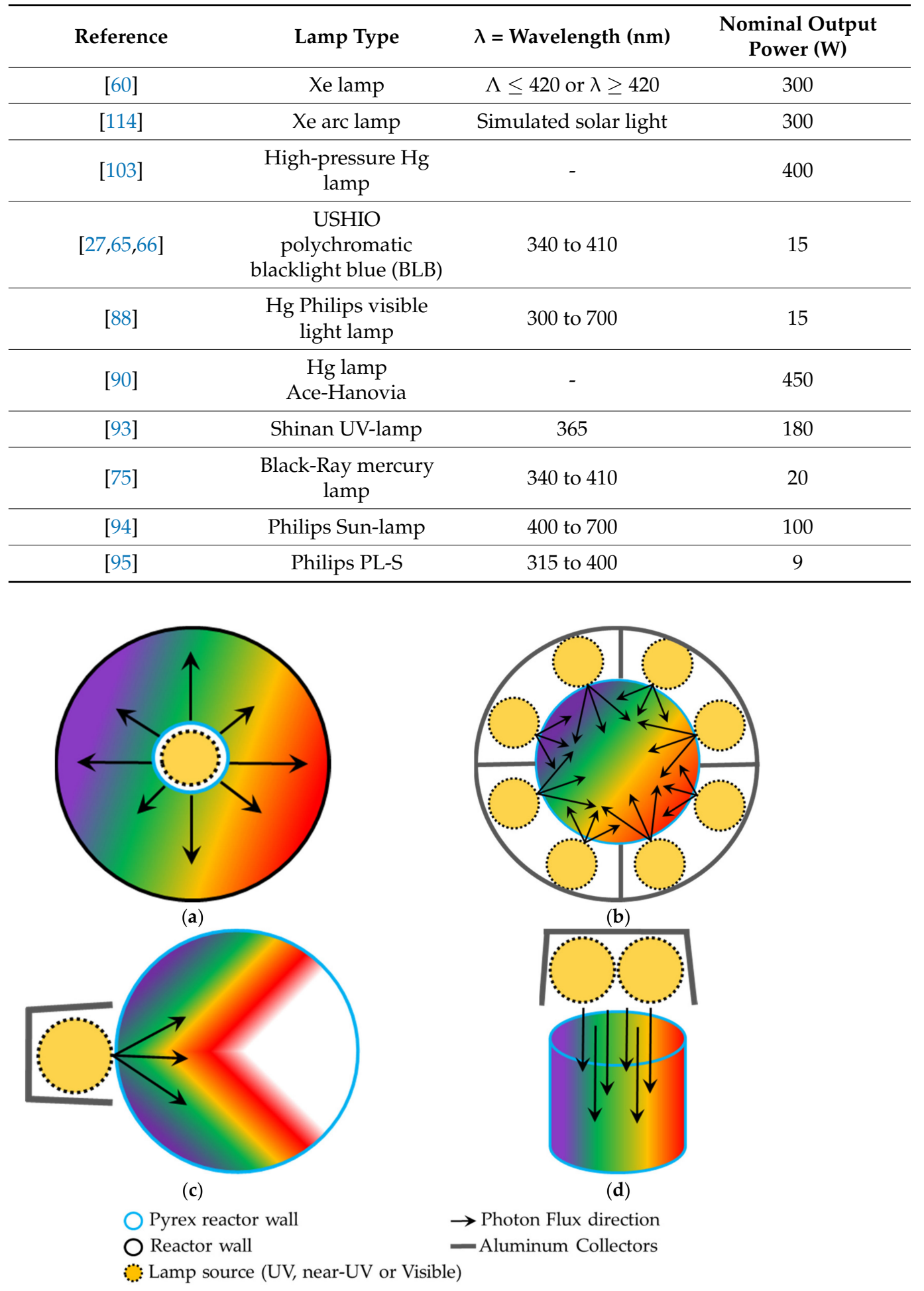

Figure 6. Light sources in photocatalytic reactors can be placed as follows: (a) internal-annular radial irradiation (top view); (b) external-annular radial irradiation (top view); (c) external-side radial irradiation (top view); and (d) top axial irradiation (side view). Cylindrical geometries are not exclusive, and rectangular geometries can also be applied [122-125]. 
Furthermore, it is important to mention that the photocatalytic reactor efficiency depends on the irradiation distribution on the photocatalyst surface. This irradiated photocatalyst surface can be available in a photoreactor as: (1) A film or; (2) Suspended particles in a slurry [113].

\subsection{Experimental Photocatalytic Reactors for the Photocatalytc Production of Hydrogen}

Escobedo et al. [65] employed a Photo-CREC Water-II (PCW-II) reactor to photodegrade organic pollutants and to produce hydrogen. This reactor includes an inner Pyrex glass tube with a black light blue lamp of $15 \mathrm{~W}$, with an emission range of 340-410 nm placed inside the inner tube. This photoreactor configuration produces a radial and axial symmetric radiation field. The PCW-II unit operates at standard room conditions (pressure and temperature), with a slurry solution being recirculated with a centrifugal pump in an annular space between the inner lamp in the Pyrex tube and an outer opaque polyethylene tube, resulting in fluid dynamic conditions without mass transfer processes limiting the overall photoconversion rate [71]. It also involves a sealed mixed hydrogen storage tank. The main reactor components and accessories are described in Figure 7. This system also facilitates the spectroradiometer measurements to obtain the macroscopic irradiation energy balances. Prior to the experiments, $0.9 \mathrm{~g}$ of a slurried photocatalyst was sonicated. This was performed to ensure good particle distribution, before the slurry was poured into a 6-L solution in the hydrogen storage tank. The 6-L solution was prepared with 2 vol. $\%$ ethanol (electron/hole scavenger) in water, and tested at different $\mathrm{pH}$ concentrations: 4, 7, and 10. The $\mathrm{pH}$ solution was adjusted to the level of 4, with 1-mL aliquots of $\mathrm{H}_{2} \mathrm{SO}_{4}$ [2M] This acidic process in the 2 vol. $\%$ ethanol solution with $\mathrm{DP} 25\left(\mathrm{TiO}_{2}\right)$ or $1 \mathrm{wt} . \%$ of $\mathrm{Pt} / \mathrm{TiO}_{2}$ (DP25) photocatalysts, resulted in the best hydrogen-producing conditions, yielding up to $202 \mu \mathrm{mol}$ and $1536 \mu \mathrm{mol}$ of hydrogen, respectively, during $6 \mathrm{~h}$ of irradiation time. The $\mathrm{pH}$ of 4 in the aqueous solution appears to promote a high concentration of $\mathrm{H}^{+}$ions, favoring water dissociation and the formation of hydronium ions. Furthermore, the excess of protons absorbed on the photocatalyst can interact more easily with the produced and stored electrons, boosting $\mathrm{H}^{\bullet}$ radicals formation and, consequently, hydrogen production $[65,126]$.

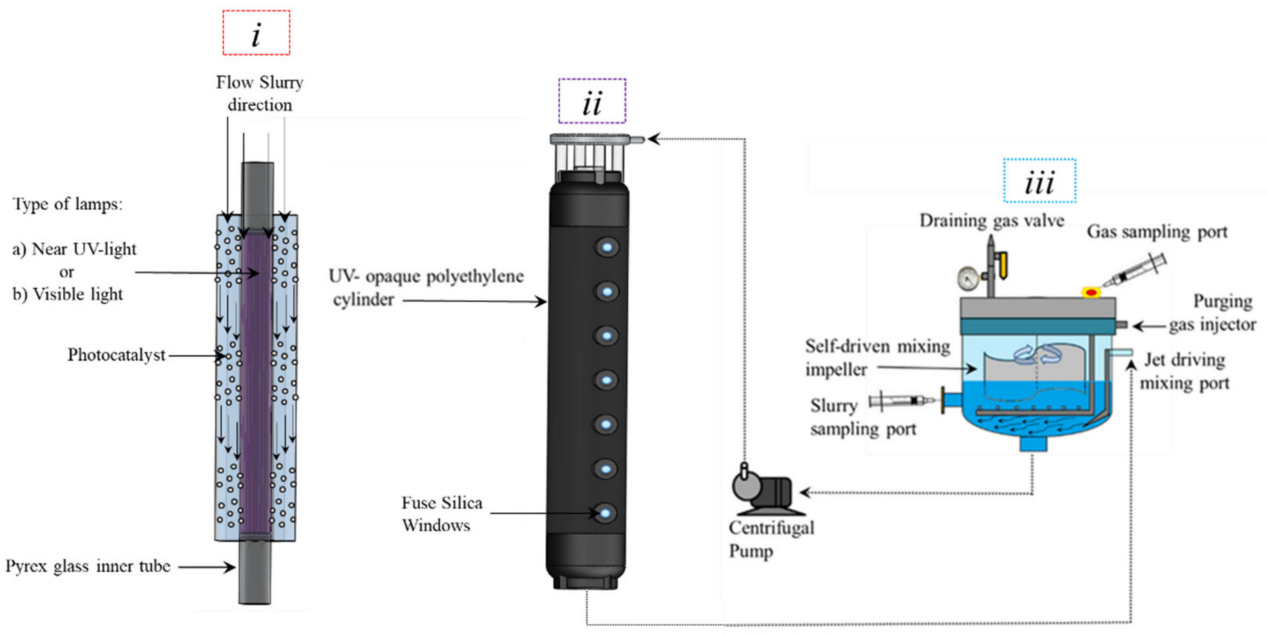

Figure 7. Schematic representation of the PCW-II reactor: (i) annular internal reactor view with lamp and photocatalyst slurry suspension; (ii) external tubular reactor view; and (iii) hydrogen storage tank view. Figure is reproduced with permission of the IEEC Research journal [39].

Enhanced results were observed by Guayaquil-Sosa et al. [27] with a mesoporous $\mathrm{TiO}_{2}$ photocatalyst. When loaded with $2.5 \mathrm{wt} . \% \mathrm{Pt} / \mathrm{mpTiO}_{2}-550{ }^{\circ} \mathrm{C}$, this yielded up to $1372 \mu \mathrm{mol}$ of $\mathrm{H}_{2}$. Furthermore, hydrogen production was 2.7 times higher for a photoconversion process of $6 \mathrm{~h}$. Rusinque et al. [66] also improved these findings by loading palladium (Pd) as a noble metal in mesoporous $\mathrm{TiO}_{2}$. These authors observed a large $\mathrm{H}_{2}$ evolution of 
$1617 \mu \mathrm{mol}$ and $5660 \mu \mathrm{mol}$, for mesoporous $\mathrm{TiO}_{2}$ and for $1 \mathrm{wt} . \% \mathrm{Pd} / \mathrm{mpTiO}_{2}-500{ }^{\circ} \mathrm{C}$, respectively [66]. Furthermore, Rusinque et al. [88] tested the $\mathrm{Pd} / \mathrm{mpTiO}_{2}-500{ }^{\circ} \mathrm{C}$ under visible irradiation, and found that the $0.25 \mathrm{wt} . \% \mathrm{Pd} / \mathrm{mpTiO}_{2}-500{ }^{\circ} \mathrm{C}$ photocatalyst displayed the best performance under visible light irradiation, producing $323 \mu \mathrm{mol}$ of $\mathrm{H}_{2}$.

Rayees Ahmad et al. [92] developed a reactor that was comprised of a simple Pyrex tube of a $20-\mathrm{cm}^{3}$ volume, which was horizontally placed under direct sunlight. This reactor contained $6 \mathrm{~g} / \mathrm{L}$ of $3 \mathrm{wt} . \% \mathrm{Cu}$ on $\mathrm{TiO}_{2}$ in a mixture of water/methanol (4:1). The reactor was purged with Ar and irradiated with direct sunlight during the months of May and August 2016, with an average solar energy flux of $\sim 637 \mathrm{~W} / \mathrm{m}^{2}$ and a temperature of $\sim 35^{\circ} \mathrm{C}$. These conditions generated, respectively, $400 \mu \mathrm{mol}$ of $\mathrm{H}_{2}$, or up to $1000 \mu \mathrm{mol}$ of $\mathrm{H}_{2}$ by using $3 \mathrm{wt}$. $\%$ of $\mathrm{Cu}$ on $\mathrm{TiO}_{2}$ (DP25), or, alternatively, by employing $3 \mathrm{wt} . \%$ of $\mathrm{Cu}$ on $\mathrm{mpTiO}_{2}$ during $6 \mathrm{~h}$ of irradiation.

Wang et al. [60] used a gas-closed system with a top-window Pyrex cell under visible light $(\lambda>420 \mathrm{~nm})$. These authors added $0.02 \mathrm{~g}$ of photocatalyst powder $\left(\mathrm{Zn}_{0.5} \mathrm{Cd}_{0.5} \mathrm{~S}\right.$ or g- $\mathrm{C}_{3} \mathrm{~N}_{4}$ ) to $100 \mathrm{~mL}$ of a liquid containing a mixture of sacrificial agents. The $\mathrm{Na}_{2} \mathrm{~S} / \mathrm{Na}_{2} \mathrm{SO}_{3}$ photocatalyst mixed with $\mathrm{Na}_{2} \mathrm{~S} / \mathrm{Na}_{2} \mathrm{SO}_{3}$ (1.4 M ratio), at a $\mathrm{pH} \sim 13$, resulted in $\sim 235 \mu \mathrm{mol}$ of $\mathrm{H}_{2}$ produced. The second g- $\mathrm{C}_{3} \mathrm{~N}_{4}$ photocatalyst was added to a solution of triethanolamine (20 vol. \%) at a $\mathrm{pH} 11$, which generated $\sim 28 \mu \mathrm{mol}$ of $\mathrm{H}_{2}$.

Kumaravel et al. [114] utilized g- $\mathrm{C}_{3} \mathrm{~N}_{4}$ and CdS photocatalysts to evaluate $\mathrm{H}_{2}$ production in a tightly closed immersion-type reactor of $1000 \mathrm{~mL}$ total volume (refer to Figure 8a). The experiments were carried out in $500 \mathrm{~mL}$ of double distilled water, mixed with a concentration of either a $10 \mathrm{vol} . \%$ of any alcohol (methanol, ethanol, etc.), or $0.1 \mathrm{M}$ of glucose, $\mathrm{Na}_{2} \mathrm{~S}$, $\mathrm{Na}_{2} \mathrm{SO}_{3}$, or a sulfide/sulfite mixture with $0.25 \mathrm{~g}$ of several photocatalysts. The highest $\mathrm{H}_{2}$ yields were reported when a triethanolamine (TEAO) solution was mixed with g- $\mathrm{C}_{3} \mathrm{~N}_{4}$ or CdS photocatalysts, showing $247 \mu \mathrm{mol}$ and $283 \mu \mathrm{mol}$ of $\mathrm{H}_{2}$ produced, respectively, at a $\mathrm{pH}$ of 12 . These results suggest the absence of surface hydrophilicity and the poor binding affinity with alcohols on the surface of $\mathrm{g}-\mathrm{C}_{3} \mathrm{~N}_{4}$ and $\mathrm{CdS}$.

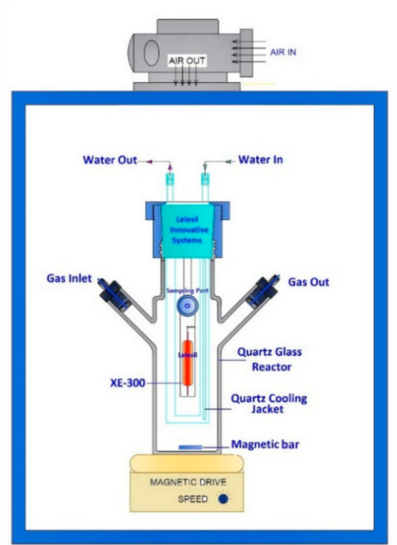

(a)

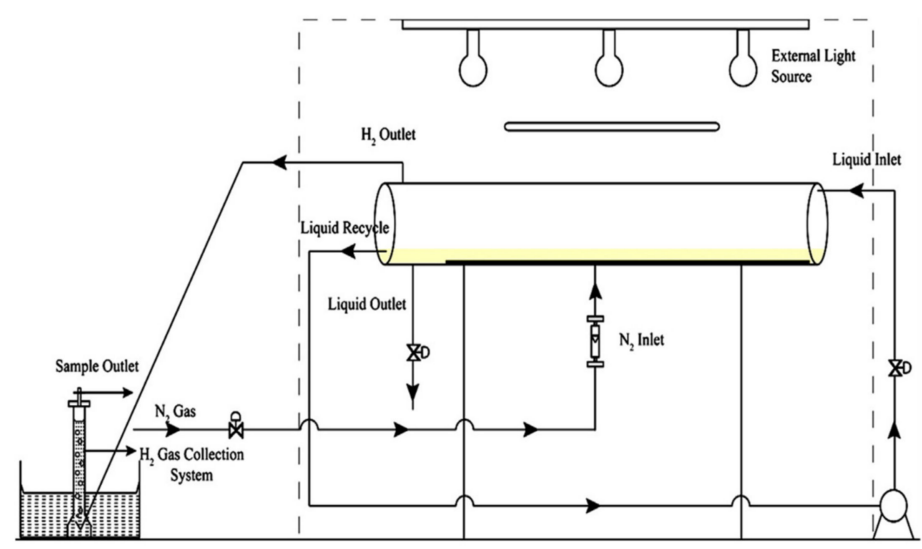

(b)

Figure 8. Schematic representation of two types of batch photocatalytic reactors for $\mathrm{H}_{2}$ production: (a) immersion unit, and (b) tubular unit. Figures are reproduced with permission of the MDPI journals, Catalysts [114] and Energy [94].

Ruban and Sellappa [94] designed a 5-L bench-scale plexiglass tubular reactor (refer to Figure $8 \mathrm{~b}$ ). The geometry of the system was selected to optimize the photocatalyst exposure to light, with three Philips lamps surrounding the reactor. These lamps consisted of two visible light lamps of $100 \mathrm{~W}(400-700 \mathrm{~nm})$, and one near-UV lamp of $8 \mathrm{~W}(365 \mathrm{~nm})$. The reactor consisted of two inlets (for $\mathrm{N}_{2}$ purging and for solution feeding) and two outlets (for $\mathrm{H}_{2}$ and for residual solution collection). These authors slurried the CdS-ZnS/DP25 photocatalyst in a solution of sodium sulfide $\left(\mathrm{Na}_{2} \mathrm{~S}\right)$ and sodium sulfite $\left(\mathrm{Na}_{2} \mathrm{SO}_{3}\right)$. The photocatalyst-water suspension was degassed with $\mathrm{N}_{2}$ for $\mathrm{O}_{2}$ removal. Then, $1 \mathrm{~L}$ of the suspension was recycled by a peristaltic pump and was maintained at $25^{\circ} \mathrm{C}$. These 
experiments studied the influence of different operating variables, obtaining an optimum $\mathrm{H}_{2}$ yield of $384 \mathrm{~mL}$ during $90 \mathrm{~min}$ of irradiation. The optimal conditions for the operation of this reactor were determined to be as follows: (a) Concentration of sulfide ion $=0.05 \mathrm{M}$; (b) Concentration of sulfite ion $=0.2 \mathrm{M}$; (c) $\mathrm{pH}=11$; (d) Catalyst concentration $=0.5 \mathrm{~g} / \mathrm{L}$; (f) Volume of wastewater $=250 \mathrm{~mL}$; and (g) Recycle flow rate $=18 \mathrm{~L} / \mathrm{h}$.

A different approach was adopted by Akihiko Kudo [103], where tantalate photocatalysts were synthesized by solid-state reactions or, alternatively, by using a flux method. This author found that a $0.2 \mathrm{wt} . \% \mathrm{NiO}$ on $\mathrm{NaTaO}_{3}: \mathrm{La}(1.5 \mathrm{~mol} \%)$ yielded a highly active photocatalyst, producing up to $882 \mathrm{mmol}$ of $\mathrm{H}_{2}$. This amount of $\mathrm{H}_{2}$ was obtained, after $400 \mathrm{~h}$, using a quartz cell, irradiated with a 400-W high-pressure lamp, with $1 \mathrm{~g}$ of suspended photocatalyst in $390 \mathrm{~mL}$ of water, and with $1 \mathrm{mM}$ of added $\mathrm{NaOH}$. The 4.1-eV-wide band gap and the $\mathrm{O}_{2}$ generation did not significantly hinder the high $\mathrm{H}_{2}$ production without sacrificial reagents.

In summary, the photocatalytic reactors reported in this review strongly suggest that the photocatalytic hydrogen yield is influenced by $e^{-} / h^{+}$scavengers, the $\mathrm{pH}$, the irradiation source, the photocatalyst type, and the reactor configuration. These parameters, however, should be examined further, in our view, in order to improve the photocatalytic reactions and the reactor performance for hydrogen production.

\section{Reaction Engineering of Photocatalytic Hydrogen Production}

The quantification of the liquid- and gas-phase intermediates and their evaluation are critical to the development of adequate kinetic models for photocatalytic hydrogen production. There are three important kinetic parameters required to assess photocatalytic performance: (i) The photoreaction rates; (ii) The adsorption constants; and (iii) The intrinsic kinetic constants. These parameters can be influenced by: (a) humidity, (b) temperature, (c) wavelength, (d) radiation intensity, (e) gas velocity, (f) residence time, (g) photocatalyst loading, (h) oxygen, and (i) the organic pollutant concentration. The improvement of these parameters can help us to advance the scale-up of photocatalytic processes [127].

\section{1. "Series-Parallel" Reaction Networks}

Photocatalytic reactions for hydrogen production can be described by using the formation of various by-products as a basis. Formed by-products are the result of photoinduced reduction and oxidation reactions. Furthermore, differences of kinetics are closely dependent on the photocatalyst type, and the electron/hole scavenger. Escobedo et al. [65] described a "series-parallel model", as reported in Figure 9. These authors modeled the photoconversion of ethanol (electron/hole scavenger) in water, with suspended $\mathrm{Pt} / \mathrm{DP} 25$ photocatalyst particles, in the PCW-II reactor. The quantified by-products were acetaldehyde $\left(\mathrm{C}_{2} \mathrm{H}_{4} \mathrm{O}\right)$, acetic acid $\left(\mathrm{CH}_{3} \mathrm{COOH}\right)$, methane $\left(\mathrm{CH}_{4}\right)$, ethane $\left(\mathrm{C}_{2} \mathrm{H}_{6}\right)$, and carbon dioxide $\left(\mathrm{CO}_{2}\right)$. In this case, by identifying several key formed chemical species, the reaction mechanism was adequately formulated. This was given the expected chemical changes occurring when the ethanol was consumed and the hydrogen was formed, under variable photon density, in the PCW-II reactor. In agreement with this, Dey and Pushpa [128] also found $\mathrm{CH}_{4}$ - and $\mathrm{CO}_{2}$-formed products using a suspension of $\mathrm{TiO}_{2}$ in alcohol solutions.

Later, Escobedo et al. [129] proposed a few modifications to the original "series-parallel" model by including hydrogen peroxide $\left(\mathrm{H}_{2} \mathrm{O}_{2}\right)$ to the formed by-products. Figure 10 describes the observable chemical species and the proposed reaction network during the photocatalytic generation of hydrogen.

Other interesting reaction networks of a similar nature were proposed by GuayaquilSosa et al. [130]. These authors also describe hydrogen formation with ethanol as a scavenger, while using a $\mathrm{Pt} / \mathrm{mpTiO}_{2}-550^{\circ} \mathrm{C}$ photocatalyst. The "series-parallel" model was also considered, as described in Figure 11. This process included the generation of $\mathrm{H}_{2} \mathrm{O}_{2}$ and the details of the oxidation/reduction network on the $\mathrm{mpTiO}_{2}$ and Pt sites, respectively. 


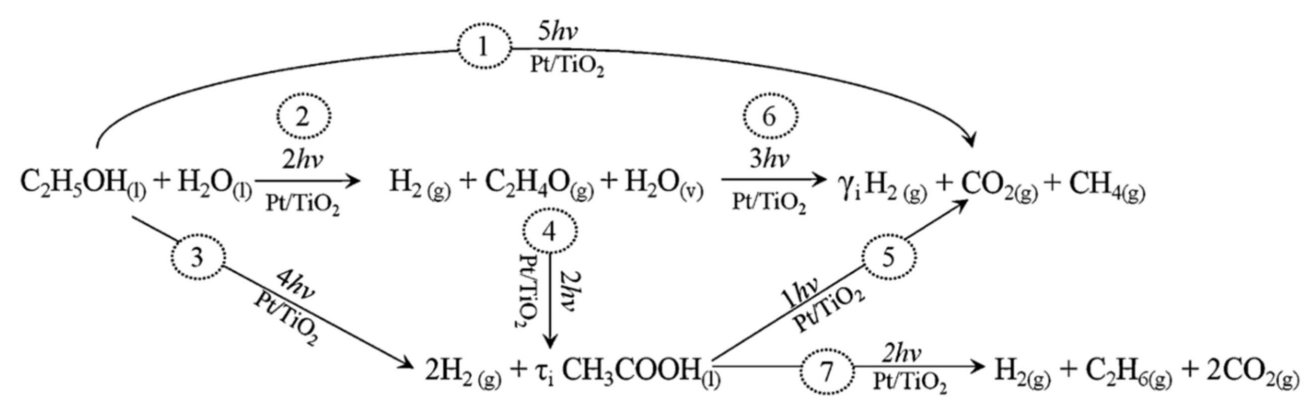

With: $\gamma_{1}=2, \gamma_{5}=0, \gamma_{6}=1$

$\tau_{5}=1, \quad \tau_{7}=2$

Figure 9. "Series-parallel" reaction network for photocatalytic $\mathrm{H}_{2}$ production when ethanol is the organic source pollutant (electron/hole scavenger), and when a Pt/DP25 photocatalyst is used. Note: the stoichiometric coefficients are designated as $\gamma_{i}$ and $\tau_{i}$. Figure is reproduced with the permission of the APCATB: Environmental research journal [65].

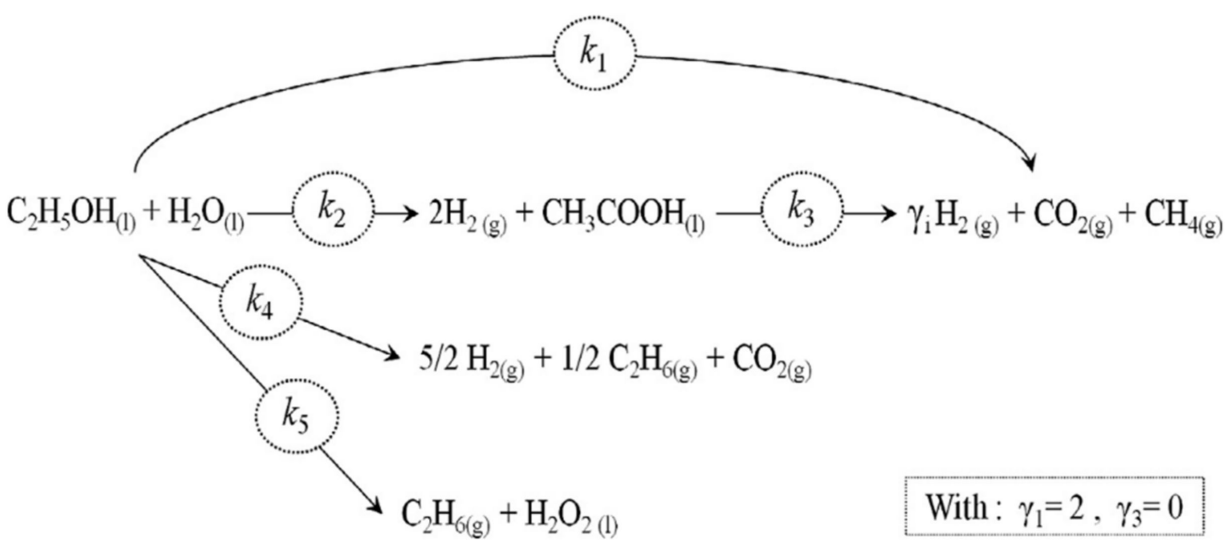

Figure 10. New proposed "series-parallel" reaction network for the photoconversion of ethanol during hydrogen generation using a Pt/DP25 photocatalyst. Note: $\gamma \mathrm{i}$ being $\gamma_{1}=2$ for path 1 , and $\gamma_{3}$ $=0$ for path 2 are the stoichiometric coefficients for steps 1 and 3 , respectively. Figure is reproduced with the permission of the Fuel research journal [129].

(a)

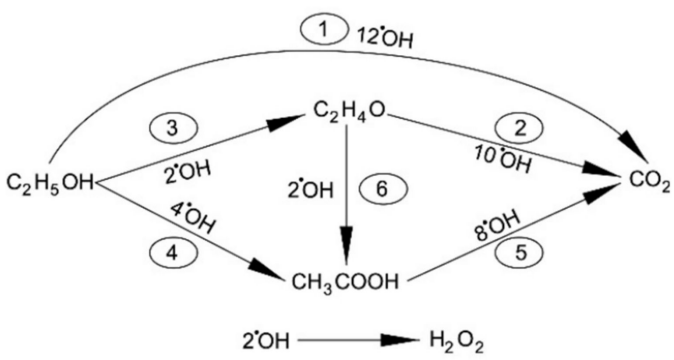

(b)

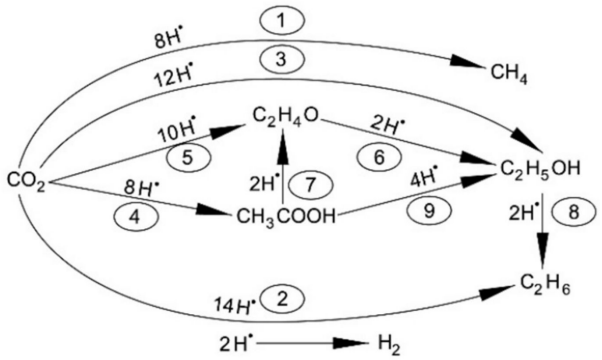

Figure 11. Alternative "series-parallel" reaction network for the photoconversion of ethanol during hydrogen formation using a $\mathrm{Pt} / \mathrm{mpTiO}_{2}-550^{\circ} \mathrm{C}$ photocatalyst: (a) oxidation on the $\mathrm{mpTiO}_{2}$ site, and (b) reduction on the Pt site. Figure is replicated with permission of the MDPI Catalysts research journal [130].

As shown in Figure 12a, Rusinque et al. [126] further considered a similar "seriesparallel" reaction network. These authors propose a reaction mechanism with suspended $\mathrm{Pd} / \mathrm{mpTiO}_{2}$ photocatalyst particles reacting with a solution of $2 \mathrm{vol}$. $\%$ ethanol. This mechanism involved a number of formed by-products, such as methane $\left(\mathrm{CH}_{4}\right)$, ethane $\left(\mathrm{C}_{2} \mathrm{H}_{6}\right)$, ethylene $\left(\mathrm{C}_{2} \mathrm{H}_{4}\right)$, acetaldehyde $\left(\mathrm{C}_{2} \mathrm{H}_{4} \mathrm{O}\right)$, carbon monoxide $(\mathrm{CO})$, and carbon dioxide $\left(\mathrm{CO}_{2}\right)$. 
In agreement with this, Bahruji et al. [91] report that the decomposition of the several alcohols on well-defined and pure $\mathrm{Pd}$ surfaces plays an important role in modified $\mathrm{TiO}_{2}$ activity. The findings obtained by Bahruiji et al. were not limited to alcohols, but also pertain to a variety of oxygenates [91]. In this way, these authors emphasize the role of $\mathrm{Pd}$ particles deposited on DP25 during irradiation, preventing $\mathrm{CO}$ poisoning on the photocatalytic surface, while allowing alcohol adsorption and reforming at ambient conditions. The decomposition scheme of $\mathrm{CH}_{3} \mathrm{OH}$ suggested by Bahruji et al. is shown in Figure 12b.

(a)

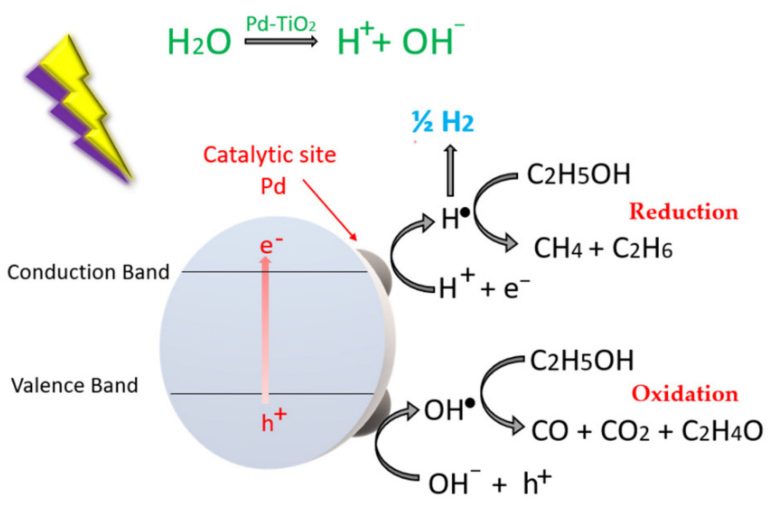

(b)

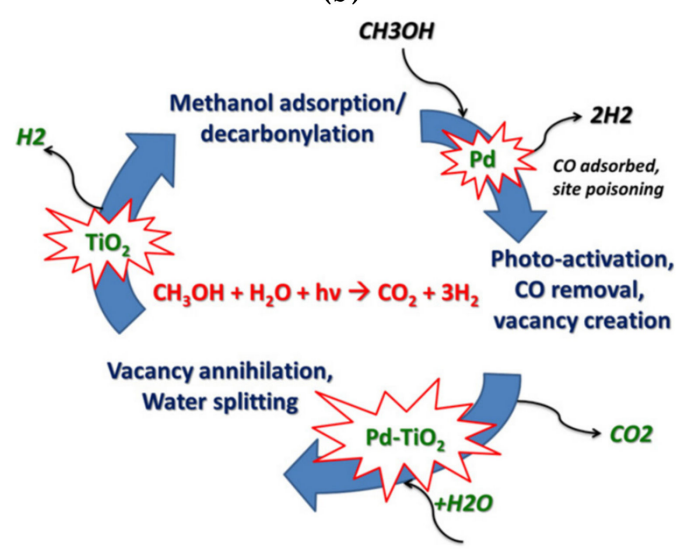

Figure 12. Conceptual diagrams of two different reaction schemes for the decomposition of alcohols: (a) "in-seriesparallel" hydrogen reaction network for the photoconversion of ethanol using a $\mathrm{Pd} / \mathrm{mpTiO}_{2}-500{ }^{\circ} \mathrm{C}$ photocatalyst, and (b) photocatalytic cycle of $\mathrm{CH}_{3} \mathrm{OH}$, using a of $5 \mathrm{wt} . \% \mathrm{Pd} / \mathrm{DP} 25$. Photocatalyst figures are replicated with the permission of the MDPI Catalysts research journal [126] and the APCATB: Environmental research journal [91]. Note for (a): the $\mathrm{OH}^{\bullet}$ and $\mathrm{H}^{\bullet}$ radical species refer to the $\mathrm{OH}^{\bullet}$ and $\mathrm{H}^{\bullet}$ adsorbed species on the photocatalyst surface.

To address the role of the scavenger, other authors have studied the influence of the incorporation of metal oxides to the $\mathrm{mpTiO}_{2}$, as well as the use of different electron/hole scavengers, such as methanol $\left(\mathrm{CH}_{3} \mathrm{OH}\right)$, in the hydrogen formation reaction network. On this basis, Rayees et al. [92] propose a mechanism, as shown in Figure 13a, for a $\mathrm{Cu} / \mathrm{mpTiO}_{2}$ photocatalyst. A similar pathway for a reaction network was proposed by Montoya and Gillan [90] using a Cu or a Ni/DP25 $\left(\mathrm{TiO}_{2}\right)$ photocatalyst, as described in Figure $13 b$.

(a)

(i) $\mathrm{CH}_{3} \mathrm{OH} \stackrel{h v / \text { photocatalyst }}{\longrightarrow} \mathrm{HCHO}+\mathrm{H}_{2}$

(ii) $\mathrm{HCHO}+\mathrm{H}_{2} \mathrm{O} \stackrel{\text { hv/photocatalyst }}{\longrightarrow} \mathrm{HCOOH}+\mathrm{H}_{2}$

(iii) $\mathrm{HCOOH} \stackrel{\text { hv/photocatalyst }}{\longrightarrow} \mathrm{CO}_{2}+\mathrm{H}_{2}$ (b)

$$
\begin{aligned}
& \text { a) } \mathrm{TiO}_{2}+\mathrm{hv}(>\mathrm{Eg}) \rightarrow \mathrm{e}^{-}\left(\mathrm{TiO}_{2} \mathrm{CB}\right)+\mathrm{h}^{+}\left(\mathrm{TiO}_{2} \mathrm{VB}\right) \\
& \text { b) } \mathrm{e}^{-}\left(\mathrm{TiO}_{2} \mathrm{CB}\right)+\operatorname{Surface}\left(\mathrm{M}^{+} / \mathrm{M}^{2+}\right) \rightarrow \mathrm{TiO}_{2} / \mathrm{M}_{(\text {reduced })} \\
& \text { c) } 2 \mathrm{e}^{-}\left(\mathrm{TiO}_{2} \mathrm{CB}\right)+{ }^{\mathrm{TiO}_{2}} / \mathrm{M}_{(\text {reduced })}+2 \mathrm{H}^{+} \rightarrow \mathrm{H}_{2}+\mathrm{TiO}_{2} / \mathrm{M}_{\text {(reduced }} \\
& \text { d) } 2 \mathrm{~h}^{+}\left(\mathrm{TiO}_{2} \mathrm{VB}\right)+\mathrm{CH}_{3} \mathrm{OH} \rightarrow \mathrm{CH}_{2} \mathrm{O}+2 \mathrm{H}^{+}
\end{aligned}
$$

Figure 13. Hydrogen formation reaction network consisting of the photoconversion of $\mathrm{CH}_{3} \mathrm{OH}$ by two photocatalysts: (a) a $\mathrm{Cu} / \mathrm{mpTiO}_{2}$ [92], and (b) a M/DP25 $\left(\mathrm{TiO}_{2}\right)$ [90]. Note that the metal promotor, designated with "M", represents either $\mathrm{Cu}$ or Ni.

Furthermore, other important photocatalytic routes for hydrogen production involved other scavengers, such as glycerol $\left(\mathrm{C}_{3} \mathrm{H}_{8} \mathrm{O}_{3}\right)$. Fujita et al. [97] propose an overall stoichiometry using $\mathrm{NiO}_{\mathrm{x}} / \mathrm{TiO}_{2}$ photocatalysts, as shown in Figure 14a. This reaction was also described at the more basic mechanistic level by Panagiotopoilou et al. [131], as shown in Figure $14 \mathrm{~b}$. The proposed mechanism displays the different possible reactions that might occur while using a $\mathrm{Pt} / \mathrm{TiO}_{2}$ photocatalyst. 
(a)

$$
\mathrm{C}_{3} \mathrm{H}_{8} \mathrm{O}_{3}+3 \mathrm{H}_{2} \mathrm{O} \underset{h v}{\stackrel{\mathrm{NiO}_{\mathrm{x}} / \mathrm{TiO}_{2}}{\longrightarrow}} 7 \mathrm{H}_{2}+3 \mathrm{CO}_{2}
$$

(b)

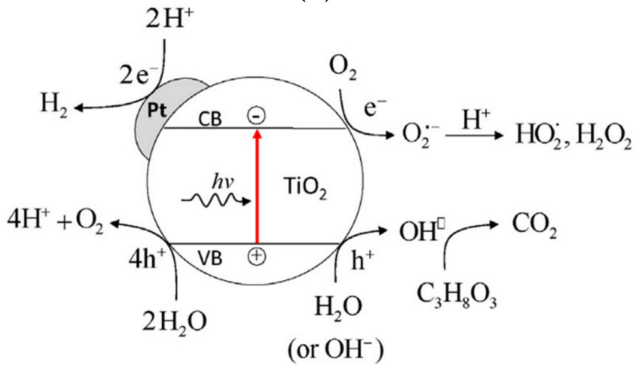

Figure 14. Photocatalytic conversion scheme for $\mathrm{H}_{2}$ production from glycerol and water, using two different photocatalysts: (a) $\mathrm{NiO}_{\mathrm{x}} / \mathrm{TiO}_{2}$ [97], and (b) $\mathrm{Pt} / \mathrm{TiO}_{2}$. Figure (b) is reproduced with the permission of the Elsevier journal, Catalysis Today [131].

\subsection{Adsorption Models}

\subsubsection{Langmuir Isotherm}

It is essential that the adsorption constants of all the chemical species involved in photocatalytic hydrogen production processes be assessed. Adsorption models, including Langmuir isotherms, are recommended to accomplish this. Thus, the Langmuir adsorption isotherm can also be considered a suitable expression to determine the adsorbed species on the $\mathrm{TiO}_{2}$, at equilibrium $[71,129,132,133]$. This equation is represented as follows:

$$
\theta_{A}=\frac{Q_{e q, a d s}}{Q_{e q, \max }}=\frac{K_{e q, i}^{A} C_{e q, i}}{\left(1+K_{e q, i}^{A} C_{e q, i}\right)}
$$

where $\theta_{A}$ stands for the dimensionless surface species concentration; $Q_{e q, a d s}$ and $Q_{e q, \text { max }}$ represent the existing and maximum equilibrium adsorption surface concentrations ( $\left.\mathrm{mol} / \mathrm{g}_{\text {cat }}\right)$, respectively; $C_{e q, i}$ denotes " $i$ ", which is the species equilibrium concentration in the gas/liquid phase $(\mathrm{mol} / \mathrm{L})$; and $K_{e q, i}^{A}$ is the adsorption equilibrium constant $(\mathrm{L} / \mathrm{mol})$. In this respect, only a few studies estimate the adsorption constants using independent equilibrium experiments. Adsorption parameters can be assessed using "dark" conditions (without irradiation). This precondition allows for independently calculated adsorption parameters, minimizing the cross-correlation of the intrinsic kinetic parameters. Therefore, it is acceptable to independently calculate the Langmuir adsorption parameters in order to minimize both the cross-correlation and the uncertainty of the parameter calculations [134-136]. Bahruji et al. [91] confirmed that the adsorption of alcohols (methanol, ethanol, n-propanol, i-propanol) is, indeed, carried out at ambient conditions, on $\mathrm{Pd} / \mathrm{TiO}_{2}$ photocatalysts.

Interesting studies have been developed to understand the photocatalytic performance of alcohols (electron/hole scavengers). This has led to extensive surface studies, with different photocatalyst materials. Escobedo et al. [6,129] present an adsorption study using 2 vol.\% ethanol on $\mathrm{Pt} / \mathrm{DP} 25$, at a $\mathrm{pH}$ of 4 . The authors recirculated the photocatalyst slurry in the PCW-II reactor, under "dark conditions" (no irradiation provided), to measure the equilibrium adsorption of ethanol $\left(\mathrm{C}_{2} \mathrm{H}_{5} \mathrm{OH}\right)$, with a regression coefficient $\left(\mathrm{R}^{2}\right)$ of 0.998 . Rusinque et al. [126] also determined the adsorption isotherm parameter of hydrogen peroxide $\left(\mathrm{H}_{2} \mathrm{O}_{2}\right)$ in the liquid phase, using a $\mathrm{Pd} / \mathrm{mpTiO}_{2}$ in the PCW-II reactor, with an $\mathrm{R}^{2}$ of 0.995. Rivero et al. [95] calculated the adsorption parameter of $\mathrm{CH}_{3} \mathrm{OH}$ for a $\mathrm{Pt} / \mathrm{rGO} / \mathrm{DP} 25$ photocatalyst, with an $\mathrm{R}^{2}$ of 0.993 . Table 3 presents the Langmuir parameters assessed in the different studies. 
Table 3. Langmuir adsorption parameters obtained when using different sacrificial agents and photocatalysts for $\mathrm{H}_{2}$ generation.

\begin{tabular}{|c|c|c|c|c|}
\hline \multirow{2}{*}{ Ref. } & \multirow{2}{*}{ Photocatalyst } & \multirow{2}{*}{ Adsorbate } & Adsorption Constants & \multirow{2}{*}{$\mathbf{R}^{2}$} \\
\hline & & & $K_{e q, i}^{A}\left(\mathrm{~L} \mathrm{~mol}^{-1}\right)$ & \\
\hline$[6,129]$ & $1 \mathrm{wt} . \% \mathrm{Pt} / \mathrm{DP} 25$ & $\mathrm{C}_{2} \mathrm{H}_{5} \mathrm{OH}$ & 1.427 & 0.998 \\
\hline [126] & 0.25 wt. $\% \mathrm{Pd} / \mathrm{mpTiO}_{2}$ & $\mathrm{H}_{2} \mathrm{O}_{2}$ & $31.633 \times 10^{3}$ & 0.995 \\
\hline [95] & 0.5 wt. $\%$ Pt/(5 wt. $\%)$ rGO/DP25 & $\mathrm{CH}_{3} \mathrm{OH}$ & 1.138 & 0.993 \\
\hline$[52,95]$ & $\mathrm{Pt} / \mathrm{TiO}_{2}$ & $\mathrm{C}_{2} \mathrm{H}_{5} \mathrm{OH}$ & 1.521 & 0.990 \\
\hline [97] & 2 wt. $\% \mathrm{NiO} / \mathrm{TiO}_{2}$ & $\mathrm{C}_{3} \mathrm{H}_{8} \mathrm{O}_{3}$ & 3.000 & 0.930 \\
\hline
\end{tabular}

\subsubsection{Langmuir-Hinshelwood Kinetic Model}

It is important to establish kinetic models for photocatalytic hydrogen production. These studies help us to design, develop, and scale-up high-efficiency photoreactors. It is proposed that, for this type of model development, the rate equations should include the organic pollutant (e.g., $\mathrm{CH}_{3} \mathrm{OH}, \mathrm{C}_{2} \mathrm{H}_{6} \mathrm{OH}$, etc.) adsorption and conversion, as well as the formation of $\mathrm{H}_{2}$ and other by-products [129]. In general, it is also valid to use the empirical rates of the chemical species during the oxidation/reduction process, without considering the detailed reaction networks or mechanistic steps [137].

In most studies, the photocatalytic hydrogen production is a heterogeneous process. These processes take advantage of organic chemical pollutants (or electron/hole scavengers). The photocatalytic activities of these systems can also be easily and commonly described with the Langmuir-Hinshelwood (L-H) model, which is represented with the following equation:

$$
r_{i}=\operatorname{LVRPA} f\left[H^{+}\right] \frac{K_{i}^{A} k_{i}^{l} C_{i}}{1+\sum_{j=1}^{n} K_{j}^{A} C_{j}}=\frac{K_{i}^{A} k^{*} C_{i}}{1+\sum_{j=1}^{n} K_{j}^{A} C_{j}}
$$

The parameters involved are: (a) The LVRPA, which denotes the local volumetric rate of photon absorption; (b) $f\left[\mathrm{H}^{+}\right]$, which represents the variability of the $\mathrm{pH}$ on the photocatalytic reaction; (c) $K_{i}^{A}$, which is the adsorption constant $(\mathrm{L} / \mathrm{mol})$; (d) $k^{*}$, which denotes the apparent reaction kinetic constant $\left(\mathrm{mol} / \mathrm{g}_{\text {cat }} \mathrm{h}\right)$; and (e) $C_{i}$, which stands for the concentration of chemical species $(\mathrm{mol} / \mathrm{L})$.

Escobedo et al. [129] studied a PCW-II photoreactor, operated in the batch mode. This unit allows one to account for the chemical species balances for each observable individual chemical species, " $i$ ", which can be represented with the following photoreaction rate equation:

$$
r_{i}=\frac{1}{W_{i r r, c a t}} \frac{d N_{i}}{d t}=\frac{V}{W_{i r r, c a t}} \frac{d C_{i}}{d t}
$$

with $W_{i r r, c a t}$ being the irradiated photocatalyst mass ( $\left.\mathrm{g}_{\mathrm{cat}}\right) ; \mathrm{V}$ being the total reactor volume $(\mathrm{L}) ; N_{i}$ being the moles of the " $i$ " chemical species; and $t$ being the irradiation time (min).

By combining Equations (3) and (4), as well as by incorporating an apparent constant photoreaction rate, $k_{i}^{a p p}$, for the " $i$ " chemical species, one can obtain Equation (5):

$$
r_{i}=\frac{d C_{i}}{d t}=\frac{k_{i}^{a p p} C_{i}}{1+\sum_{j=1}^{n} K_{j}^{A} C_{j}}
$$

Equation (5) is useful for describing the chemical changes of species, " $i$ ", in the PCW-II reactor, including the organic pollutants and intermediate species [71]. Escobedo et al. [129] modeled the various reaction steps of the photocatalytic hydrogen production, from a solution of ethanol and a Pt/DP25 photocatalyst, using the L-H equation. These authors considered some specific assumptions: (a) The organic pollutant and by-products can be adsorbed on the surface of the photocatalyst; (b) The adsorption is considered to be in 
dynamic equilibrium; and (c) No chemical species are affected by the photolysis process. The kinetic model for this photocatalytic system was described with a set of ordinary differential equations (ODEs). These equations were established based on the "seriesparallel" reaction network presented in Figure 9, assuming that the ethanol batch mode photoreactor was the dominant adsorbed species, such as $\sum_{j=1}^{n} K_{j}^{A} C_{j} \approx K_{E t O H}^{A} C_{E t O H}$

(1) Ethanol $(E t O H)$

$$
r_{E t O h}=\frac{d N_{E t O H}}{d t}=\frac{-V C_{E t O H}\left(k_{1}+k_{2}+k_{4}+k_{5}\right)}{1+K_{E t O H}^{A} C_{E t O H}}
$$

(2) Acetic Acid $(A A)$

$$
\frac{d N_{A A}}{d t}=\frac{V C_{E t O H}\left(k_{2} C_{E t O H}-k_{3} C_{A A}\right)}{1+K_{E t O H}^{A} C_{E t O H}}
$$

(3) Carbon Dioxide $(C D)$

$$
\frac{d N_{C D}}{d t}=\frac{V\left[C_{E t O H}\left(k_{1}+k_{4}\right)+k_{3} C_{A A}\right]}{1+K_{E t O H}^{A} C_{E t O H}}
$$

(4) Ethane $(E)$

$$
\frac{d N_{E}}{d t}=\frac{V C_{E t O H}\left(\frac{1}{2} k_{4}+k_{5}\right)}{1+K_{E t O H}^{A} C_{E t O H}}
$$

(5) Methane (M)

$$
\frac{d N_{M}}{d t}=\frac{V\left(k_{1} C_{E t O H}+k_{3} C_{A A}\right)}{1+K_{E t O H}^{A} C_{E t O H}}
$$

(6) Hydrogen $(H)$

$$
\frac{d N_{H}}{d t}=\frac{V C_{E t O H}\left(2 k_{1}+2 k_{2}+2.5 k_{4}\right)}{1+K_{E t O H}^{A} C_{E t O H}}
$$

The results obtained for the five kinetic constants, after solving the set of ODEs, are reported in Table 4 . These are optimized values that are reported with their $95 \%$ confidence intervals $(\mathrm{CI})$ and standard deviations $( \pm \mathrm{SD})$. These results confirm the adequacy of the model approach for obtaining reliable kinetic parameters.

Table 4. Optimized kinetic parameters calculated with a set of ODEs, using the L-H Equation to obtain the "series-parallel" reaction network of Figure 9, for the photoconversion of ethanol during $\mathrm{H}_{2}$ generation [129].

\begin{tabular}{cccc}
\hline Parameter & Value (h-1) & $\mathbf{9 5 \% ~ C I ~ ( \% ) ~}$ & \pm SD (\%) \\
\hline$k_{1}$ & $2.01 \times 10^{-6}$ & 21.6 & 11.5 \\
\hline$k_{2}$ & $2.23 \times 10^{-6}$ & 23.5 & 10.4 \\
\hline$k_{3}$ & $1.63 \times 10^{-2}$ & 4.6 & 83.0 \\
\hline$k_{4}$ & $5.18 \times 10^{-6}$ & 3.9 & 2.3 \\
\hline$k_{5}$ & $6.63 \times 10^{-6}$ & 4.4 & 2.2 \\
\hline
\end{tabular}

In this respect, Rivero et al. [95] described a similar simplification of the L-H kinetic model with methanol scavenger, used to obtain the maximum generated rate of hydrogen as follows:

$$
\frac{d N_{\mathrm{H}}}{d t}=\frac{k_{\mathrm{H}_{2}} K_{\mathrm{MeOH}}^{A} C_{\mathrm{MeOH}}}{1+K_{\mathrm{MeOH}}^{A} C_{\mathrm{MeOH}}}
$$


The experimental data was fitted with the initial methanol $(\mathrm{MeOH})$ concentrations, ranging from 1.23 to $27.27 \mathrm{~mol} / \mathrm{L}$ (5-70 vol.\%), and with a photocatalyst of Pt/rGO/DP25. The value of $k_{\mathrm{H}_{2}}$ was $1.37 \times 10^{-4} \mathrm{~mol} / \mathrm{h}$, and that of $\mathrm{K}_{\mathrm{MeOH}}^{A}$ was $1.1138 \mathrm{~L} / \mathrm{mol}$ [95].

\section{Energy Efficiency Studies in Photoreactors for Hydrogen Production}

In this review, we summarize some of the efficiency parameters in photocatalytic processes. These parameters are the quantum yields (QYs or $\varphi$ ), and photocatalytic thermodynamic efficiency factors (PTEFs), which are the key energy efficiency performance estimators in photocatalysis. Furthermore, these parameters help us to evaluate the photoreactor's efficiency during the hydrogen formation. Appendices A and B Table A2 report a comparison of the QYs and the PTEFs, using different doped and nondoped $\mathrm{TiO}_{2}$-based photocatalysts, as well as heterojunction photocatalysts, for photocatalytic $\mathrm{H}_{2}$ production.

While one can understand the relevance of energy efficiencies to establish the photocatalytic reactor design performance to produce hydrogen, their evaluation remains a challenge. This is due to the lack of information about the following key parameters: (1) The photocatalyst absorbed irradiation; (2) The reaction mechanism (or networks);

(3) The adsorption constant $\left(K_{e q, i}^{A}\right)$; and (4) The intrinsic kinetic constants $\left(k_{i}\right)$.

\subsection{Quantum Yields (QYs or $\varphi$ )}

The quantum yield (QY or $\varphi$ ) is known as an important energy-efficiency estimator used to determine the efficiency of photocatalytic photoconversion processes. This parameter can be defined as the photoreaction rate (photoconverted molecules per unit time) divided by the photon absorption rate (number of photons entering the reactor) [71]. The quantum yield designation, which has been used by several authors, can be classified into several subcategories: (a) The primary quantum yield; (b) The overall quantum yield; (c) the apparent or global quantum yield; and (d) The quantum yield.

In this respect, Cassano et al. [138] consider a primary quantum yield always smaller than 1, as follows:

$$
\text { Primary } Q Y=\frac{\text { moles of pollutant degraded from a primary process } / \mathrm{s}}{\text { moles of photons absorbed } / \mathrm{s}}
$$

Cassano et al. [138], and Davydov et al. [139] proposed and implemented an overall quantum yield, with interesting prospects for photocatalytic processes, which, in principle, could be greater than 1 :

$$
Q Y_{\text {Overall }}=\frac{\text { moles of pollutant degraded via primary and a secundary process } / \mathrm{s}}{\text { moles of photons absorbed } / \mathrm{s}}
$$

Furthermore, and in cases where the moles of the absorbed photons were not available, an apparent quantum yield $\left(\mathrm{QY}_{a p p}\right)$ was considered as an alternative by using the photons irradiated into a reactor unit. While this approach is one frequently considered in the literature because of its relatively easy application, it is not very accurate [90,92,137,140-142]. The apparent QYapp can be defined as follows:

$$
Q Y_{a p p}=\frac{\text { moles of pollutant degraded via a primary process } / \mathrm{s}}{\text { moles of incident photons entering the photoreactor } / \mathrm{s}}
$$

Finally, a valuable variation of the quantum yield definition was proposed by Salaices et al. [67] as the ratio of the $\mathrm{OH}^{\bullet}$ radical consumption rate over the absorbed photons rate $\left(P_{a}\right)$. The $P_{a}$ was primarily measured in photocatalytic reactors to determine the organic pollutant conversion in water, by developing MIEBs (macroscopic irradiation energy balances), and by accounting for the back and forward photon-scattering, using spectrophotoradiometers and collimators $[67,143]$. Later, these measurements were adapted in the 
Photo-CREC-Air Reactor (PCAR) by Garcia et al., using the ratio of the rate of $\mathrm{OH}^{\bullet}$ radicals consumed over the rate of photons absorbed by $\mathrm{TiO}_{2}(\lambda \leq 388 \mathrm{~nm})[73,144]$.

Furthermore, this QY definition was modified by Escobedo et al. [65] to account for photocatalytic hydrogen production in the Photo-CREC Water-II reactor. Thus, the QY definition becomes the rate of $\mathrm{H}^{\bullet}$ molecules produced over the number of photons absorbed by the photocatalysts $[27,64-66,88]$.

$$
Q Y=\frac{\text { rate of } H^{\bullet} \text { produced }}{\text { rates of photons absorbed }}=\frac{\left[\frac{d N_{H^{\bullet}}}{d t}\right]}{P_{a}}=\frac{2\left[\frac{d N_{H_{2}}}{d t}\right]}{P_{a}}
$$

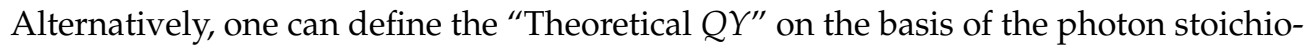
metric requirements for the formation of a $H^{\bullet}$ radical, as follows [65]:

$$
Q Y_{\text {theor }}=\frac{\text { moles of } H^{\bullet}}{\text { moles of photons }}
$$

The $Q Y_{\text {theor }}$ can be used to determine the complete mineralization of the organic pollutants (electron/hole scavengers) in water. This parameter can be used as a reference only and represents the maximum $Q Y$ that the photocatalytic process can yield. Escobedo et al. [65] calculated the "Theoretical QY" for the "series-parallel" model, postulated in Figure 6 of Section 4.2. These authors report these $Q Y_{\text {theor }}$ in Table 5. These values assume that ethanol was fully mineralized with an $80 \%$ efficiency.

Table 5. Theoretical QYs for the different steps involved in the photoconversion of ethanol during $\mathrm{H}_{2}$ Generation [65], as

\begin{tabular}{|c|c|c|c|c|c|}
\hline Reaction Path & Reactant & Product & \# Photons & $\mathrm{H}_{2}$ Generated & $Q Y_{\text {theor }}$ \\
\hline 1 & \multirow{3}{*}{$\mathrm{C}_{2} \mathrm{H}_{5} \mathrm{OH}$} & $\mathrm{CH}_{4}, \mathrm{CO}_{2}$ & 5 & 2 & 0.80 \\
\hline 2 & & $\mathrm{C}_{2} \mathrm{H}_{4} \mathrm{O}$ & 2 & 1 & 1 \\
\hline 3 & & \multirow{2}{*}{$\mathrm{C}_{2} \mathrm{H}_{3} \mathrm{OOH}$} & 4 & 2 & 1 \\
\hline 4 & $\mathrm{C}_{2} \mathrm{H}_{4} \mathrm{O}$ & & 2 & 1 & 1 \\
\hline 5 & $\mathrm{C}_{2} \mathrm{H}_{3} \mathrm{OOH}$ & \multirow{2}{*}{$\mathrm{CH}_{4}, \mathrm{CO}_{2}$} & 1 & 0 & 0 \\
\hline 6 & $\mathrm{C}_{2} \mathrm{H}_{4} \mathrm{O}$ & & 3 & 1 & 0.66 \\
\hline 7 & $2 \mathrm{C}_{2} \mathrm{H}_{3} \mathrm{OOH}$ & $\mathrm{C}_{2} \mathrm{H}_{6}, \mathrm{CO}_{2}$ & 2 & 2 & 1 \\
\hline
\end{tabular}
shown in the "In-Series-Parallel Model" in Figure 9, Section 4.1.

While the assessment of the $Q Y_{\text {theor }}$ on the basis of stoichiometric considerations, as reported in Table 5, is valuable, more recent results from Escobedo et al. [39], which are based on thermodynamic considerations (refer to Section 5.2), show that the $Q Y_{\max }$ is limited to 0.5 for both near-UV and visible light irradiation.

Effect of Platinum Loading and $\mathrm{pH}$ on the Quantum Yields for $\mathrm{H}_{2}$ Production

QYs can be studied under different $\mathrm{pHs}$ and $\mathrm{Pt}$ loading conditions. This research is very important given that it allows one to determine the optimum $\mathrm{Pt}$ loadings and $\mathrm{pH}$ parameters, at ambient pressure and temperature. Escobedo et al. [65] found that the $1 \mathrm{wt} . \% \mathrm{Pt} / \mathrm{DP} 25$, using ethanol as an electron/hole scavenger and an acidic $\mathrm{pH}$, are the most favorable conditions for hydrogen production. This leads to a progressive and steady $\mathrm{H}_{2}$ formation, reaching maximum values after $30 \mathrm{~min}$ of $8 \% \mathrm{QYs}$. These experimentally observed QYs are lower than the maximum "Theoretical QY". These results can be justified given that the photocatalytic conversion of $\mathrm{H}^{\bullet}$ radicals using organic scavengers requires a two-photon one-photocatalyst site quasi simultaneous interaction [6].

Figure 15a reports the variations of the QYs at different $\mathrm{pHs}$ (acidic, alkaline, and neutral) and Pt loadings. Figure $15 \mathrm{~b}$ reports the QYs for various photocatalysts at an optimal $\mathrm{pH}$ of 4 , as well as for two sources of irradiation: (i) near-UV, and (ii) visible light. 
(a)

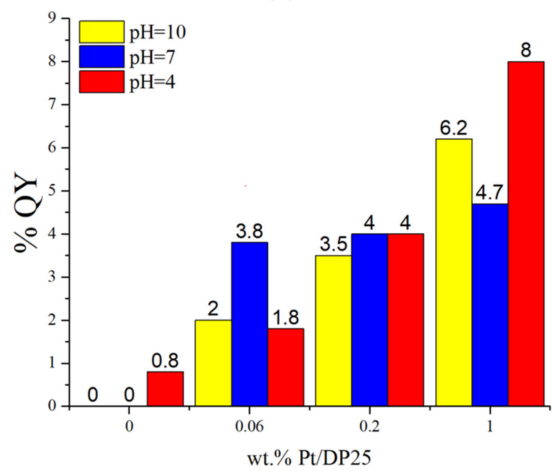

(b)

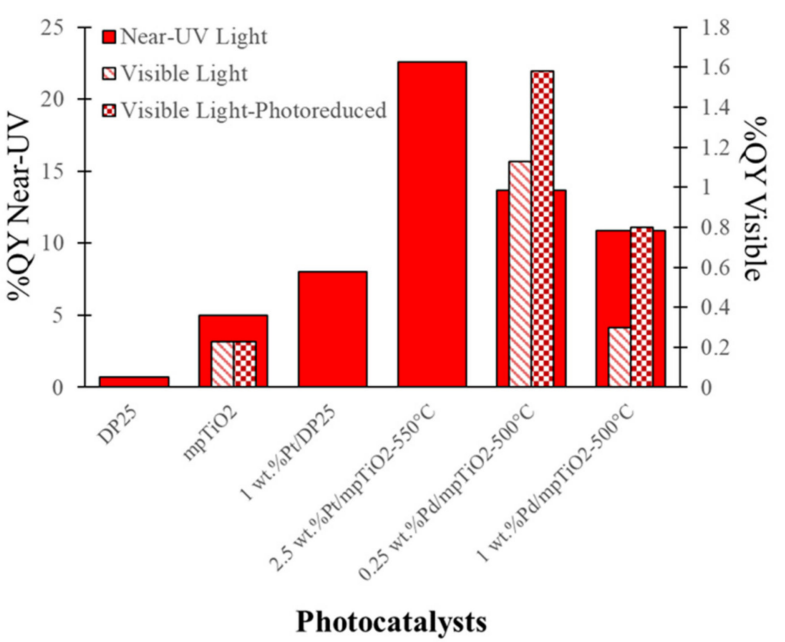

Figure 15. Quantum yields obtained for $\mathrm{H}_{2}$ generation in 2 vol.\% of ethanol: (a) using various $\mathrm{Pt}$ loadings on $\mathrm{TiO}_{2}(\mathrm{DP} 25)$, with $\mathrm{pH}$ conditions of acidity, alkalinity, and neutrality; and (b) using different $\mathrm{DP} 25$ or $\mathrm{mpTiO}_{2}$ photocatalysts loaded with $\mathrm{Pt}$ or $\mathrm{Pd}$, at acidic $\mathrm{pH}$ conditions of 4 .

Recent research by our team also determined the QYs for the optimum $\mathrm{pH}$ of 4 , under near-UV light. Guayaquil-Sosa et al. [27] calculated QYs of 9.3\% and $22.6 \%$ for a $\mathrm{mpTiO}_{2}$ $550{ }^{\circ} \mathrm{C}$ and a $2.5 \mathrm{wt} . \% \mathrm{Pt} / \mathrm{mpTiO}_{2}-550{ }^{\circ} \mathrm{C}$, respectively. Similarly, Rusinque et al. $[66,88]$ determined QYs of $5 \%$ and $10.9 \%$ for a $\mathrm{mpTiO}_{2}-500{ }^{\circ} \mathrm{C}$ and for a $1 \mathrm{wt} . \% \mathrm{Pd} / \mathrm{mpTiO}_{2}-550{ }^{\circ} \mathrm{C}$, respectively. Furthermore, a $1.13 \%$ QY for $0.25 \mathrm{wt} . \% \mathrm{Pd} / \mathrm{mpTiO}_{2}-500{ }^{\circ} \mathrm{C}$, under visible light, was obtained.

Other authors, such as Montoya et al. [90], observed apparent $Q Y_{a p p} \mathrm{~s}$ of $7 \%$ and $2.8 \%$ for $\mathrm{TiO}_{2}$ loaded with $1 \mathrm{wt} . \% \mathrm{Cu}$ and $1 \mathrm{wt} . \% \mathrm{Ni}$, respectively, under near-UV light conditions. Similarly, Rayees Ahmad et al. [92] calculated a 4.1\% QY app and an 11.4\% QY app $_{\text {for DP25 }}$ and $-\mathrm{mpTiO}_{2}$ photocatalysts, respectively, containing $3 \mathrm{wt} . \% \mathrm{Cu}$, under sunlight irradiation. One should mention that the $\mathrm{QY}_{a p p} \mathrm{~s}$ calculated by these authors, while important, provide solely an approximate efficiency value, given that they are based on incident photons, instead of on the absorbed photons, as required by the QYs presented in Equation (16).

\subsection{Photochemical Thermodynamic Efficiency Factors (PTEFs)}

The PTEF was first defined for water decontamination by Serrano and de Lasa [145]. Then, it was adapted for air purification by Garcia-Hernandez et al. [73] as the product of the experimental quantum yield $\left(\mathrm{QY}_{\mathrm{Exp}}\right)$ and the fraction of the photon energy utilized $\left(n_{\left[\mathrm{OH}^{\bullet}\right]}\right)$ to form $\mathrm{OH}^{\bullet}$ radicals. The maximum value of $n_{\left[\mathrm{OH}^{\bullet}\right]}$, assigned to the organic pollutant conversion in photocatalytic processes, was 1.33.

The following expressions represent the PTEFs for hydrogen production in photocatalytic reactors. They include both generated radicals, $\mathrm{H}^{\bullet}$ and $\mathrm{OH}^{\bullet}$, resulting in the fraction of photon energy $\left(n_{\left[\mathrm{H}^{\bullet}+\mathrm{OH}\right.}\right)$, as follows [39]:

$$
\begin{aligned}
& P T E F=Q Y_{E x p} * n_{\left[H^{\bullet+O H}\right]} \\
& n_{\left[H^{\bullet}+O H^{\bullet}\right]}=\frac{\Delta H_{\left[H^{\bullet}+\mathrm{OH}^{\bullet}\right]}}{\left(E_{a v}\right)}
\end{aligned}
$$

where $\Delta H_{\left[H^{\bullet}+\mathrm{OH}^{\bullet}\right]}$ is the enthalpy of the formation of the $\mathrm{H}^{\bullet}$ and $\mathrm{OH}^{\bullet}$ radicals $(\mathrm{kJ} / \mathrm{mol})$, and $\mathrm{E}_{\mathrm{av}}$ stands for the average emitted photon energy.

Calculations of PTEFs for hydrogen production were first established by Escobedo et al. [39], with the thermodynamic consideration that, for the photocatalytic reaction to take place, it should involve a QY smaller than a QY $\max$ of 0.5 , given that two absorbed photons are required for the simultaneous formation of one $\mathrm{H}^{\bullet}$ radical and one $\mathrm{OH}^{\bullet}$ radical. 
Figure 15 reports the maximum experimental PTEFs for different optimum photocatalysts, under near-UV and visible light irradiation. It was determined that the PTEF for bare $\mathrm{TiO}_{2}$ under near-UV light, was near to seven times larger for the $\mathrm{mpTiO}_{2}-550{ }^{\circ} \mathrm{C}$ than for the DP25. This suggests that a larger photocatalyst specific surface area favors the better utilization of the formed $e^{-} / h^{+}$pairs under a higher concentration of adsorbed $\mathrm{OH}^{-}$and $\mathrm{H}^{+}$species. The PTEF also increased significantly, with the presence of dispersed $\mathrm{Pt}$ or Pd crystallites, in the structures of the $\mathrm{DP} 25$ and the $\mathrm{mpTiO}_{2}$ photocatalysts (see Figure 16). Similar activity was observed for visible light. Therefore, by increasing the surface area of the photocatalyst, and by adding dispersed transition metals ( $\mathrm{Pt}$ or $\mathrm{Pd}$ ) to $\mathrm{TiO}_{2}$, an enhancement of the photocatalytic production of hydrogen was obtained.

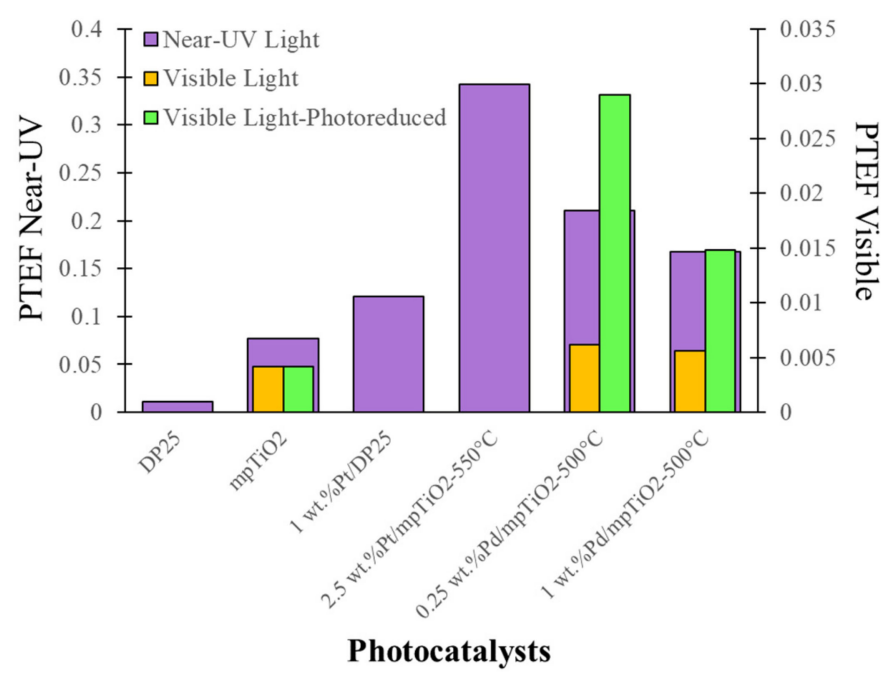

Figure 16. Experimental maximum PTEFs for photocatalytic hydrogen production under two types of energy irradiation: (1) near-UV, and (2) visible light. Note: PTEFs were calculated as per Equation (19).

\section{Future Opportunities for the Photocatalytic Conversion of Hydrogen Artificial Intelligence in Photocatalysis}

The establishment of the optimized operating parameters is of importance for chemical processes, such as the photocatalytic production of hydrogen and its scale up. It is expected, in this respect, that artificial intelligence (AI) will help considerably to optimize the operating conditions, increasing the photon conversion efficiency in solar-light-irradiated photoreactors [146-149].

Estahbanati et al. [75] used artificial neural network (ANN) models to predict the photocatalytic hydrogen production from glycerol, using Pt/DP25. To evaluate the performance of the ANN, the coefficient of determination $\left(R^{2}\right)$, the adjusted coefficient of determination $\left(R_{a d j}^{2}\right)$, the root mean squared error (RMS), the mean absolute error (MAE), and the absolute average deviation (AAD) were determined using the following equations:

$$
\begin{gathered}
R^{2}=1-\sum_{i=1}^{n}\left(\frac{\left(x_{i, \text { cal }}-x_{i, \exp }\right)^{2}}{\left(x_{\text {ave } \exp }-x_{i, \exp }\right)^{2}}\right) \\
R_{a d j}^{2}=1-\left[\left(1-R^{2}\right) \frac{n-1}{n-K-1}\right] \\
R M S=\sqrt{\frac{\sum_{i=1}^{n}\left(x_{i, c a l}-x_{i, \exp }\right)^{2}}{n}} \\
M A E=\frac{\sum_{i=1}^{n}\left|x_{i, c a l}-x_{i, \text { exp }}\right|}{n}
\end{gathered}
$$




$$
A A D=\frac{\sum_{i=1}^{n}\left(\frac{\left|x_{i, c a l}-x_{i, \text { exp }}\right|}{x_{i, c a l}}\right)}{n} \times 100
$$

where $n$ is the number of data points; $K$ represents the number of input variables; and $x_{i, c a l}$, $x_{i, \text { exp }}$, and $x_{\text {ave,exp }}$ are the predictive response, the experimental, and the arithmetic mean of all the experimental data, respectively. These equations could help to reveal the most influential parameters during the photoconversion of $\mathrm{H}_{2}$.

Estahbanati et al. [75] investigated the individual and interactive operating parameter effects in the photocatalytic process by taking the following into account: (1) The glycerol concentration; (2) The photocatalyst loading; (3) Pt \%; and (4) The pH. A generic algorithm (GA) was developed, together with an ANN model, for process optimization. This study found that the overall optimum parameters of the system were $50 \mathrm{vol} . \%$ glycerol, $3.9 \mathrm{~g} / \mathrm{L}$ photocatalyst, $3.1 \mathrm{wt} . \% \mathrm{Pt}$, and a $\mathrm{pH}$ of 4.5 . Figure 17a shows the experimental data obtained for the cumulative hydrogen produced during $4 \mathrm{~h}$, while operating at the identified optimum conditions. Furthermore, these results demonstrate that $\mathrm{H}_{2}$ increases quasi-linearly during the experiments. Figure $17 \mathrm{~b}$ reports the relative importance of the various operating parameters to produce hydrogen, on a percentual basis.

(a)

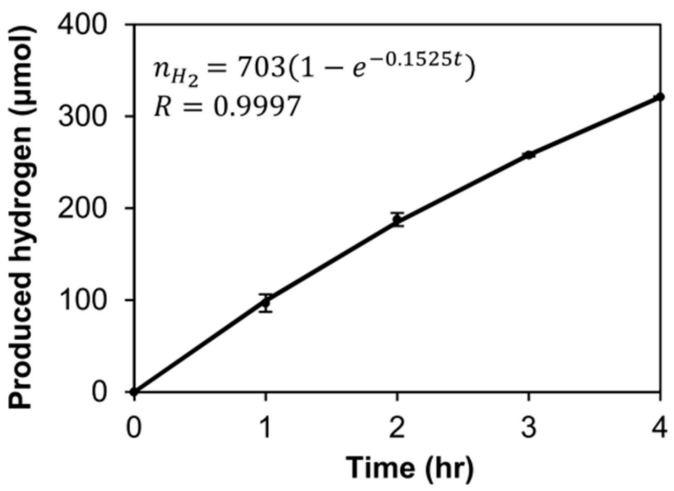

(b)

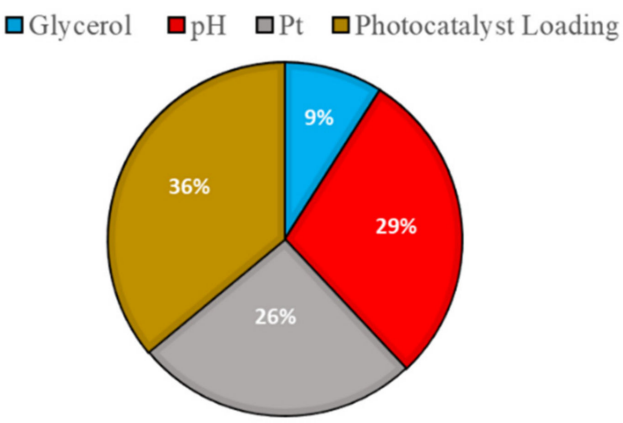

Figure 17. (a) Hydrogen formation rate after $4 \mathrm{~h}$ of photoconversion, with the reactor operating at optimum experimental conditions, and (b) optimal operating parameters determined with the generic algorithm. Duplicated with the permission of the APCATB: Environmental research journal [75].

Ren et al. [77] developed a "memetic" algorithm integrating the advantages of a "whale" optimization method and those of a simulated "annealing" random algorithm. This was performed to find a high-quality model solution. The authors also employed a "Sobol" variance-based method to find the most influential input parameters and to quantify how these factors affect the maximum generation of $\mathrm{H}_{2}$. In this regard, these authors found that the most important parameters were: (a) The photocatalyst volume fraction, (b) The inlet velocity of the photocatalyst suspension; and (c) The diameter of the photocatalytic particles (see Figure 18a-c).

Masood et al. [146] present a "holistic" approach for machine learning (ML) in order to research a new solar-photocatalytic-driven process for hydrogen production (see Figure 19). These authors established that one can consider an empirical data domain, with numerous experiments being required, to validate the existing model assumptions. Given this, the authors advised the following: (a) Training of the ML models by integrating theoretical and empirical knowledge; (b) Incorporating the established knowledge in the ML space; and (c) Employing a current material database to constrain the ML predictions. It is envisioned that this combination of ML and empirical knowledge may pave the way towards the development of robust data collection and the selection of the best photocatalyst reactors. 
(a)
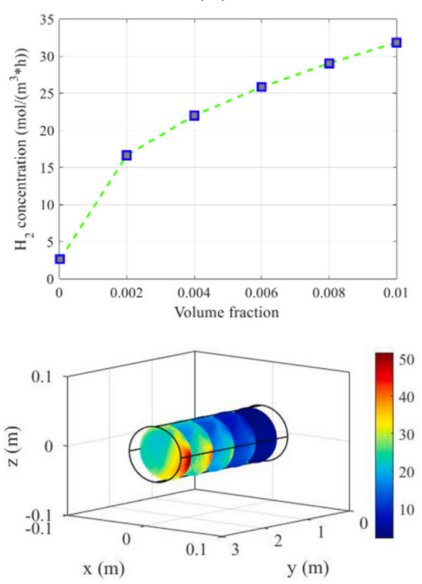

(b)
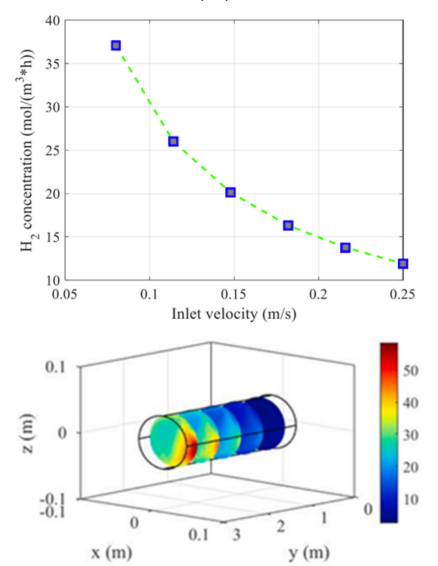

(c)
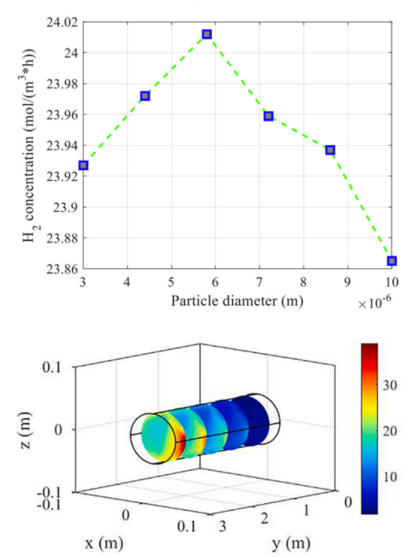

Figure 18. Changes in hydrogen production as a function of (a) the particle volume fraction; (b) the inlet velocity; and (c) the particle diameter. Reproduced with the permission of the Energy Conversion and Management journal [77].

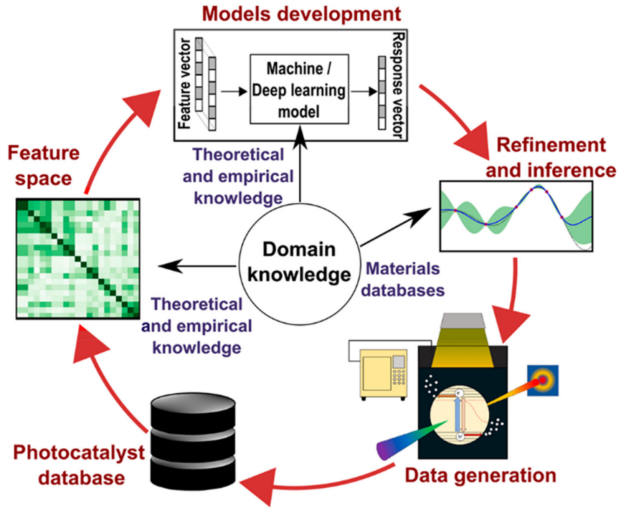

Figure 19. Overall process of the discovery of new photocatalysts by the integration of a photocatalysis domain database in an ML framework. Figure is reproduced with the permission of ACS Catalysis [146].

Alyaa K. Mageed [150] also modeled the production of hydrogen using various ML techniques, including an ANN, a support vector machine (SVM), a nonlinear regression model (NLM), and a response surface model (RSM). This author considered the input effects of parameters, such as the irradiation time, the $\mathrm{CuO}$ content, the photocatalyst dosage, and the electron/hole scavenger $\left(\mathrm{C}_{2} \mathrm{H}_{5} \mathrm{OH}\right)$ concentration, in the proposed modeling process. On this basis, Alyaa K. Mageed [150] observed that the ANNs have a superior ability to predict $\mathrm{H}_{2}$ production, compared to SVMs, NLMs, and RSMs, as indicated by the higher $\mathrm{R}$ value of 0.998 obtained. These types of results demonstrate the importance of ML applications to predict and optimize models for complex photochemical processes, which would otherwise be expensive and time-consuming.

As reported throughout this technical review, the scarcity of consistent research data in heterogeneous photocatalysis, with a proper definition of QYs, is still a major issue for the scaling up of hydrogen production. This review also introduces future perspectives and the importance of applying and adapting AI in future research. These computational advancements, supplemented with accurate data, may assist in accelerating the discovery of new solar photocatalyst processes. These hybrid techniques could promote new technologies to improve photocatalytic hydrogen production, and future opportunities that might help to speed up industrial applications. 


\section{Conclusions}

This review reports a detailed description of the preparation of several $\mathrm{TiO}_{2}$-based and heterojunction composite photocatalysts with assorted frames. It is observed that sol-gel, and other methods, have been commonly employed for the synthesis of $\mathrm{TiO}_{2}-$ based and complex composite photocatalysts, with the sol-gel method being the most viable method for the scaling-up of photocatalyst applications. Furthermore, impregnation, doping, and precipitation have been frequent metal and nonmetal precursor deposition methods used to enhance the physicochemical properties of photocatalysts to produce "green" hydrogen. This review also reports a classification of the different lamp types, on the basis of the wavelength spectrum and the nominal output power. On this basis, the criteria for photoreactor design are discussed by helping to identify the most suitable and efficient light-source positions for new photoreactor units. Moreover, the illustration and description of the different configurations of the current lab- and bench- scale photoreactors, their operation, and their experimental procedures are provided. Kinetic models for "green" $\mathrm{H}_{2}$ production are also assessed by analyzing and evaluating the observed reaction rates on the basis of: (a) the reaction mechanisms, (b) the adsorption constants, and (c) the intrinsic rate constants. Furthermore, the photon utilization efficiencies, such as the QYs and the PTEFs of photoreactors for photocatalytic $\mathrm{H}_{2}$ production, are taken into account. This review is completed with a discussion of new modeling tools, such as AI and ML, and the future opportunities of these approaches to improve and optimize photocatalytic scaled-up processes for "green" hydrogen production.

\section{Directions for Future Works on "Green" $\mathrm{H}_{2}$ Production}

While the implementation of photocatalytic $\mathrm{H} 2$ production will certainly benefit from low costs and stable photocatalysts, better reaction engineering will strongly contribute to the successful process scale up. Thus, future reaction engineering research for $\mathrm{H} 2$ production should consider reliable and consistent measurements of both the photon transmission and the photon absorption fluxes. This will allow the photon utilization ranking of different photoreactor designs, taking as a reference meaningful efficiency parameters, such as the QY. In addition, validated and scalable kinetic models, such as the ones reviewed in this article, will also help in the ranking of photoreactors, using as the basis the organic scavenger conversion and the hydrogen formation. These findings will similarly facilitate the engineering of large-scale units and their operation, while taking advantage of $\mathrm{AI}$ and ML methods.

Author Contributions: Investigating scientific literature, drafting figures and tables, preparation, writing and editing of the original-draft review article, S.E.; writing, editing, and reviewing final version of the original manuscript, H.d.L. All authors have read and agreed to the published version of the manuscript.

Funding: This research was funded by the Natural Science and Engineering Research Council of Canada (NSERC), through the Hugo de Lasa's NSERC Discovery Grant.

Acknowledgments: The authors would like to thank Florencia de Lasa, who assisted with the editing and proofreading of this manuscript.

Conflicts of Interest: The authors declare no conflict of interest.

\section{Nomenclature}

A Uniformly irradiated mesh area holding an optimum loading of $\mathrm{TiO}_{2}\left(\mathrm{~m}^{2}\right)$

Ag Silver

Ar Argon

Au Gold

c Speed of light $\left(3 \times 10^{8} \mathrm{~m} / \mathrm{s}\right)$

C Carbon 


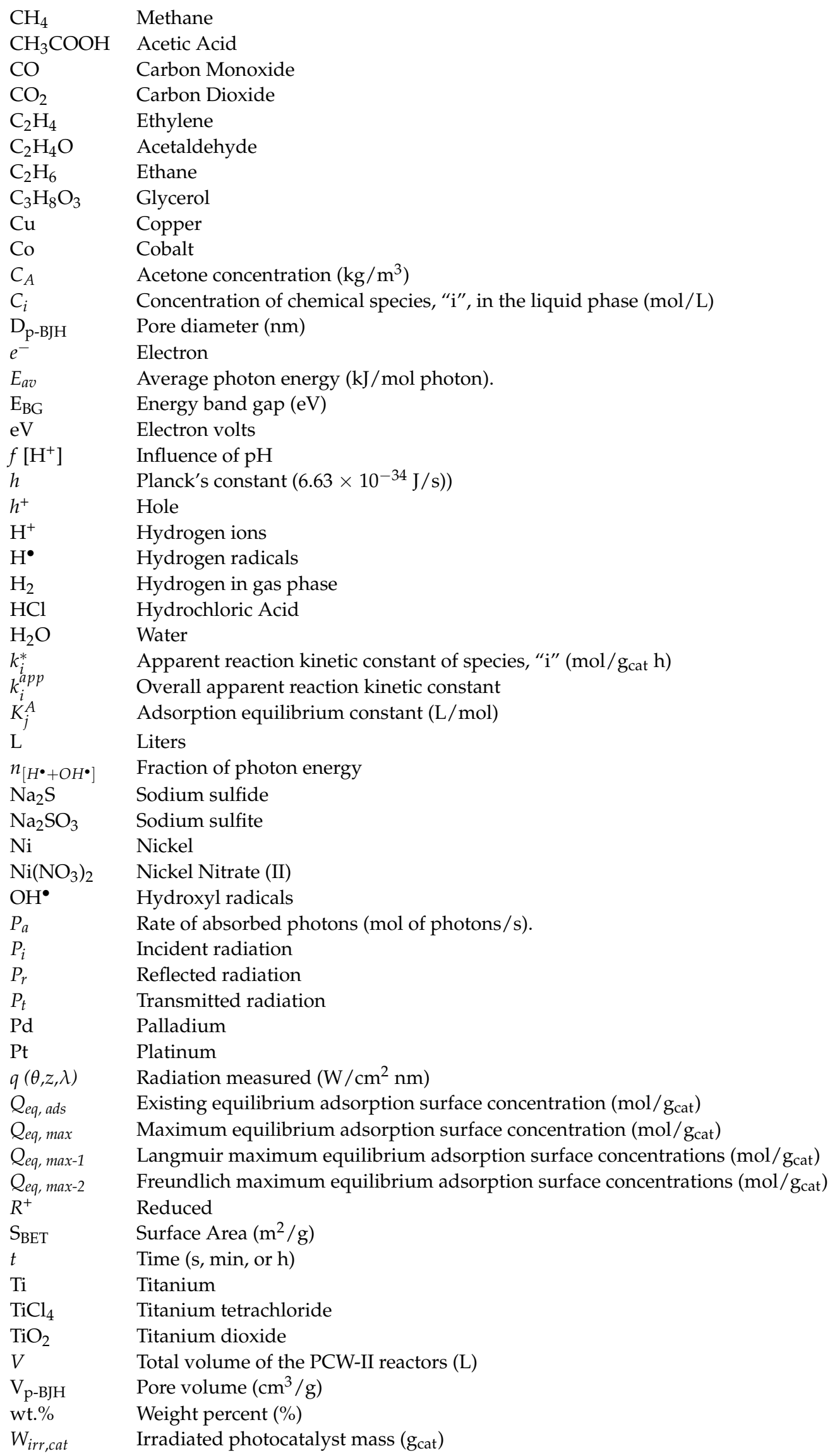


Acronyms

\begin{tabular}{|c|c|}
\hline A & Anatase \\
\hline AAD & Absolute Average Deviation \\
\hline AI & Artificial Intelligence \\
\hline ANN & Artificial Neural Network \\
\hline BET & Brunauer-Emmett-Teller \\
\hline $\mathrm{BJH}$ & Barrett-Joyner-Halenda \\
\hline BTX & Benzene-Toluene-Xylene \\
\hline CB & Conduction Band \\
\hline CFD & Computational Fluid Dynamics \\
\hline CREC & Chemical Reactor Engineer Centre \\
\hline CVD & Chemical Vapor Deposition \\
\hline DDTC & Diethyldithiocarbamate Trihydrate \\
\hline DB & Debye-Scherrer \\
\hline DP25 & Degussa P25 (Commercial $\left.\mathrm{TiO}_{2}\right)$ \\
\hline $\mathrm{EtOH}$ & Ethanol \\
\hline GA & Generic Algorithms \\
\hline $\mathrm{GO}$ & Graphene Oxide \\
\hline LED & Light-Emitting Diode \\
\hline L-H & Langmuir-Hinshelwood \\
\hline LVRPA & Local Volumetric Rate of Photon Absorption \\
\hline $\mathrm{MeOH}$ & Methanol \\
\hline MAE & Mean Absolut Error \\
\hline MIEB & Macroscopic Irradiation Energy Balances \\
\hline $\mathrm{mp}$ & Mesoporous \\
\hline NLM & Nonlinear Regression Model \\
\hline PAHs & Polycyclic Aromatic Hydrocarbons \\
\hline PCW-II & Photo-CREC Water-II Reactor \\
\hline PTEFs & Photocatalytic Thermodynamic Efficiency Factors \\
\hline QYs & Quantum Yields \\
\hline $\mathrm{QY}_{a p p}$ & Apparent Quantum Yield \\
\hline $\mathrm{QY}_{\text {overall }}$ & Overall Quantum Yield \\
\hline QY theor & Theoretical QYs \\
\hline $\mathrm{R}$ & Rutile \\
\hline $\mathrm{R}^{2}$ & Coefficient of determination \\
\hline $\mathrm{R}^{2}$ adj & Adjusted coefficient of determination \\
\hline RMS & Root Mean Squared Error \\
\hline RSM & Response Surface Model \\
\hline RVE & Representative Volume Element \\
\hline SVM & Support Vector Machine \\
\hline TEAO & Triethanolamine \\
\hline UV & Ultraviolet \\
\hline VB & Valence Band \\
\hline \multicolumn{2}{|l|}{ Symbols } \\
\hline$\theta$ & Angular position $\left(^{\circ}\right)$ \\
\hline$\theta_{A}$ & Dimensionless surface species concentration \\
\hline$r_{i}$ & Rate of photoconversion of the model pollutant " $\mathrm{i}$ " (mol/t $\left.\mathrm{g}_{\mathrm{cat}}\right)$ \\
\hline$\Delta H_{O H} \cdot$ & Enthalpy invested in the formation of the $\mathrm{OH}^{\bullet}$ radicals $(\mathrm{J} / \mathrm{mol})$ \\
\hline$\lambda$ & Radiation wavelength (nm) \\
\hline$\rho$ & Fluid density $\left(\mathrm{kg} / \mathrm{m}^{3}\right)$ \\
\hline$v$ & Stoichiometric coefficient \\
\hline$r$ & Radial position (cm) \\
\hline$n_{\mathrm{OH}} \bullet$ & Fraction of photon energy used to form $\mathrm{OH}^{\bullet}$ radicals \\
\hline
\end{tabular}

\section{Appendix A}

This Appendix shows a list of different $\mathrm{TiO}_{2}$-based photocatalyst for $\mathrm{H}_{2}$ production and their most relevant features. 
Table A1. Characterization of different $\mathrm{TiO}_{2}$-based photocatalysts, and evaluation of hydrogen production using these photocatalysts, as reported in recent research literature.

\begin{tabular}{|c|c|c|c|c|c|c|c|c|c|c|c|c|c|c|c|}
\hline No. & Ref. & Year & Photocatalyst & $\begin{array}{l}\text { Dopant } \\
\text { (wt.\%) }\end{array}$ & $\begin{array}{c}\text { Load } \\
\left(\mathrm{g} \mathrm{L}^{-1}\right)\end{array}$ & $\begin{array}{l}\text { Crystalline } \\
\text { Phase (\%) }\end{array}$ & $\begin{array}{l}\mathrm{S}_{\mathrm{BET}} \\
\left(\mathrm{m}^{2} / \mathrm{g}\right)\end{array}$ & $\begin{array}{l}E_{B G} \\
(e V)\end{array}$ & $\begin{array}{c}e^{-} / h^{+} \\
\text {Scavenger }\end{array}$ & $\mathrm{pH}$ & $\begin{array}{c}\text { Source } \\
\text { of } \\
\text { Light }\end{array}$ & $\underset{(\mathrm{nm})}{\lambda}$ & $\begin{array}{c}\mathrm{H}_{2} \\
\begin{array}{c}\text { Production } \\
\left(\mu \mathrm{mol} \mathrm{h}^{-1}\right)\end{array}\end{array}$ & QYs\% & PTEFs \% \\
\hline 1 & \multirow{2}{*}[39,65]{} & \multirow{2}{*}{2013} & $\mathrm{TiO}_{2}$ (DP25) & - & \multirow{7}{*}{0.15} & \multirow{2}{*}{$\begin{array}{l}\text { A: R } \\
\text { 87: } 13\end{array}$} & \multirow[b]{2}{*}{54} & 3.20 & \multirow{7}{*}{$\mathrm{C}_{2} \mathrm{H}_{3} \mathrm{OH}$} & \multirow{7}{*}{$\begin{array}{l}4 \pm \\
0.05\end{array}$} & \multirow{6}{*}{$\begin{array}{l}\text { Near } \\
\text { UV }\end{array}$} & \multirow{6}{*}{$\begin{array}{l}340- \\
410\end{array}$} & 34 & 0.7 & 0.57 \\
\hline 2 & & & $\mathrm{Pt} / \mathrm{TiO}_{2}(\mathrm{DP} 25)$ & 1 & & & & 2.73 & & & & & 256 & 7.9 & 6.05 \\
\hline 3 & \multirow[b]{2}{*}{ [27] } & \multirow[b]{2}{*}{2017} & $\mathrm{mpTiO}_{2}-550^{\circ} \mathrm{C}$ & - & & \multirow{5}{*}{$\begin{array}{c}\mathrm{A} \\
100\end{array}$} & 168 & 3.10 & & & & & 229 & 9.3 & - \\
\hline 4 & & & $\begin{array}{l}\mathrm{Pt} / \mathrm{mpTiO}_{2-} \\
550^{\circ} \mathrm{C}\end{array}$ & 2.5 & & & 150 & 2.34 & & & & & 629 & 22.6 & 17.1 \\
\hline 5 & \multirow{2}{*}[39,66]{} & \multirow{2}{*}{2019} & $\mathrm{mpTiO}_{2}-500^{\circ} \mathrm{C}$ & - & & & 140 & 3.0 & & & & & 269 & 5 & 3.85 \\
\hline 6 & & & \multirow[b]{2}{*}{$\begin{array}{l}\mathrm{Pd} / \mathrm{mpTiO}_{2}- \\
50{ }^{\circ} \mathrm{C}\end{array}$} & 1 & & & 123 & 2.55 & & & & & 943 & 10.9 & 8.39 \\
\hline 7 & {$[39,88]$} & 2020 & & 0.25 & & & 131 & 2.51 & & & Visible & $\begin{array}{l}300- \\
700\end{array}$ & 54 & 1.13 & 1.04 \\
\hline 8 & \multirow{2}{*}[90]{} & \multirow{2}{*}{2018} & $\mathrm{Cu} / \mathrm{TiO}_{2}(\mathrm{DP} 25)$ & \multirow{2}{*}{1} & \multirow[b]{2}{*}{2} & \multirow{2}{*}{$\begin{array}{l}\text { A: R } \\
80: 20\end{array}$} & \multirow{2}{*}{45} & \multirow{2}{*}{3.1} & \multirow{5}{*}{$\mathrm{CH}_{3} \mathrm{OH}$} & \multirow{2}{*}{-} & \multirow{2}{*}{ UV } & \multirow{2}{*}{-} & 85 & $7^{\alpha}$ & \multirow{2}{*}{-} \\
\hline 9 & & & $\mathrm{Ni} / \mathrm{TiO}_{2}(\mathrm{DP} 25)$ & & & & & & & & & & 34 & 2.8 & \\
\hline 10 & \multirow{3}{*}{ [92] } & \multirow{3}{*}{2017} & $\mathrm{mpTiO}_{2}$ & \multirow{3}{*}{3} & \multirow{3}{*}{6} & \multirow{3}{*}{$\begin{array}{c}\mathrm{A} \\
100\end{array}$} & 188 & & & \multirow{3}{*}{-} & & & 0 & $0^{\alpha}$ & \\
\hline 11 & & & $\mathrm{Cu} / \mathrm{TiO}_{2}(\mathrm{DP} 25)$ & & & & - & - & & & Sunlight & - & 67 & $\underset{\alpha}{4.1}$ & - \\
\hline 12 & & & $\mathrm{Cu} / \mathrm{mpTiO}_{2}$ & & & & 75 & & & & & & 167 & 11.4 & \\
\hline 13 & [94] & 2014 & CdS-ZnS/DP25 & - & 0.5 & $\begin{array}{c}\text { A: R } \\
70: 30\end{array}$ & 55 & 2.88 & $\begin{array}{c}\mathrm{Na}_{2} \mathrm{~S} \\
\mathrm{Na}_{2} \mathrm{SO}_{3}\end{array}$ & 11.3 & $\begin{array}{l}\text { Visible } \\
\text { UV }\end{array}$ & $\begin{array}{l}400- \\
700 \\
365\end{array}$ & 1035 & $\stackrel{2.2}{\alpha}$ & - \\
\hline 14 & [95] & 2019 & $\mathrm{Pt} / \mathrm{rGO} / \mathrm{DP} 25$ & $0.5 / 5 / 5$ & 1 & $\begin{array}{c}\text { A: R } \\
75: 25\end{array}$ & 48 & - & $\mathrm{CH}_{3} \mathrm{OH}$ & 4 & $\begin{array}{l}\text { Near- } \\
\text { UV }\end{array}$ & $\begin{array}{l}315- \\
400\end{array}$ & 505 & 1.57 & - \\
\hline 15 & [97] & 2016 & $\mathrm{NiO} / \mathrm{TiO}_{2}$ & 2 & 1.67 & $\begin{array}{c}\text { A: R } \\
70: 30\end{array}$ & 54 & 2.4 & & 6.6 & $\begin{array}{l}\text { Near- } \\
\text { UV }\end{array}$ & $\begin{array}{l}340- \\
460\end{array}$ & 2054 & - & - \\
\hline 16 & {$[98]$} & 2013 & $\mathrm{Co} / \mathrm{DP} 25$ & 1 & 2 & $\begin{array}{c}\text { A: R } \\
80: 20\end{array}$ & 50 & 2.9 & $\mathrm{C}_{3} \mathrm{H}_{8} \mathrm{O}_{3}$ & 6 & Visible & $\begin{array}{l}300- \\
700\end{array}$ & 1102 & - & - \\
\hline
\end{tabular}

Note: Acronyms are also provided in the "Nomenclature" section. $\mathrm{S}_{\mathrm{BET}}=$ Brunauer-Emmett-Teller surface area; $\mathrm{E}_{\mathrm{BG}}=$ energy band gap; $\mathrm{A}=$ anatase; $\mathrm{R}=$ rutile; $\mathrm{B}=$ brookite; $\lambda=$ wavelength; $\alpha=\mathrm{QY}_{\text {app }}$.

\section{Appendix B}

This Appendix shows a list of different non $\mathrm{TiO}_{2}$-based photocatalyst for $\mathrm{H}_{2}$ production and their most relevant features.

Table A2. Characterization of different assorted frame-based photocatalysts and evaluation of hydrogen production obtained using these photocatalysts, as reported in recent research literature.

\begin{tabular}{|c|c|c|c|c|c|c|c|c|c|c|c|c|c|}
\hline No. & Ref. & Year & Photocatalyst & $\begin{array}{l}\text { Dopant } \\
\text { (wt.\%) }\end{array}$ & $\begin{array}{c}\text { Load } \\
\left(\mathrm{g} \mathrm{L} \mathrm{L}^{-1}\right)\end{array}$ & $\begin{array}{c}\mathrm{S}_{\mathrm{BET}} \\
\left(\mathrm{m}^{2} / \mathrm{g}\right)\end{array}$ & $\begin{array}{l}\mathrm{E}_{\mathrm{BG}} \\
(\mathrm{eV})\end{array}$ & $\begin{array}{c}e^{-} / h^{+} \\
\text {Scavenger }\end{array}$ & $\mathrm{pH}$ & $\begin{array}{l}\text { Source } \\
\text { of Light }\end{array}$ & $\underset{(\mathrm{nm})}{\lambda}$ & $\begin{array}{c}\mathrm{H}_{2} \\
\text { Production } \\
\left(\mu \text { mol h}^{-1}\right)\end{array}$ & QYs\% \\
\hline 17 & \multirow[t]{2}{*}{ [60] } & \multirow[t]{2}{*}{2017} & $\mathrm{Zn}_{0.5} \mathrm{Cd}_{0.5} \mathrm{~S}$ & \multirow[t]{2}{*}{-} & \multirow[t]{2}{*}{0.2} & \multirow[t]{2}{*}{-} & \multirow[t]{2}{*}{-} & $\begin{array}{c}\mathrm{Na}_{2} \mathrm{~S} / \\
\mathrm{Na}_{2} \mathrm{SO}_{3} \\
\end{array}$ & $\sim 13$ & \multirow{2}{*}{ Xe Lamp } & \multirow{2}{*}{$\begin{array}{l}420 \leq \lambda \\
\geq 420\end{array}$} & 47 & - \\
\hline 18 & & & $\mathrm{~g}-\mathrm{C}_{3} \mathrm{~N}_{4}$ & & & & & \multirow{4}{*}{ TEAO } & $\sim 11$ & & & 5.6 & - \\
\hline 19 & \multirow{2}{*}{ [114] } & \multirow{2}{*}{2019} & CdS & \multirow{2}{*}{-} & \multirow{2}{*}{0.5} & \multirow{2}{*}{-} & \multirow{2}{*}{-} & & \multirow{2}{*}{12} & \multirow{2}{*}{$\begin{array}{l}\text { Xe arc } \\
\text { Lamp }\end{array}$} & \multirow{2}{*}{$\begin{array}{l}\text { Simulated } \\
\text { Solar light }\end{array}$} & 47 & - \\
\hline 20 & & & $\mathrm{~g}-\mathrm{C}_{3} \mathrm{~N}_{4}$ & & & & & & & & & 41 & - \\
\hline 21 & {$[105]$} & 2014 & $\mathrm{WO}_{3} / \mathrm{g}-\mathrm{C}_{3} \mathrm{~N}_{4}$ & 10 & 1 & - & 2.81 & & - & Xe Lamp & $>420$ & 110 & $0.9^{\alpha}$ \\
\hline 22 & [106] & 2014 & $\mathrm{Ag}_{2} \mathrm{~S} / \mathrm{g}-\mathrm{C}_{3} \mathrm{~N}_{4}$ & 5 & 0.625 & 13.02 & 2.58 & $\mathrm{CH}_{3} \mathrm{OH}$ & - & $\begin{array}{c}\text { Low } \\
\text { power } \\
\text { UV-LEDs }\end{array}$ & $\geq 420$ & 10 & - \\
\hline 23 & \multirow{2}{*}{ [103] } & \multirow{2}{*}{2006} & \multirow{2}{*}{$\begin{array}{l}\mathrm{NiO} / \mathrm{NaTaO}_{3}: \\
\mathrm{La}\end{array}$} & - & \multirow{2}{*}{2.56} & \multirow{2}{*}{-} & \multirow{2}{*}{$\sim 4.1$} & \multirow{2}{*}{-} & \multirow{2}{*}{-} & \multirow{2}{*}{$\begin{array}{l}\text { High } \\
\text { pressure } \\
\text { Hg lamp }\end{array}$} & \multirow{2}{*}{-} & 16 & - \\
\hline 24 & & & & 0.2 & & & & & & & & 2180 & - \\
\hline 25 & [107] & 2012 & $\mathrm{MoO}_{3} / \mathrm{CdS}$ & $\sim 9$ & 0.5 & 25.82 & 2.65 & $\begin{array}{l}\mathrm{Na}_{2} \mathrm{SO}_{3} \\
/ \mathrm{Na}_{2} \mathrm{~S}\end{array}$ & - & & $>420$ & 2100 & $28.86^{\alpha}$ \\
\hline 26 & \multirow{2}{*}{ [108] } & \multirow{2}{*}{2014} & $\mathrm{TiS}_{2} / \mathrm{CdS}$ & \multirow{2}{*}{42} & \multirow{2}{*}{0.05} & 48.2 & \multirow{2}{*}{-} & \multirow{2}{*}{$\begin{array}{c}\text { Benzyl } \\
\text { alcohol/ } \\
\mathrm{CH}_{3} \mathrm{COOH}\end{array}$} & - & & $>399$ & 742 & - \\
\hline 27 & & & $\mathrm{TaS}_{2} / \mathrm{CdS}$ & & & 20.8 & & & 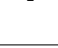 & Xe Lamp & $>399$ & 1758 & \\
\hline 28 & [109] & 2021 & $\mathrm{CuNi@C=O/g-}$ & 8 & 0.2 & - & - & TEOA & - & & $340-780$ & 47.2 & $21.51^{\alpha}$ \\
\hline & & & $\mathrm{C}_{3} \mathrm{~N}_{4}$ & 0 & 0.2 & 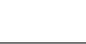 & 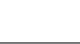 & 1 EUA & 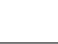 & & $340-780$ & 47.2 & $10.22^{\alpha}$ \\
\hline 29 & [110] & 2011 & $\begin{array}{l}\mathrm{Fe} / \mathrm{Al}_{2} \mathrm{O}_{3}- \\
\text { MCM-41 }\end{array}$ & 5 & 2 & 834 & 1.9 & $\mathrm{CH}_{3} \mathrm{OH}$ & - & $\begin{array}{c}\text { High } \\
\text { pressure } \\
\text { Hg lamp }\end{array}$ & $\geq 400$ & 146 & $6.1^{\alpha}$ \\
\hline 30 & [112] & 2012 & $\mathrm{In}_{2} \mathrm{O}_{3} / \mathrm{Ta}_{2} \mathrm{O}_{5}$ & 5 & 1.5 & - & $\sim 2.75$ & & - & Xe Lamp & $\begin{array}{c}320<\lambda \\
<780\end{array}$ & 78 & - \\
\hline
\end{tabular}

Note: Acronyms are also provided in the "Nomenclature" section. $\mathrm{S}_{\mathrm{BET}}=$ Brunauer-Emmett-Teller surface area; $\mathrm{E}_{\mathrm{BG}}=$ energy band gap; $\lambda=$ wavelength; $\alpha=\mathrm{QY}_{\text {app }}$. 


\section{References}

1. Dincer, I.; Acar, C. Smart energy solutions with hydrogen options. Int. J. Hydrog. Energy 2018, 43, 8579-8599. [CrossRef]

2. Acar, C.; Dincer, I. Energy and exergy analyses of a novel photoelectrochemical hydrogen production system. Int. J. Hydrog. Energy 2017, 42, 30550-30558. [CrossRef]

3. Watts, N.; Adger, W.N.; Agnolucci, P.; Blackstock, J.; Byass, P.; Cai, W.; Chaytor, S.; Colbourn, T.; Collins, M.; Cooper, A.; et al. Health and climate change: Policy responses to protect public health. Lancet Comm. 2015, 386, 1861-1914. [CrossRef]

4. Reza Gholipour, M.; Dinh, C.T.; Beland, F.; Do, T.O. Nanocomposite heterojunctions as sunlight-driven photocatalysts for hydrogen production from water splitting. Nanoscale 2015, 7, 8187-8208. [CrossRef]

5. Haines, A.; Kovats, R.S.; Campbell-lendrum, D.; Corvalan, C. Climate change and human health: Impacts, vulnerability and public health. Public Health 2006, 120, 585-596. [CrossRef]

6. Escobedo, S. Photocatalytic Water Splitting using a Modified Pt- $\mathrm{TiO}_{2}$. Kinetic Modeling and Hydrogen Production Efficiency. Ph.D. Thesis, The University of Western Ontario, London, ON, Canada, 2013.

7. Kayfeci, M.; Kecebas, A.; Bayat, M. Hydrogen production. In Solar Hydrogen Production: Processes, Systems and Technologies; Academic Press: Cambridge, MA, USA, 2019; pp. 45-83, ISBN 9780128148532.

8. Mazloomi, K.; Gomes, C. Hydrogen as an energy carrier: Prospects and challenges. Renew. Sustain. Energy Rev. 2012, 16, 3024-3033. [CrossRef]

9. Guo, S.; Li, X.; Li, J.; Wei, B. Boosting photocatalytic hydrogen production from water by photothermally induced biphase systems. Nat. Commun. 2021, 12, 1343. [CrossRef]

10. Nikolaidis, P.; Poullikkas, A. A comparative overview of hydrogen production processes. Renew. Sustain. Energy Rev. 2017, 67, 597-611. [CrossRef]

11. Lee, D.H.; Hung, C.P. Toward a clean energy economy: With discussion on role of hydrogen sectors. Int. J. Hydrog. Energy 2012, 37, 15753-15765. [CrossRef]

12. Rafal, Ł.; Holowacz, I.; Kucharska, K.; Glinka, M.; Rybarczyk, P.; Przyjazny, A.; Kaminski, M. Hydrogen production from biomass using dark fermentation. Renew. Sustain. Energy Rev. 2018, 91, 665-694. [CrossRef]

13. The 4th Generation I Life Cycle Emissions of Hydrogen. Available online: https:/ / 4thgeneration.energy/life-cycles-emissions-ofhydrogen/ (accessed on 12 May 2021).

14. Muradov, N.Z.; Veziroğlu, T.N. “Green” path from fossil-based to hydrogen economy: An overview of carbon-neutral technologies. Int. J. Hydrog. Energy 2008, 33, 6804-6839. [CrossRef]

15. Solar Panel Splits Water to Produce Hydrogen-IEEE Spectrum. Available online: https://spectrum.ieee.org/energywise/greentech/fuel-cells/solar-panel-prototype-splits-water-to-produce-hydrogen (accessed on 12 May 2021).

16. Producing Green Hydrogen through the Exposure of Nanomaterials to Sunlight I INRS. Available online: https: / /inrs.ca/en/ news / producing-green-hydrogen-through-the-exposure-of-nanomaterials-to-sunlight (accessed on 12 May 2021).

17. Torres-martínez, L.M.; Gómez, R.; Vázquez-cuchillo, O.; Juárez-ramírez, I. Enhanced photocatalytic water splitting hydrogen production on $\mathrm{RuO}_{2} / \mathrm{La}: \mathrm{NaTaO}_{3}$ prepared by sol-Gel method. Catal. Commun. 2010, 12, 268-272. [CrossRef]

18. Rawool, S.A.; Pai, M.R.; Banerjee, A.M.; Bapat, R.D.; Nayak, C.; Tripathi, A.K. Lab scale optimization of various factors for photocatalytic hydrogen generation over low cost $\mathrm{Cu} 0.02 \mathrm{Ti} 0.98 \mathrm{O} 2-\mathrm{S}$ photocatalyst under UV/Visible irradiation and sunlight. Int. J. Hydrog. Energy 2018, 43, 1271-1284. [CrossRef]

19. Vamathevan, V.; Amal, R.; Beydoun, D.; Low, G.; McEvoy, S. Silver metallisation of titania particles: Effects on photoactivity for the oxidation of organics. Chem. Eng. J. 2004, 98, 127-139. [CrossRef]

20. Dupont, V. Steam Reforming of Sunflower Oil for Hydrogen Gas Production. Helia 2007, 30, 103-132. [CrossRef]

21. Fujishima, A.; Honda, K. Electrochemical Photolysis of Water at a Semiconductor Electrode. Nature 1972, 238, 37-38. [CrossRef] [PubMed]

22. Licht, S. Multiple Band Gap Semiconductor/Electrolyte Solar Energy Conversion. J. Phys. Chem. B 2001, 105, 6281-6294. [CrossRef]

23. Rusinque, B. Hydrogen Production by Photocatalytic Water Splitting Under Near-UV and Visible Light Using Doped Pt and Pd $\mathrm{TiO}_{2}$. Master's Thesis, The University of Western Ontario, London, ON, Canada, 2018.

24. Leung, D.Y.C.; Fu, X.; Wang, C.; Ni, M.; Leung, M.K.H.; Wang, X.; Xianzhi, F. Hydrogen Production over Titania-Based Photocatalysts. ChemSusChem 2010, 350002, 681-694. [CrossRef]

25. Ray, A.K. A new photocatalytic reactor for destruction of toxic water pollutants by advanced oxidation process. Catal. Today 1998, 44, 357-368. [CrossRef]

26. Akach, J.; Ochieng, A. Monte Carlo simulation of the light distribution in an annular slurry bubble column photocatalytic reactor. Chem. Eng. Res. Des. 2017, 129, 248-258. [CrossRef]

27. Guayaquil-Sosa, J.F.; Serrano-Rosales, B.; Valadés-Pelayo, P.J.; de Lasa, H. Photocatalytic hydrogen production using mesoporous $\mathrm{TiO}_{2}$ doped with Pt. Appl. Catal. B Environ. 2017, 211, 337-348. [CrossRef]

28. Sirivallop, A.; Escobedo, S.; Areerob, T.; de Lasa, H.; Chiarakorn, S. Photocatalytic Conversion of Organic Pollutants in Air: Quantum Yields Using a Silver/Nitrogen/ $\mathrm{TiO}_{2}$ Mesoporous Semiconductor under Visible Light. Catalysts 2021, 11, 529. [CrossRef] 
29. Yang, J.; Yan, H.; Wang, X.; Wen, F.; Wang, Z.; Fan, D.; Shi, J. Roles of cocatalysts in Pt-PdS/CdS with exceptionally high quantum efficiency for photocatalytic hydrogen production. J. Catal. 2012, 290, 151-157. [CrossRef]

30. Chen, H.; Matsumoto, A.; Nishimiya, N.; Tsutsumi, K. Preparation and characterization of $\mathrm{TiO}_{2}$ incorporated Y-zeolite. Colloids Surfaces A Physicochem. Eng. Asp. 1999, 157, 295-305. [CrossRef]

31. Rusinque, B. Hydrogen Production Via Photocatalytic Water Splitting Under Near-UV and Visible Light Using Doped Pd TiO 2 Ph.D. Thesis, The University of Western Ontario, London, ON, Canada, 2021.

32. Dubey, N.; Rayalu, S.; Labhsetwar, N.; Devotta, S. Visible light active zeolite-based photocatalysts for hydrogen evolution from water. Int. J. Hydrog. Energy 2008, 33, 5958-5966. [CrossRef]

33. Sreethawong, T.; Junbua, C.; Chavadej, S. Photocatalytic $\mathrm{H}_{2}$ production from water splitting under visible light irradiation using Eosin Y-sensitized mesoporous-assembled $\mathrm{Pt} / \mathrm{TiO}_{2}$ nanocrystal photocatalyst. J. Power Sources 2009, 190, 513-524. [CrossRef]

34. Kim, S.; Hwang, S.-J.; Choi, W. Visible light active platinum-ion-doped $\mathrm{TiO}_{2}$ photocatalyst. J. Phys. Chem. B 2005, 109 , $24260-24267$. [CrossRef] [PubMed]

35. Lin, C.; Lee, C.; Chao, J.; Kuo, C.; Cheng, Y.; Huang, W.; Chang, H.; Huang, Y. Photocatalytic generation of $\mathrm{H}_{2}$ gas from neat ethanol over Pt/TiO2 nanotube catalysts. Catal. Lett. 2004, 98, 61-66. [CrossRef]

36. Bahruji, H.; Bowker, M.; Davies, P.R.; Morgan, D.J.; Morton, C.A.; Egerton, T.A.; Kennedy, J.; Jones, W. Rutile TiO $2-P d$ Photocatalysts for Hydrogen Gas Production from Methanol Reforming. Top. Catal. 2015, 70-76. [CrossRef]

37. Yu, J.; Hai, Y.; Jaroniec, M. Photocatalytic hydrogen production over CuO-modified titania. J. Colloid Interface Sci. 2011, 357, 223-228. [CrossRef]

38. Choudhury, B.; Choudhury, A. Luminescence characteristics of cobalt doped $\mathrm{TiO}_{2}$ nanoparticles. J. Lumin. 2012, 132, 178-184. [CrossRef]

39. Escobedo, S.; Rusinque, B.; de Lasa, H. Photochemical Thermodynamic Efficiency Factors (PTEFs) for Hydrogen Production Using Different $\mathrm{TiO}_{2}$ Photocatalysts. Ind. Eng. Chem. Res. 2019, 58, 22225. [CrossRef]

40. Ning, X.; Lu, G. Photocorrosion inhibition of CdS-based catalysts for photocatalytic overall water splitting. Nanoscale 2020, 12, 1213-1223. [CrossRef] [PubMed]

41. Ilie, M.; Cojocaru, B.; Parvulescu, V.I.; Garcia, H. Improving $\mathrm{TiO}_{2}$ activity in photo-production of hydrogen from sugar industry wastewaters. Int. J. Hydrog. Energy 2011, 36, 15509-15518. [CrossRef]

42. Draz, M.A.; El-maghrabi, H.H.; Soliman, F.S.; Selim, H. Large scale hybrid magnetic $\mathrm{ZnFe}_{2} \mathrm{O}_{4} / \mathrm{TiO}_{2}$ nanocomposite with highly photocatalytic activity for water splitting. J. Nanoparticle Res. 2021, 23, 10. [CrossRef]

43. Castañeda, C.; Tzompantzi, F.; Rodríguez-Rodríguez, A.; Sánchez-dominguez, M.; Gómez, R. Improved photocatalytic hydrogen production from methanol/water solution using $\mathrm{CuO}$ supported on fluorinated $\mathrm{TiO}_{2}$. J. Chem. Technol. Biotechnol. 2018, 93, 1113-1120. [CrossRef]

44. Wysmulek, K.; Sar, J.; Osewski, P.; Orlinski, K.; Kolodziejak, K.; Trenczek-zajac, A.; Radecka, M.; Pawlak, D.A. A SrTiO 3 -TiO 2 eutectic composite as a stable photoanode material for photoelectrochemical hydrogen production. Appl. Catal. B Environ. 2017, 206, 538-546. [CrossRef]

45. Fan, W.; Zhang, Q.; Wang, Y. Semiconductor-based nanocomposites for photocatalytic $\mathrm{H}_{2}$ production and $\mathrm{CO}_{2}$ conversion. Phys. Chem. Chem. Phys. 2013, 2632-2649. [CrossRef] [PubMed]

46. Reisner, E.; Powell, D.J.; Cavazza, C.; Fontecilla-camps, J.C.; Armstrong, F.A. Visible Light-Driven $\mathrm{H}_{2}$ Production by Hydrogenases Attached to Dye-Sensitized $\mathrm{TiO}_{2}$ Nanoparticles. JACS 2009, 131, 18457-18466. [CrossRef] [PubMed]

47. Willkomm, J.; Orchard, K.L.; Reynal, A.; Pastor, E.; Durrant, J.R.; Reisner, E. Chem Soc Rev Dye-sensitised semiconductors modified with molecular catalysts for light-driven $\mathrm{H}_{2}$ production. Chem. Soc. Rev. 2016, 45, 9-23. [CrossRef]

48. Ranwaha, T.; Elegbeleye, I.; Maluta, N.; Maphanga, R. Optical and electronic properties of croconates dye molecules adsorbed on $\mathrm{TiO}_{2}$ brookite nanocluster for dye sensitized solar cells application. Mater. Express 2020, 10, 1917-1924. [CrossRef]

49. Barrios, C.E.; Albiter, E.; Gracia y Jimenez, J.M.; Tiznado, H.; Romo-Herrera, J.; Zanella, R. Photocatalytic hydrogen production over titania modified by gold - Metal (palladium, nickel and cobalt) catalysts. Int. J. Hydrog. Energy 2016, 41, 23287-23300. [CrossRef]

50. Caudillo-Flores, U.; Muñoz-Batista, M.J.; Cortés, J.A.; Fernández-García, M.; Kubacka, A. UV and visible light driven $\mathrm{H}_{2}$ photo-production using $\mathrm{Nb}$-doped $\mathrm{TiO}_{2}$ : Comparing Pt and Pd co-catalysts. Mol. Catal. 2017, 437, 1-10. [CrossRef]

51. Navarro, R.M.; Arenales, J.; Vaquero, F.; González, I.D.; Fierro, J.L.G. The effect of Pt characteristics on the photoactivity of $\mathrm{Pt} / \mathrm{TiO}_{2}$ for hydrogen production from ethanol. Catal. Today 2013, 210, 33-38. [CrossRef]

52. Strataki, N.; Bekiari, V.; Kondarides, D.I.; Lianos, P. Hydrogen production by photocatalytic alcohol reforming employing highly efficient nanocrystalline titania films. Appl. Catal. B Environ. 2007, 77, 184-189. [CrossRef]

53. Asal, S.; Saif, M.; Hafez, H.; Mozia, S.; Heciak, a.; Moszyński, D.; Abdel-Mottaleb, M.S.A. Photocatalytic generation of useful hydrocarbons and hydrogen from acetic acid in the presence of lanthanide modified $\mathrm{TiO}_{2}$. Int. J. Hydrog. Energy 2011, 36, 6529-6537. [CrossRef]

54. Min, S.; Lu, G. Dye-cosensitized graphene/Pt photocatalyst for high efficient visible light hydrogen evolution. Int. J. Hydrog. Energy 2012, 37, 10564-10574. [CrossRef]

55. Srta, N.O.; Adhikari, S.P.; Hood, Z.D.; Wang, H.; Peng, R.; Krall, A.; Li, H.; Chen, V.W.; More, K.L.; Wu, Z.; et al. Environmental Enhanced visible light photocatalytic water reduction from a $g-\mathrm{C}_{3} \mathrm{~N}_{4} / \mathrm{SrTa} \mathrm{O}_{6}$ heterojunction. Appl. Catal. B Environ. 2017, 217, 448-458. [CrossRef] 
56. Lin, B.; An, H.; Yan, X.; Zhang, T.; Wei, J.; Yang, G. Environmental Fish-scale structured g- $\mathrm{C}_{3} \mathrm{~N}_{4}$ nanosheet with unusual spatial electron transfer property for high-efficiency photocatalytic hydrogen evolution. Appl. Catal. B Environ. 2017, 210, 173-183. [CrossRef]

57. Cai, X.; Zhang, J.; Fujitsuka, M.; Majima, T. Environmental layered composites as efficient visible-light-driven photocatalyst. Appl. Catal. B Environ. 2017, 202, 191-198. [CrossRef]

58. Kudo, A.; Miseki, Y. Heterogeneous photocatalyst materials for water splitting. Chem. Soc. Rev. 2009, 38, 253-278. [CrossRef] [PubMed]

59. Schneider, J.; Bahnemann, D.W. Undesired Role of Sacri fi cial Reagents in Photocatalysis. J. Phys. Chem. Lett. 2013, 4, 3479-3483. [CrossRef]

60. Wang, M.; Shen, S.; Li, L.; Tang, Z.; Yang, J. Effects of sacrificial reagents on photocatalytic hydrogen evolution over different photocatalysts. J. Mater. Sci. 2017, 52, 5155-5164. [CrossRef]

61. Alkaim, A.F.; Kandiel, T.A.; Dillert, R.; Bahnemann, D.W. Photocatalytic hydrogen production from biomass-derived compounds: A case study of citric acid. Environ. Technol. 2016, 37, 2687-2693. [CrossRef] [PubMed]

62. Speltini, A.; Sturini, M.; Maraschi, F.; Dondi, D.; Fisogni, G.; Annovazzi, E.; Profumo, A.; Buttafava, A. ScienceDirect Evaluation of UV-A and solar light photocatalytic hydrogen gas evolution from olive mill wastewater. Int. J. Hydrog. Energy 2015, 40, 4303-4310. [CrossRef]

63. Villa, K.; Domenec, X.; Malato, S.; Maldonado, M.I.; Peral, J. Heterogeneous photocatalytic hydrogen generation in a solar pilot plant. Int. J. Hydrog. Energy 2013, 8, 12718-12724. [CrossRef]

64. Sakata, T.; Kawai, T. Heterogeneous photocatalytic production of hydrogen and methane from ethanol and water. Chem. Phys. Lett. 1981, 80, 341-344. [CrossRef]

65. Escobedo, S.; Serrano, B.; de Lasa, H. Quantum yield with platinum modified $\mathrm{TiO}_{2}$ photocatalyst for hydrogen production Appl. Catal. B Environ. 2013, 140, 523-536. [CrossRef]

66. Rusinque, B.; Escobedo, S.; de Lasa, H. Photocatalytic Hydrogen Production Under Near-UV Using Pd-Doped Mesoporous TiO 2 and Ethanol as Organic Scavenger. Catalysts 2019, 19, 33. [CrossRef]

67. Salaices, M.; Serrano, B.; de Lasa, H. Photocatalytic Conversion of Organic Pollutants Extinction Coefficients and Quantum Efficiencies. Ind. Eng. Chem. Res. 2001, 40, 5455-5464. [CrossRef]

68. Salaices, M.; Serrano, B.; de Lasa, H. Experimental evaluation of photon absorption in an aqueous $\mathrm{TiO}_{2}$ slurry reactor. Chem. Eng. J. 2002, 90, 219-229. [CrossRef]

69. Moreira, J.; Serrano, B.; Ortiz, A.; de Lasa, H. Evaluation of Photon Absorption in an Aqueous $\mathrm{TiO}_{2}$ Slurry Reactor Using Monte Carlo Simulations and Macroscopic Balance. Ind. Eng. Chem. Res. 2010, 49, 10524-10534. [CrossRef]

70. Serrano, B.; Ortíz, A.; Moreira, J.; de Lasa, H. Photocatalytic Thermodynamic Efficiency Factors. Practical Limits in Photocatalytic Reactors. Ind. Eng. Chem. Res. 2010, 49, 6824-6833. [CrossRef]

71. De Lasa, H.; Serrano, B.; Salaices, M. Photocatalytic Reaction Engineering, 1st ed.; Springer: Berlin/Heidelberg, Germany, 2005; ISBN 978-0-387-27591-8.

72. Serrano, B.; Ortíz, A.; Moreira, J.; de Lasa, H. Energy efficiency in photocatalytic reactors for the full span of reaction times. Ind. Eng. Chem. Res. 2009, 48, 9864-9876. [CrossRef]

73. Hernandez, J.M.G.; Rosales, B.S.; de Lasa, H. The photochemical thermodynamic efficiency factor (PTEF) in photocatalytic reactors for air treatment. Chem. Eng. J. 2010, 165, 891-901. [CrossRef]

74. Lugo-Vega, C.S.; Serrano-Rosales, B.; de Lasa, H. Energy efficiency limits in Photo-CREC-Air photocatalytic reactors. Chem. Eng. Sci. 2016, 156, 77-88. [CrossRef]

75. Estahbanati, M.R.K.; Feilizadeh, M.; Iliuta, M.C. Photocatalytic valorization of glycerol to hydrogen: Optimization of operating parameters by artificial neural network. Appl. Catal. B Environ. 2017, 209, 483-492. [CrossRef]

76. Farsi, A.; Dincer, I.; Naterer, G.F. Multi-objective optimization of an experimental integrated thermochemical cycle of hydrogen production with an artificial neural network. Int. J. Hydrog. Energy 2020, 45, 24355-24369. [CrossRef]

77. Ren, T.; Wang, L.; Chang, C.; Li, X. Machine learning-assisted multiphysics coupling performance optimization in a photocatalytic hydrogen production system. Energy Convers. Manag. 2020, 216, 112935. [CrossRef]

78. Nurul, M.; Podder, J.; Saadat, K.; Sagadevan, S. Band gap tuning of p-type al-doped $\mathrm{TiO}_{2}$ thin films for gas sensing applications. Thin Solid Film. 2020, 714, 138382. [CrossRef]

79. Moctezuma, E.; Leyva, E.; Aguilar, C.A.; Luna, R.A.; Montalvo, C. Photocatalytic degradation of paracetamol: Intermediates and total reaction mechanism. J. Hazard. Mater. 2012, 243, 130-138. [CrossRef] [PubMed]

80. Kiyama, M.; Akita, T.; Tsutsumi, Y.; Takada, T. Formation of Titanic Oxides of Anatase, Brookite, and Rutiles Types by Aerial Oxidation of Titanous Solutions. Chem. Lett. 1972, 1, 21-24. [CrossRef]

81. Freyria, F.S.; Blangetti, N.; Esposito, S.; Nasi, R. Effects of the Brookite Phase on the Properties of Different $\mathrm{Nanostructured} \mathrm{TiO}_{2}$ Phases Photocatalytically Active Towards the Degradation of N-Phenylurea. Chem. Open 2020, 9, 903-912. [CrossRef]

82. Zu, M.; Zhou, X.; Zhang, S.; Qian, S.; Li, D. Sustainable engineering of $\mathrm{TiO}_{2}$-based advanced oxidation technologies: From photocatalyst to application devices. J. Mater. Sci. Technol. 2021, 78, 202-222. [CrossRef]

83. Li, R.; Hu, B.; Yu, T.; Shao, Z.; Wang, Y.; Song, S. New TiO - -Based Oxide for Catalyzing Alkaline Hydrogen Evolution Reaction with Noble Metal-Like Performance. Small Methods 2021, 5, 2100246. [CrossRef] 
84. Sescu, A.M.; Favier, L.; Lutic, D.; Soto-donoso, N.; Ciobanu, G.; Harja, M. TiO2 Doped with Noble Metals as an Efficient Solution for the Photodegradation of Hazardous Organic Water Pollutants at Ambient Conditions. Water 2021, 13, 19. [CrossRef]

85. Bellamkonda, S.; Thangavel, N.; Yusuf, H.; Neppolian, B. Highly active and stable multi-walled carbon nanotubes-graphene-TiO 2 nanohybrid: An e ffiicient non-noble metal photocatalyst for water splitting. Catal. Today 2019, 321-322, 120-127. [CrossRef]

86. Mishra, A.; Mehta, A.; Kainth, S.; Basu, S. A comparative study on the effect of different precursors for synthesis and efficient photocatalytic activity of $\mathrm{g}-\mathrm{C}_{3} \mathrm{~N}_{4} / \mathrm{TiO}_{2}$ / bentonite nanocomposites. J. Mater. Sci. 2018, 53, 13126-13142. [CrossRef]

87. Kapilashrami, M.; Zhang, Y.; Liu, Y.; Hagfeldt, A.; Guo, J. Probing the Optical Property and Electronic Structure of TiO 2 Nanomaterials for Renewable Energy Applications. Chem. Rev. 2014, 114, 9662-9707. [CrossRef]

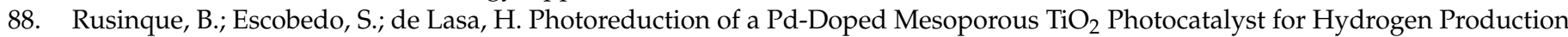
under Visible Light. Catalysts 2020, 74, 74. [CrossRef]

89. Mehta, A.; Sharma, M.; Kumar, A.; Basu, S. Effect of Au content on the enhanced photocatalytic efficiency of mesoporous $\mathrm{Au} / \mathrm{TiO}_{2}$ nanocomposites in UV and sunlight. Gold Bull. 2017, 50, 33-41. [CrossRef]

90. Tio, S.; Montoya, A.T.; Gillan, E.G. Enhanced Photocatalytic Hydrogen Evolution from Transition-Metal Surface-Modi fi ed TiO 2 . ACS Omega 2018, 3, 2947-2955. [CrossRef]

91. Bahruji, H.; Bowker, M.; Brookes, C.; Davies, P.R.; Wawata, I. The adsorption and reaction of alcohols on $\mathrm{TiO}_{2}$ and $\mathrm{Pd} / \mathrm{TiO} 2$ catalysts. Appl. Catal. A Gen. 2013, 454, 66-73. [CrossRef]

92. Rather, R.A.; Singh, S.; Pal, B. A Cu${ }^{+1} / \mathrm{Cu}^{0}-\mathrm{TiO}_{2}$ mesoporous nanocomposite exhibits improved $\mathrm{H}_{2}$ production from $\mathrm{H}_{2} \mathrm{O}$ under direct solar irradiation. J. Catal. 2017, 346, 1-9. [CrossRef]

93. Choi, H.J.; Kang, M. Hydrogen production from methanol/water decomposition in a liquid photosystem using the anatase structure of $\mathrm{Cu}$ loaded $\mathrm{TiO}_{2}$. Int. J. Hydrog. Energy 2007, 32, 3841-3848. [CrossRef]

94. Ruban, P.; Sellappa, K. Development and performance of bench-scale reactor for the photocatalytic generation of hydrogen. Energy 2014, 73, 926-932. [CrossRef]

95. Rivero, M.J.; Iglesias, O.; Ribao, P.; Ortiz, I. Kinetic performance of $\mathrm{TiO}_{2} / \mathrm{Pt} /$ reduced graphene oxide composites in the photocatalytic hydrogen production. Int. J. Hydrog. Energy 2018, 44, 101-109. [CrossRef]

96. Liu, R.; Yoshida, H.; Fujita, S.; Arai, M. Environmental Photocatalytic hydrogen production from glycerol and water with $\mathrm{NiO}_{\mathrm{x}} / \mathrm{TiO}_{2}$ catalysts. Appl. Catal. B Environ. 2014, 144, 41-45. [CrossRef]

97. Fujita, S.; Kawamori, H.; Honda, D.; Yoshida, H.; Arai, M. Environmental Photocatalytic hydrogen production from aqueous glycerol solution using $\mathrm{NiO} / \mathrm{TiO}_{2}$ catalysts: Effects of preparation and reaction conditions. Appl. Catal. B Environ. 2016, 181, 818-824. [CrossRef]

98. Sadanandam, G.; Lalitha, K.; Durga, V. Cobalt doped $\mathrm{TiO}_{2}$ : A stable and efficient photocatalyst for continuous hydrogen production from glycerol: Water mixtures under solar light irradiation. Int. J. Hydrog. Energy 2013, 38, 9655-9664. [CrossRef]

99. Li, Y.; Jin, Z.; Zhang, L.; Fan, K. Controllable design of Zn-Ni-P on g- $\mathrm{C}_{3} \mathrm{~N}_{4}$ for efficient photocatalytic hydrogen production. Chin. J. Catal. 2019, 40, 390-402. [CrossRef]

100. Singla, S.; Sharma, S.; Basu, S.; Shetti, N.P.; Raghava, K. Graphene/graphitic carbon nitride-based ternary nanohybrids: Synthesis methods, properties, and applications for photocatalytic hydrogen production. FlatChem 2020, 24, 100200. [CrossRef]

101. Xiong, J.; Li, X.; Huang, J.; Gao, X.; Chen, Z.; Liu, J.; Li, H.; Kang, B.; Yao, W.; Zhu, Y. CN/rGO@BPQDs high-low junctions with stretching spatial charge separation ability for photocatalytic degradation and $\mathrm{H}_{2} \mathrm{O}_{2}$ production. Appl. Catal. B Environ. 2020, 266, 118602. [CrossRef]

102. Cheng, L.; Xiang, Q.; Liao, Y. CdS-Based Photocatalysts. Energy Environ. Sci. 2018, 11, 1362-1391. [CrossRef]

103. Kudo, A. Development of photocatalyst materials for water splitting. Int. J. Hydrog. Energy 2006, 31, 197-202. [CrossRef]

104. Jing, X.; Lu, N.; Huang, J.; Zhang, P.; Zhang, Z. One-step hydrothermal synthesis of S-defect-controlled ZnIn $\mathrm{S}_{4}$ microflowers with improved kinetics process of charge-carriers for photocatalytic $\mathrm{H}_{2}$ evolution. J. Energy Chem. 2021, 58, 397-407. [CrossRef]

105. Katsumata, H.; Tachi, Y.; Suzuki, T.; Kaneco, S. Z-scheme photocatalytic hydrogen production over $\mathrm{WO}_{3} / \mathrm{g}-\mathrm{C}_{3} \mathrm{~N}_{4}$ composite photocatalysts. RSC Adv. 2014, 21405-21409. [CrossRef]

106. Jiang, D.; Chen, L.; Xie, J.; Chen, M. Ag2S/g-C3N4 composite photocatalysts for efficient Pt-free hydrogen production. The co-catalyst function of $\mathrm{Ag} / \mathrm{Ag}_{2} \mathrm{~S}$ formed by simultaneous photodeposition. Dalt. Trans. 2014, 43, 4878-4885. [CrossRef]

107. Shen, Z.; Chen, G.; Yu, Y.; Wang, Q.; Zhou, C.; Hao, L.; Li, Y.; Heb, L.; Mu, R. Sonochemistry synthesis of nanocrystals embedded in a $\mathrm{MoO}_{3}-\mathrm{CdS}$ core-shell photocatalyst with enhanced hydrogen production and photodegradation. J. Mater. Sci. 2012, 19646-19651. [CrossRef]

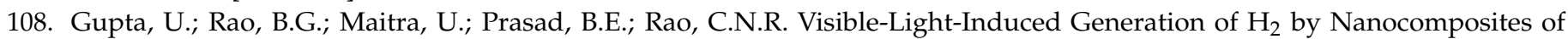
Few-Layer. Chem. Asian J. 2014, 1311-1315. [CrossRef]

109. Chen, S.; Liao, J.; Zhou, Z.; Yang, S.; Gao, Q.; Cai, X.; Peng, F.; Fang, Y.; Zhang, S. Boosting photocatalytic hydrogen evolution using a noble-metal-free co-catalyst: CuNi@C with oxygen-containing functional groups. Appl. Catal. B Environ. 2021, 291, 120139. [CrossRef]

110. Pradhan, A.C.; Martha, S.; Mahanta, S.K.; Parida, K.M. Mesoporous nanocomposite Fe $/ \mathrm{Al}_{2} \mathrm{O}_{3}$-MCM-41: An efficient photocatalyst for hydrogen production under visible light. Int. J. Hydrog. Energy 2011, 36, 12753-12760. [CrossRef]

111. Trens, P.; Russell, M.L.; Spjuth, L.; Hudson, M.J.; Liljenzin, J.; Normale, Ä.; Cedex, M. Preparation of Malonamide-MCM-41 Materials for the Heterogeneous Extraction of Radionuclides. Ind. Eng. Chem. Res. 2002, 5220-5225. [CrossRef] 
112. Leilei, X.U.; Lei, N.I.; Weidong, S.H.I.; Jianguo, G. Photocatalytic Activity for Hydrogen Evolution over Well-Dispersed Heterostructured In2O3/Ta2O 5 Composites. Chin. J. Catal. 2012, 33, 1101-1108. [CrossRef]

113. Escobedo, S.; de Lasa, H. Photocatalysis for Air Treatment Processes: Current Technologies and Future Applications for the Removal of Organic Pollutants and Viruses. Catalysts 2020, 10, 966. [CrossRef]

114. Kumaravel, V.; Imam, M.D.; Badreldin, A.; Chava, R.K.; Do, J.Y.; Kang, M.; Abdel-Wahab, A. Photocatalytic hydrogen production: Role of sacrificial reagents on the activity of oxide, carbon, and sulfide catalysts. Catalysts 2019, 9, 276. [CrossRef]

115. Imoberdorf, G.E.; Cassano, A.E.; Irazoqui, H.A.; Alfano, O.M. Optimal design and modeling of annular photocatalytic wall reactors. Catal. Today 2007, 129, 118-126. [CrossRef]

116. Lugo-Vega, C.S.; Moreira, J.; Serrano-Rosales, B.; de Lasa, H. Kinetics of the pollutant photocatalytic conversion in a Photo-CRECAir Reactor. Chem. Eng. J. 2017, 317, 1069-1082. [CrossRef]

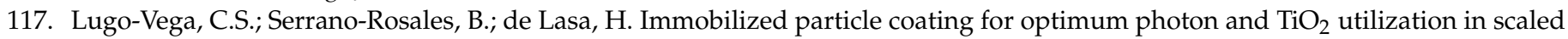
air treatment photo reactors. Appl. Catal. B Environ. 2016, 198, 211-223. [CrossRef]

118. Imoberdorf, G.E.; Irazoqui, H.A.; Cassano, A.E.; Alfano, O.M. Photocatalytic Degradation of Tetrachloroethylene in Gas Phase on $\mathrm{TiO}_{2}$ Films: A Kinetic Study. Ind. Eng. Chem. Res. 2005, 44, 6075-6085. [CrossRef]

119. Héquet, V.; Batault, F.; Raillard, C.; Thévenet, F.; Le Coq, L.; Dumont, É. Determination of the clean air delivery rate (CADR) of photocatalytic oxidation (PCO) purifiers for indoor air pollutants using a closed-loop reactor. Part II: Experimental results. Molecules 2017, 22, 408. [CrossRef]

120. Xu, T.; Zheng, H.; Zhang, P. Performance of an innovative VUV-PCO purifier with nanoporous $\mathrm{TiO}_{2}$ film for simultaneous elimination of VOCs and by-product ozone in indoor air. Build. Environ. 2018, 142, 379-387. [CrossRef]

121. Debono, O.; Thévenet, F.; Gravejat, P.; Héquet, V.; Raillard, C.; Le Coq, L.; Locoge, N. Gas phase photocatalytic oxidation of decane at ppb levels: Removal kinetics, reaction intermediates and carbon mass balance. J. Photochem. Photobiol. A Chem. 2013, 258, 17-29. [CrossRef]

122. Sirivallop, A.; Areerob, T.; Chiarakorn, S. Enhanced Visible Light Photocatalytic Activity of N and Ag Doped and Co-Doped TiO 2 Synthesized by Using an In-Sity Solvothermal Method for Gas Phase Ammonia Removal. Catalysts 2020, 10, 251. [CrossRef]

123. Zhong, L.; Haghighat, F.; Lee, C.S.; Lakdawala, N. Performance of ultraviolet photocatalytic oxidation for indoor air applications: Systematic experimental evaluation. J. Hazard. Mater. 2013, 261, 130-138. [CrossRef] [PubMed]

124. Dong, F.; Wang, Z.; Li, Y.; Ho, W.K.; Lee, S.C. Immobilization of polymeric $\mathrm{g}^{-} \mathrm{C}_{3} \mathrm{~N}_{4}$ on structured ceramic foam for efficient visible light photocatalytic air purification with real indoor illumination. Environ. Sci. Technol. 2014, 48, 10345-10353. [CrossRef] [PubMed]

125. Esterkin, C.R.; Negro, A.C.; Alfano, O.M.; Cassano, A.E. Air pollution remediation in a fixed bed photocatalytic reactor coated with $\mathrm{TiO}_{2}$. AIChE J. 2003, 51, 2298-2310. [CrossRef]

126. Rusinque, B.; Escobedo, S.; de Lasa, H. Hydrogen Production via Pd-TiO 2 Photocatalytic Water Splitting under Near-UV and Visible Light: Analysis of the Reaction Mechanism. Catalysts 2021, 11, 405. [CrossRef]

127. Lugo-Vega, C.S. Evaluation of VOC Degradation in Photo- Catalytic Air Reactors: $\mathrm{TiO}_{2}$ Immobilization, Energy Efficiency and Kinetic Modeling. Ph.D. Thesis, The University of Western Ontario, London, ON, Canada, 2016.

128. Dey, G.R.; Pushpa, K.K. Methane generated during photocatalytic redox reaction of alcohols on $\mathrm{TiO}_{2}$ suspension in aqueous solutions. Res. Chem. Intermed. 2006, 32, 725-736. [CrossRef]

129. Escobedo, S.; Serrano, B.; Calzada, A.; Moreira, J.; de Lasa, H. Hydrogen production using a platinum modified TiO 2 photocatalyst and an organic scavenger. Kinetic modeling. Fuel 2016, 181, 438-449. [CrossRef]

130. Guayaquil, J.F.; Escobedo, S.; Calzada, A.; Serrano, B.; de Lasa, H. Hydrogen Production via Water Dissociation Using Pt-TiO 2 Photocatalysts: An Oxidation-Reduction Network. Catalysts 2017, 7, 324. [CrossRef]

131. Panagiotopoulou, P.; Karamerou, E.E.; Kondarides, D.I. Kinetics and mechanism of glycerol photo-oxidation and photo-reforming reactions in aqueous $\mathrm{TiO}_{2}$ and $\mathrm{Pt} / \mathrm{TiO}_{2}$ suspensions. Catal. Today 2013, 209, 91-98. [CrossRef]

132. Besov, A.S.; Vorontsov, A.V.; Parmon, V.N. Fast adsorptive and photocatalytic purification of air from acetone and dimethyl methylphosphonate by $\mathrm{TiO}_{2}$ aerosol. Appl. Catal. B Environ. 2009, 89, 602-612. [CrossRef]

133. Boulamanti, A.K.; Philippopoulos, C.J. Photocatalytic degradation of $C_{5}-C_{7}$ alkanes in the gas-phase. Atmos. Environ. 2009, 43, 3168-3174. [CrossRef]

134. Weibel, a.; Bouchet, R.; Knauth, P. Electrical properties and defect chemistry of anatase $\left(\mathrm{TiO}_{2}\right)$. Solid State Ionics 2006, 177, $229-236$. [CrossRef]

135. Sauer, L.M.; Ollis, F.D. Acetone Oxidation in Photocatalytic Monolith Reactor. J. Catal. 1994, 149, 81-94. [CrossRef]

136. Trong On, D.; Desplantier-Giscard, D.; Danumah, C.; Kaliaguine, S. ChemInform Abstract: Perspectives in Catalytic Applications of Mesostructured Materials. ChemInform 2010, 33, 299-357. [CrossRef]

137. Hoffmann, M.R.; Martin, S.T.; Choi, W.; Bahnemannt, D.W. Environmental Applications of Semiconductor Photocatalysis. Chem. Rev. 1995, 95, 69-96. [CrossRef]

138. Cassano, A.E.; Martín, C.A.; Brandi, R.J.; Alfano, O.M. Photoreactor Analysis and Design: Fundamentals and Applications. Ind. Eng. Chem. Res. 1995, 34, 2155-2201. [CrossRef]

139. Davydov, L.; Smirniotis, P.G.; Pratsinis, S.E. Novel differential reactor for the measurement of overall quantum yields. Ind. Eng. Chem. Res. 1999, 38, 1376-1383. [CrossRef] 
140. Yamazaki-Nishida, S.; Nagano, K.; Phillips, L.A.; Cervera-March, S.; Anderson, M.A. Photocatalytic degradation of trichloroethylene in the gas phase using titanium dioxide pelle. J. Photochem. Photobiol. A Chem. 1993, 70, 95-99. [CrossRef]

141. Ibrahim, H.; de Lasa, H. Novel photocatalytic reactor for the destruction of airborne pollutants reaction kinetics and quantum yields. Ind. Eng. Chem. Res. 1999, 38, 3211-3217. [CrossRef]

142. Ibrahim, H.; de Lasa, H. Photo-catalytic degradation of air borne pollutants apparent quantum efficiencies in a novel photoCREC-air reactor. Chem. Eng. Sci. 2003, 58, 943-949. [CrossRef]

143. Valadés-Pelayo, P.J.; Moreira del Rio, J.; Solano-Flores, P.; Serrano, B.; de Lasa, H. Establishing photon absorption fields in a Photo-CREC Water II Reactor using a CREC-spectroradiometric probe. Chem. Eng. Sci. 2014, 116, 406-417. [CrossRef]

144. Garcia-Hernandez, J.M.; Serrano-Rosales, B.; de Lasa, H. Energy efficiencies in a photo-CREC-air reactor: Conversion of model organic pollutants in air. Ind. Eng. Chem. Res. 2012, 51, 5715-5727. [CrossRef]

145. Serrano, B.; de Lasa, H. Photocatalytic Degradation of Water Organic Pollutants. Kinetic. Ind. Eng. Chem. Res. 1997, 36, 4705-4711. [CrossRef]

146. Masood, H.; Toe, C.Y.; Teoh, W.Y.; Sethu, V.; Amal, R. Machine Learning for Accelerated Discovery of Solar Photocatalysts. ACS Catal. 2019, 11774-11787. [CrossRef]

147. Eskandarloo, H.; Badiei, A.; Behnajady, M.A. Study of the Effect of Additives on the Photocatalytic Degradation of a Triphenylmethane Dye in the Presence of Immobilized $\mathrm{TiO}_{2} / \mathrm{NiO}$ Nanoparticles: Artificial Neural Network Modeling. Ind. Eng. Chem. Res. 2014, 53, 6881-6895. [CrossRef]

148. Ardabili, S.F.; Najafi, B.; Shamshirband, S.; Bidgoli, B.M.; Deo, R.C.; Chau, K. Computational intelligence approach for modeling hydrogen production: A review. Eng. Appl. Comput. Fluid Mech. 2018, 12, 438-458. [CrossRef]

149. Tabatabai-yazdi, F.; Ebrahimian, A.; Khalil, F.E.; Gilani, N. Construction of graphene based photocatalysts for photocatalytic degradation of organic pollutant and modeling using artificial intelligence techniques. Phys. B Phys. Condens. Matter 2021, 608, 412869-412887. [CrossRef]

150. Mageed, A.K. Modeling photocatalytic hydrogen production from ethanol over copper oxide nanoparticles: A comparative analysis of various machine learning techniques. Biomass Convers. Biorefinery 2021, 1-9. [CrossRef] 